Prepared in cooperation with U.S. Environmental Protection Agency

Evaluation and Application of the Purge Analyzer Tool (PAT) To Determine In-Well Flow and Purge Criteria for Sampling Monitoring Wells at the Stringfellow Superfund Site in Jurupa Valley, California, in 2017

Scientific Investigations Report $2020-5140$

U.S. Department of the Interior U.S. Geological Survey 
Cover. Photograph of the waste collection pad and surrounding hillsides, Stringfellow Superfund site, Jurupa Valley, Riverside County, California; by Philip T. Harte, U.S. Geological Survey. 


\section{Evaluation and Application of the Purge Analyzer Tool (PAT) To Determine In-Well \\ Flow and Purge Criteria for Sampling \\ Monitoring Wells at the Stringfellow \\ Superfund Site in Jurupa Valley, California, in 2017}

By Philip T. Harte, Tomas Perina, Kent Becher, Herb Levine, Daewon Rojas-Mickelson, Lesley Walther, and Anthony Brown

Prepared in cooperation with U.S. Environmental Protection Agency

Scientific Investigations Report 2020-5140 


\section{U.S. Geological Survey, Reston, Virginia: 2021}

For more information on the USGS - the Federal source for science about the Earth, its natural and living resources, natural hazards, and the environment—visit https://www.usgs.gov or call 1-888-ASK-USGS.

For an overview of USGS information products, including maps, imagery, and publications, visit https://store.usgs.gov/.

Any use of trade, firm, or product names is for descriptive purposes only and does not imply endorsement by the U.S. Government.

Although this information product, for the most part, is in the public domain, it also may contain copyrighted material and images protected by publicity rights. Use of photographs or images may require permission to reproduce copyrighted items or the likeness of a person. Permission must be secured from the copyright owner or person whose likeness is being used. For more information, visit https://usgs.gov/copyright.

Suggested citation:

Harte, P.T., Perina, T., Becher, K., Levine, H., Rojas-Mickelson, D., Walther, L., and Brown, A., 2021, Evaluation and application of the Purge Analyzer Tool (PAT) to determine in-well flow and purge criteria for sampling monitoring wells at the Stringfellow Superfund site in Jurupa Valley, California, in 2017: U.S. Geological Survey Scientific Investigations Report 2020-5140, 54 p., https://doi.org/10.3133/sir20205140.

Data associated with this publication:

Harte, P.T., 2020, Data associated with the evaluation of the PAT (Purge Analyzer Tool), Stringfellow Superfund site, Jurupa Valley, California, 2017: U.S. Geological Survey data release, https://doi.org/10.5066/P9CGINH0.

ISSN 2328-0328 (online) 


\section{Acknowledgments}

This project was funded by the U.S. Environmental Protection Agency (EPA) Fractured-Rock Remediation Initiative under interagency agreement DW014-92406101 and by EPA Region 9 under interagency agreement DW014-92526201. Edward Gilbert of the EPA contributed administrative and technical oversight to enhance the relevancy and transferability of findings to other groundwater-contamination sites in fractured-rock aquifers. David Herzog of the California Department of Toxic Substances Control helped schedule and coordinate site access. Michael Wright of the U.S. Geological Survey (USGS) provided valuable logistical assistance before, during, and after field operations at the Stringfellow Superfund site. David Dillon of the USGS assisted in deployment of passive samplers. 



\section{Contents}

Acknowledgments ……...................................................................................................................

Abstract

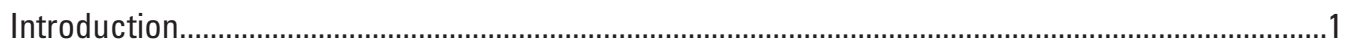

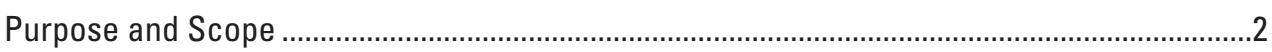

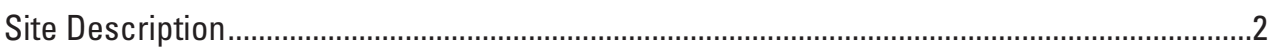

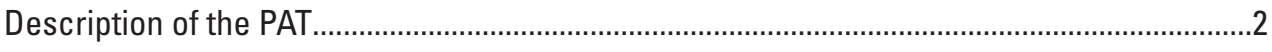

Study Approach and Methods in the Evaluation and Application of the PAT ..................................4

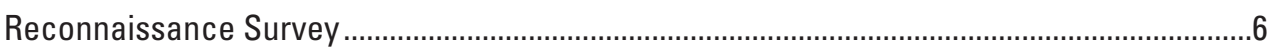

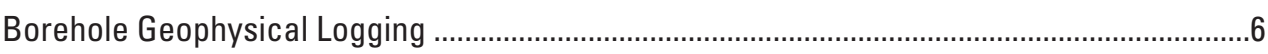

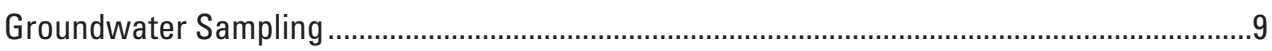

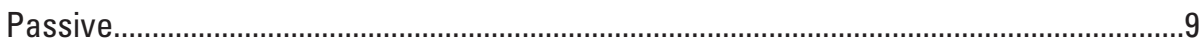

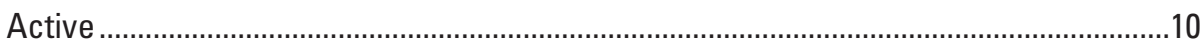

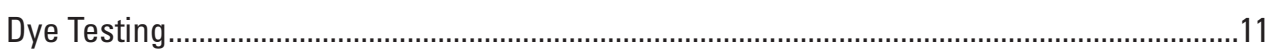

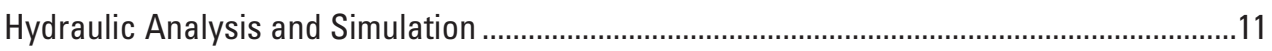

Additional Vertical Profiles of Pumped Wells ......................................................................13

Results of the Evaluation and Application of the PAT …….......................................................

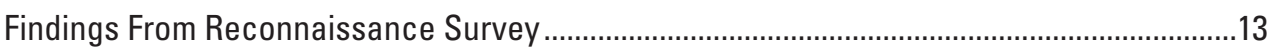

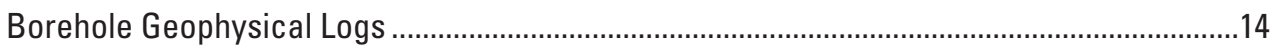

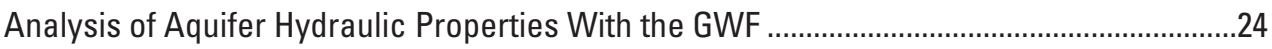

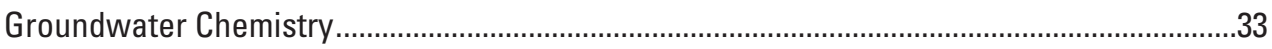

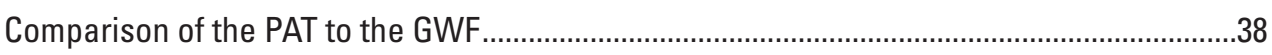

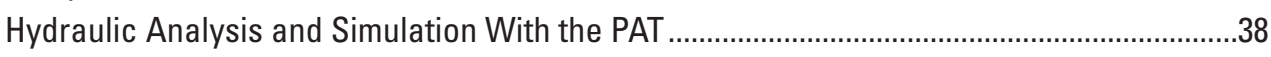

Estimates of Pump Time for Monitoring Wells With the PAT .................................................42

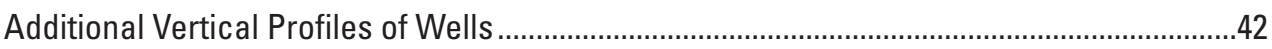

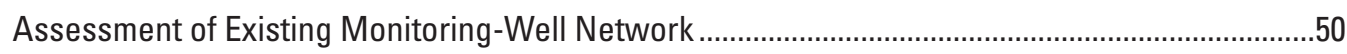

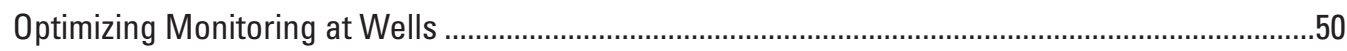

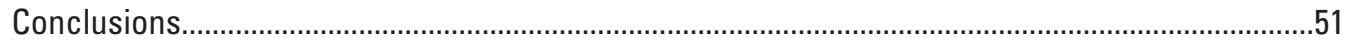

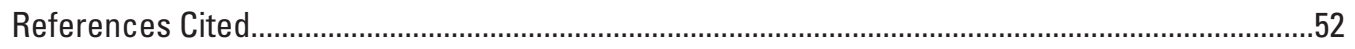

\section{Figures}

1. Map showing the location of the Stringfellow Superfund site and a groundwater plume in Jurupa Valley, California ............................................................

2. Schematic diagram of the water budget approach in the Purge Analyzer Tool................4

3. Map showing wells tested near zone $1 \mathrm{~B}$ at the Stringfellow Superfund site in Jurupa Valley, California..................................................................................................

4. Graphs of standard deviation from values measured during vertical profiles of wells for water specific conductance and temperature relative to water column length and screen length at the Stringfellow Superfund site in Jurupa Valley, California

5. Logs of natural gamma radioactivity and electromagnetic induction for well PZ-74D at the Stringfellow Superfund site in Jurupa Valley, California ..........................15

6. Logs of natural gamma radioactivity, fluid resistivity, and fluid temperature for well PZ-74D at the Stringfellow Superfund site in Jurupa Valley, California.. 
7. Logs of natural gamma radioactivity and electromagnetic induction for well OW-69D2 at the Stringfellow Superfund site in Jurupa Valley, California

8. Logs of natural gamma radioactivity, fluid resistivity, and fluid temperature for well OC-12B at the Stringfellow Superfund site in Jurupa Valley, California ... 18

9. Logs of natural gamma ray, fluid resistivity, and temperature for well OW-46B1 at the Stringfellow Superfund site in Jurupa Valley, California

10. Logs of natural gamma ray, fluid resistivity, and temperature for well OW-44B2 at the Stringfellow Superfund site in Jurupa Valley, California 19

11. Logs of natural gamma ray, fluid resistivity, and temperature for well OW-69D2 at the Stringfellow Superfund site in Jurupa Valley, California

12. Acoustic televiewer log for well OC-12B at the Stringfellow Superfund site in Jurupa Valley, California.

13. Fluid resistivity logs for well $0 \mathrm{C}-12 \mathrm{~B}$ at the Stringfellow Superfund site in Jurupa Valley, California.

14. Stationary electromagnetic flowmeter logs for well OC-12B at the Stringfellow Superfund site in Jurupa Valley, California

15. Graph showing model-computed and observed drawdown from initial static water levels for well PZ-74D at the Stringfellow Superfund site in Jurupa Valley, California

16. Graph showing model-computed inflow from aquifer and pumping rate for well PZ-74D at the Stringfellow Superfund site in Jurupa Valley, California

17. Graph showing simulated and observed drawdown from initial static water levels for well OC-12B at the Stringfellow Superfund site in Jurupa Valley, California

18. Graph showing model-computed inflow from aquifer and pumping rate for well

OC-12B at the Stringfellow Superfund site in Jurupa Valley, California.

19. Graph showing model-computed and observed drawdown from initial static water levels for well OW-44B2 at the Stringfellow Superfund site in Jurupa Valley, California

20. Graph showing model-computed inflow from aquifer and pumping rate for well OW-44B2 at the Stringfellow Superfund site in Jurupa Valley, California

21. Graphs showing well construction information and plots of trichloroethylene and perchlorate vertical chemical profiles derived from passive and bailer samples for well OW-46B1 at the Stringfellow Superfund site in Jurupa Valley, California

22. Graphs showing well construction information and plots of trichloroethylene and perchlorate vertical chemical profiles derived from passive and bailed samples for well OW-69D2 at the Stringfellow Superfund site in Jurupa Valley, California

23. Graphs showing well construction information and plots of trichloroethylene and perchlorate vertical chemical profiles derived from passive, bailed, and purge samples for well OW-44B2 at the Stringfellow Superfund site in Jurupa Valley, California

24. Graphs showing well construction information and plots of trichloroethylene and perchlorate vertical chemical profiles derived from passive, bailed, and purge samples for well PZ-74D at the Stringfellow Superfund site in Jurupa Valley, California 36

25. Graphs showing well construction information and plots of trichloroethylene and perchlorate vertical chemical profiles derived from passive, bailed, and 
purge samples for well $\mathrm{OC}-12 \mathrm{~B}$ at the Stringfellow Superfund site in Jurupa

Valley, California

26. Graphs showing measured vertical velocities from peak dye arrival and

PAT-computed vertical velocities associated with the water column above and below the pump intake at wells $0 \mathrm{C}-12 \mathrm{~B}, 0 \mathrm{~W}-44 \mathrm{~B} 2$, and $\mathrm{PZ}-74 \mathrm{D}$ at the

Stringfellow Superfund site in Jurupa Valley, California . .41

27. Graph showing vertical profile of specific conductance before and after purging for well PZ-74D at the Stringfellow Superfund site in Jurupa Valley, California

28. Graph showing vertical profile of specific conductance before and after purging for well OW-44B2 at the Stringfellow Superfund site in Jurupa Valley, California

29. Graph showing vertical profile of specific conductance before and after purging for well OC-12B at the Stringfellow Superfund site in Jurupa Valley, California

30. Diagram showing well costruction and images from a video log at indicated positions for well OC-12B at the Stringfellow Superfund site in Jurupa Valley, California

\section{Tables}

1. Reported and measured well depths and water levels from wells near zone 1B the Stringfellow Superfund site in Jurupa Valley, California...

2. Well construction information for the general well function model analysis, Stringfellow Superfund site in Jurupa Valley, California

3. Estimated pumping rates for wells used in calculations for the general well function model, Stringfellow Superfund site in Jurupa Valley, California

4. Parameters calculated by the general well function model for confined and unconfined conditions for the test wells at the Stringfellow Superfund site in Jurupa Valley, California

5. Water chemistry results from samples collected from test wells at the Stringfellow Superfund site in Jurupa Valley, California

6. Summary of historical trichloroethylene and perchlorate concentrations at reconnaissance and test wells at the Stringfellow Superfund site in Jurupa Valley, California

7. Summary of well information and PAT parameters for test wells at the Stringfellow Superfund site in Jurupa Valley, California

8. Summary of PAT-computed time of travel for reconnaissance wells and test wells based on hydraulic conductivity values from site reports at the Stringfellow Superfund site in Jurupa Valley, California

9. Physicochemical field characteristics of pumped water at well PZ-74D at the Stringfellow Superfund site in Jurupa Valley, California

10. Physicochemical field characteristics of pumped water at well $0 \mathrm{~W}-44 \mathrm{~B} 2$ at the

Stringfellow Superfund site in Jurupa Valley, California

11. Physicochemical field characteristics of pumped water at well $0 \mathrm{C}-12 \mathrm{~B}$ at the Stringfellow Superfund site in Jurupa Valley, California

12. Volumetric calculations of water for select wells at the Stringfellow Superfund site in Jurupa Valley, California. 


\section{Conversion Factors}

U.S. customary units to International System of Units

\begin{tabular}{lll}
\hline \multicolumn{1}{c}{ Multiply } & \multicolumn{1}{c}{ By } & \multicolumn{1}{c}{ To obtain } \\
\hline inch (in.) & 2.54 & centimeter $(\mathrm{cm})$ \\
foot (ft) & 0.3048 & meter $(\mathrm{m})$ \\
feet per minute (ft/min) & 0.3048 & meter per minute $(\mathrm{m} / \mathrm{min})$ \\
feet per day (ft/d) & 0.3048 & meter per day $(\mathrm{m} / \mathrm{d})$ \\
\hline
\end{tabular}

International System of Units to U.S. customary units

\begin{tabular}{lll}
\hline \multicolumn{1}{c}{ Multiply } & By & \multicolumn{1}{c}{ To obtain } \\
\hline milliliter $(\mathrm{mL})$ & 0.0338 & ounce, fluid (fl. oz) \\
liter per minute $(\mathrm{L} / \mathrm{min})$ & 0.2642 & gallon per minute $(\mathrm{gal} / \mathrm{min})$ \\
meter per minute $(\mathrm{m} / \mathrm{min})$ & 3.2808 & feet per minute $(\mathrm{ft} / \mathrm{min})$ \\
\hline
\end{tabular}

Temperature in degrees Celsius $\left({ }^{\circ} \mathrm{C}\right)$ may be converted to degrees Fahrenheit $\left({ }^{\circ} \mathrm{F}\right)$ as follows: ${ }^{\circ} \mathrm{F}$ $=\left(1.8 \times{ }^{\circ} \mathrm{C}\right)+32$.

Temperature in degrees Fahrenheit $\left({ }^{\circ} \mathrm{F}\right)$ may be converted to degrees Celsius $\left({ }^{\circ} \mathrm{C}\right)$ as follows: ${ }^{\circ} \mathrm{C}$ $=\left({ }^{\circ} \mathrm{F}-32\right) / 1.8$.

\section{Datum}

Vertical datum is not referenced in this report. All data are referred to as below land surface. Horizontal coordinate information is referenced to North American Datum of 1983 (NAD 83).

\section{Supplemental Information}

Specific conductance is given in either microsiemens per centimeter at 25 degrees Celsius ( $\mu \mathrm{S}$ ) $\mathrm{cm}$ at $25^{\circ} \mathrm{C}$ ) or millisiemens per centimeter at 25 degrees Celsius $\left(\mathrm{mS} / \mathrm{cm}\right.$ at $\left.25^{\circ} \mathrm{C}\right)$.

Concentrations of chemical constituents in water are given in parts per billion (ppb) which are equivalent to micrograms per liter $(\mu \mathrm{g} / \mathrm{L})$. 


\section{Abbreviations}

$\begin{array}{ll}\text { bls } & \text { below land surface } \\ \text { EM } & \text { electromagnetic } \\ \text { EPA } & \text { U.S. Environmental Protection Agency } \\ \text { GWF } & \text { general well function } \\ \text { HF } & \text { heterogeneity factor } \\ \mathrm{K}_{\mathrm{h}} & \text { horizontal hydraulic conductivity } \\ \mathrm{K}_{\mathrm{r}} & \text { radial hydraulic conductivity } \\ \mathrm{K}_{\mathrm{rs}} & \text { radial hydraulic conductivity of skin } \\ \mathrm{K}_{\mathrm{z}} & \text { vertical hydraulic conductivity } \\ \text { MCL } & \text { maximum contaminant level } \\ \mathrm{M}_{\mathrm{z}} & \text { mixing zone } \\ \text { PAT } & \text { Purge Analyzer Tool } \\ \text { PDB } & \text { polyethylene diffusion bag } \\ \text { PVC } & \text { polyvinyl chloride } \\ \text { RPP } & \text { rigid porous polyethylene } \\ \mathrm{S}_{\mathrm{S}} & \text { specific storage } \\ \text { TCE } & \text { trichloroethylene } \\ \text { USGS } & \text { U.S. Geological Survey } \\ \text { VBA } & \text { Visual Basic for Applications } \\ \text { VOC } & \text { volatile organic compounds }\end{array}$





\title{
Evaluation and Application of the Purge Analyzer Tool (PAT) To Determine In-Well Flow and Purge Criteria for Sampling Monitoring Wells at the Stringfellow Superfund Site in Jurupa Valley, California, in 2017
}

\author{
By Philip T. Harte, ${ }^{1}$ Tomas Perina, ${ }^{2}$ Kent Becher, ${ }^{1}$ Herb Levine, ${ }^{3}$ Daewon Rojas-Mickelson,3 Lesley Walther, ${ }^{2}$ \\ and Anthony Brown'1
}

\section{Abstract}

The U.S. Geological Survey and U.S. Environmental Protection Agency are developing analytical tools to assess the representativeness of groundwater samples from fracturedrock aquifers. As part of this effort, monitoring wells from the Stringfellow Superfund site in Jurupa Valley in Riverside County, California, approximately 50 miles east of Los Angeles, were field tested to collect information to assist in the evaluation and application of in-well flow as computed by the analytical model called the Purge Analyzer Tool, which computes in-well groundwater travel times for simple piston transport of inflowing groundwater from open intervals of a monitoring well to the pump intake and can provide insight into optimal purging parameters (duration, rate, and pump position) needed for the collection of representative groundwater samples. Field testing of wells included hydraulic, chemistry, and dye tracer analysis to investigate travel times in wells under pumping conditions. The Purge Analyzer Tool was able to replicate dye velocities (travel times) for one of three wells that had appreciable inflow from the aquifer but not the other two wells, which are screened in low-permeability sediments and rock, where flow was dominated by borehole storage. A set of criteria was established to help assess the ability to collect representative groundwater chemistry from monitoring wells; criteria included understanding the height of the static well water column and relative exchange rate between the aquifer and the well.

\footnotetext{
1U.S. Geological Survey.
}

${ }^{2}$ APTIM, Inc., under contract to the U.S. Environmental Protection Agency. 3U.S. Environmental Protection Agency.

\section{Introduction}

The U.S. Geological Survey (USGS) and U.S. Environmental Protection Agency (EPA) are developing analytical tools to help evaluate the representativeness of groundwater samples from wells, particularly monitoring wells set in fractured rock. Groundwater chemistry can be affected by physicochemical processes in the wellbore external (ex-situ) to the aquifer. Examples of physicochemical processes include mixing of groundwater from different parts of the aquifer in the well and chemical reactions (ex-situ) from exposure of well water to heating or cooling and to oxygen from the atmosphere (Vroblesky and others, 2007).

Currently [2020], most guidelines for collecting representative groundwater samples by pumping from wells involve, in part, achieving stabilization of water-level drawdowns and physicochemical properties of the water (Yeskis and Zavala, 2002). Although stabilization of hydraulics is achievable in many cases, stabilization of physicochemical properties of the water may or may not be achievable based on transient transport and pseudoequilibrium chemical conditions. Therefore, additional tools to help assess the representativeness of samples from a well are needed. For this study, the criteria for determining representativeness of a sample are based on the ability of pumped water to capture recent groundwater inflow from the aquifer to the well. Capture was assessed by computing in-well travel times using the analytical model called the Purge Analyzer Tool (PAT; Harte, 2017; Harte and others, 2019). Field testing was conducted on monitoring wells at the Stringfellow Superfund site, located in Jurupa Valley, in Riverside County, California. 


\section{Purpose and Scope}

The purpose of this report is to present findings from the "proof of concept" field testing in support of the evaluation and application of the PAT analytical model in replicating in-well flow during pumping of wells set in fractured-rock aquifers. Some specific objectives of this work include (1) identifying the likely time-dependent intervals of capture during purging (pumping) of a well, (2) assessing the heterogeneity of the fractured-rock aquifer and its effect on in-well flow, (3) measurement of in-well groundwater travel times and flow conditions, and (4) developing guidance on sampling and purging requirements needed to collect representative groundwater samples from monitoring wells.

This report includes a summary of the field data collected at the Stringfellow Superfund site in support of PAT testing (Harte, 2020), as well as analysis of field data and a discussion of the results. An important component of this work was the evaluation of the existing groundwater monitoring network at the site to collect representative groundwater samples. A subset of wells was chosen for simulations with the PAT and for further evaluation, including detailed field testing. The detailed field testing included borehole geophysical logging, vertical profiles of water chemistry, time-series collection of groundwater samples, and tracking of dispersed dyes in wells to determine pumped water flow conditions and the vertical velocity of well water. The methods used helped formulate important concepts regarding the collection of representative groundwater samples. This report does not contain a detailed explanation of how to run the PAT model; users interested in running the PAT model should consult Harte and others (2019).

\section{Site Description}

The Stringfellow Superfund site in Jurupa Valley in Riverside County, California, approximately 50 miles east of Los Angeles, was used as a disposal site of liquid hazardous waste from 1956 to 1972 (U.S. Army Corps of Engineers, 2016). The original 17-acre property is at the head of Pyrite Creek in Pyrite Canyon in the Jurupa Mountains (fig. 1). During its operation, the site received about 35 million gallons of hazardous waste. The liquid waste was disposed of in unlined disposal ponds and pits in Jurupa Valley. The waste pits and some ponds were capped in the mid-1980s as a part of an interim abatement program by the California Regional Water Quality Control Board Santa Ana Region. Because of waste disposal practices, contaminants were found in the groundwater underlying the site. Dilute plumes of contaminants, particularly trichloroethylene (TCE) and perchlorate, were found to extend southward from the former pit locations as early as 1972. For purposes of remediation, the plume has been divided geographically into four major groundwater zones (fig. 1). The established remediation goal of 5 micrograms per liter $(\mu \mathrm{g} / \mathrm{L})$ for TCE coincides with the EPA maximum contaminant level (MCL). Currently [2020], perchlorate concentrations have no remedial action level but are being compared to the California MCL of $6 \mu \mathrm{g} / \mathrm{L}$.

The subsurface geology consists of unconsolidated alluvium and underlying weathered and unweathered bedrock (granodiorite, quartz diorite, gabbro, and metasediments, including quartzite, schist, and paragneiss). Some wells have open borehole intervals in bedrock, but most of the site wells are completed with a screen and sand pack.

\section{Description of the PAT}

A brief description of the PAT analytical model is provided here; however, readers interested in additional details should consult the tool's user manual (Harte and others, 2019). The PAT computes in-well groundwater travel times for simple piston transport from open intervals of the well to the pump intake. The model provides insight into optimal purging parameters (time, rate, and pump position) needed for the collection of representative groundwater samples. The PAT can be used to predict (forward mode) purge times required to allow transport of contaminants from screen/open intervals of the well to the pump intake. The PAT can also be used to analyze existing monitoring purge records (reverse mode) to assess the role of well hydraulics on chemical stability of the pumped water.

The PAT uses a water budget approach (fig. 2) coupled with the solution of the Dupuit-Thiem equation using a Microsoft Excel VBA code that invokes the embedded iterative solver (Harte, 2017, eqs. 1 and 2; Harte and others, 2019). In this regard, the PAT is a coupled analytical-water budget model. The water budget approach assumes that all flow during pumping is composed of two components, the well storage (excluding aquifer storage) and radial inflow into the well. Radial inflow is further divided into horizontal inflow near the pump intake (the mixing zone $\left[\mathrm{M}_{\mathrm{z}}\right]$ ) and radial inflow outside of the mixing zone that becomes vertical flow. Horizontal inflow into the mixing zone is zero if the pump is situated in the casing. This conceptual model for aquifer well flow can account for different radial inflows into the well from different zones of hydraulic conductivity. Because it assumes minimal vertical-head gradients inside the well, the PAT is applicable to the relatively low purge rates utilized for groundwater sampling. 


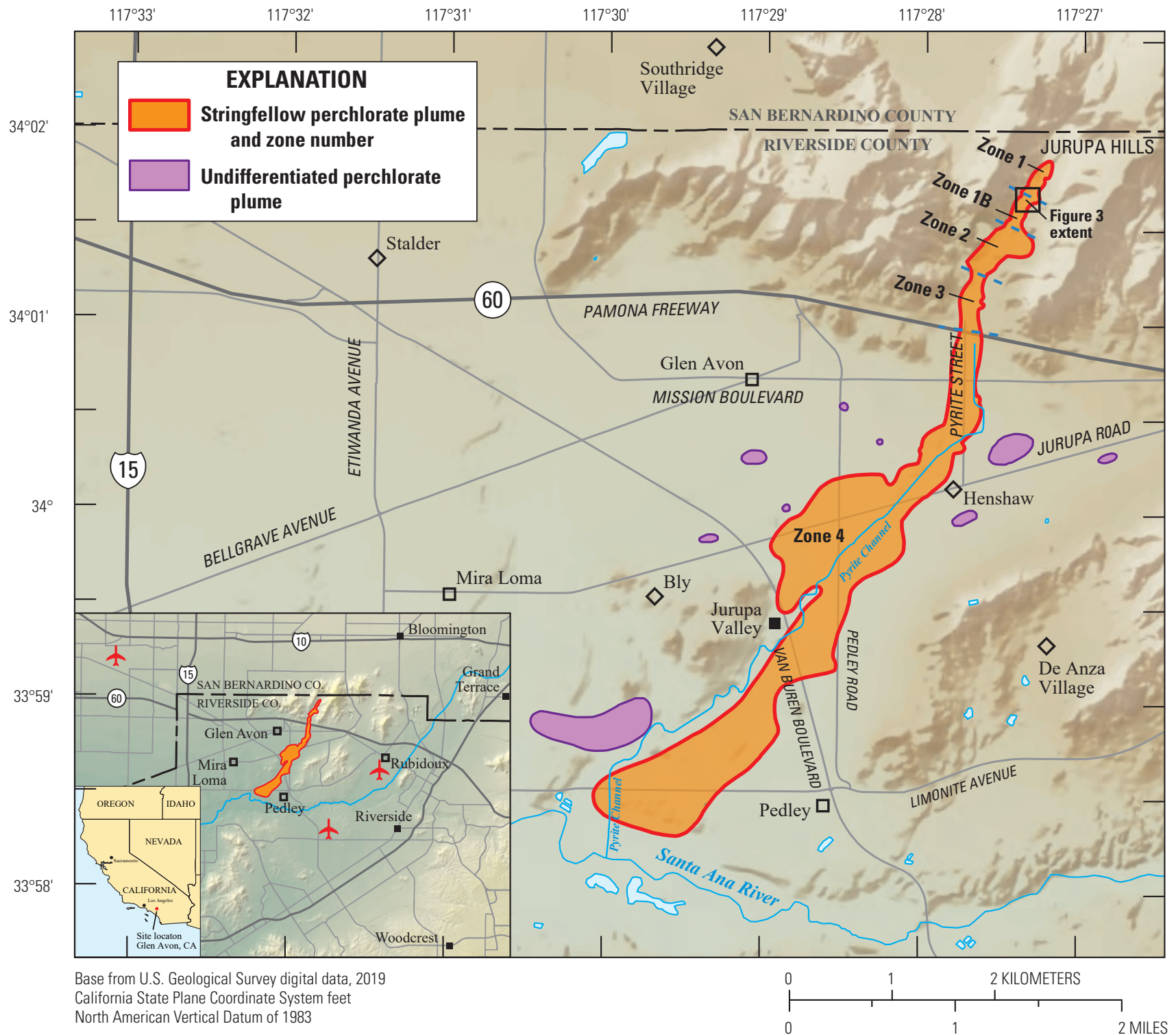

Figure 1. Map showing the location of the Stringfellow Superfund site and a groundwater plume in Jurupa Valley, California. 

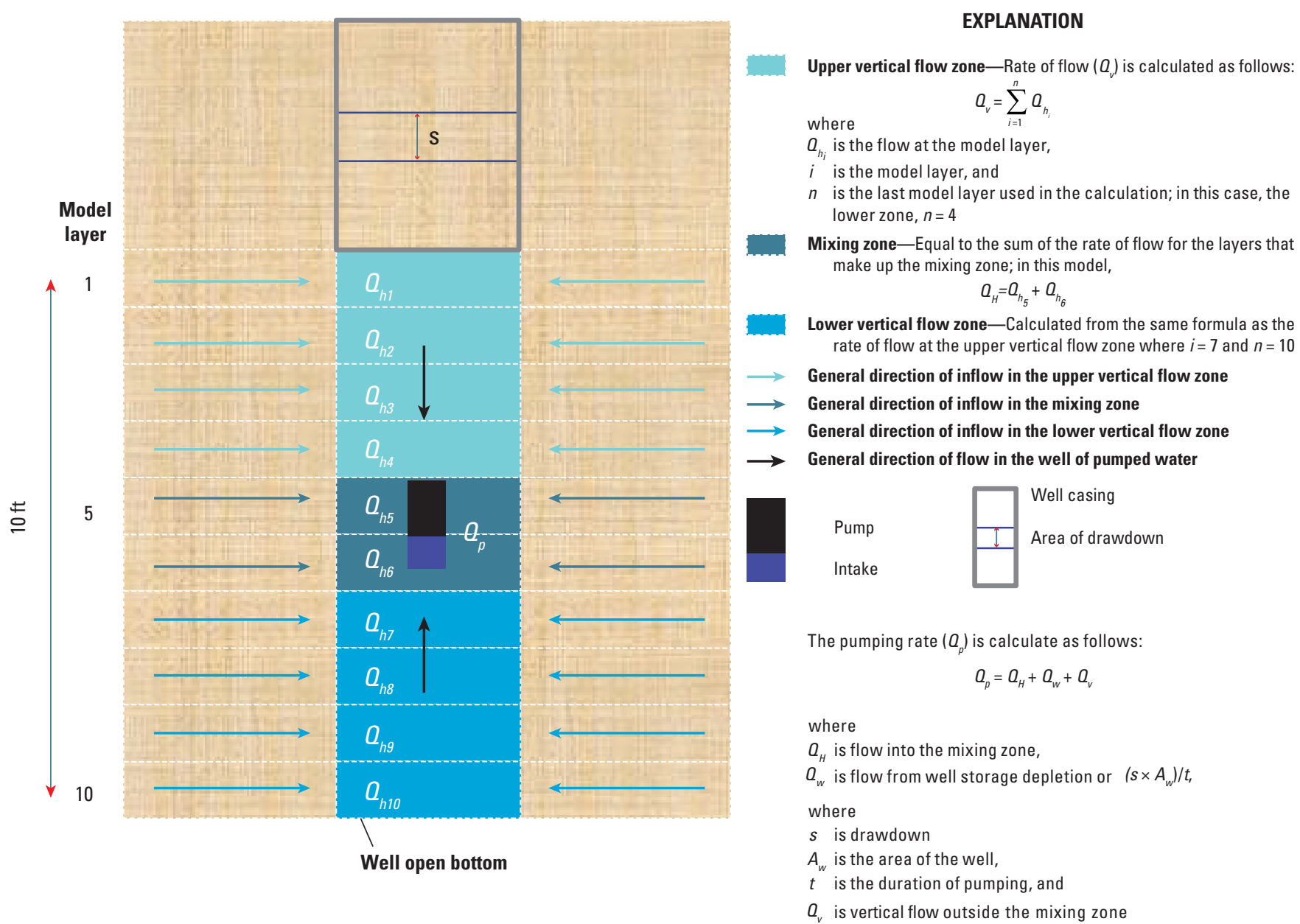

Figure 2. Schematic diagram of the water budget approach in the Purge Analyzer Tool (PAT; Harte, 2017; Harte and others, 2019).

\section{Study Approach and Methods in the Evaluation and Application of the PAT}

The criteria for assessing sample representativeness are based on the understanding of in-well groundwater travel times and on the physicochemical heterogeneity of the hydrogeologic unit. The PAT (Harte, 2017; Harte and others, 2019) software program was used to assess in-well groundwater travel times during purging and sampling. Hydraulic analysis was assessed to identify hydraulic properties and in-well flow dynamics. Chemical variability was assessed by the collection of chemical vertical profile data in the wells in conjunction with volume- and time-dependent groundwater samples from pumping. The integration of the hydraulic and chemistry information with the application of the PAT allowed for insight into the representativeness of groundwater samples from wells and whether the samples collected through routine sampling at the Stringfellow Superfund site tend to be indicative of the groundwater chemistry of the aquifer (GeoLogic Associates, 2015).
Project activities included field testing of in-well flow at selected monitoring wells near zone 1B of the Stringfellow Superfund site (fig. 3). A subset of 12 wells was reconnoitered to help refine the selection of wells on which to perform wellbore flow testing. Five wells were selected from the subset of the 12 reconnaissance wells. In-well flow and travel times under pumped conditions were assessed at the five wells through a combination of borehole geophysical logging, in-well dye tracer monitoring, chemical vertical profiles, and volume- and time-dependent groundwater sampling from pumping.

Borehole geophysical logging included natural gamma radioactivity, fluid resistivity and temperature, electromagnetic (EM) induction, and EM flowmeter. In the one open borehole, a video $\log$ and an acoustic televiewer log, a caliper, and an ambient and pumped flowmeter logs were also collected. In-well flow in these wells was tracked during pumping by releasing dyes at specified points in the wells to compute vertical travel times to the pump intake. Different dyes (rhodamine, fluorescein, and food-grade blue E133) were used at different depths of the well to map directional flow patterns to the pump intake under pumping conditions. The logging and dye data 


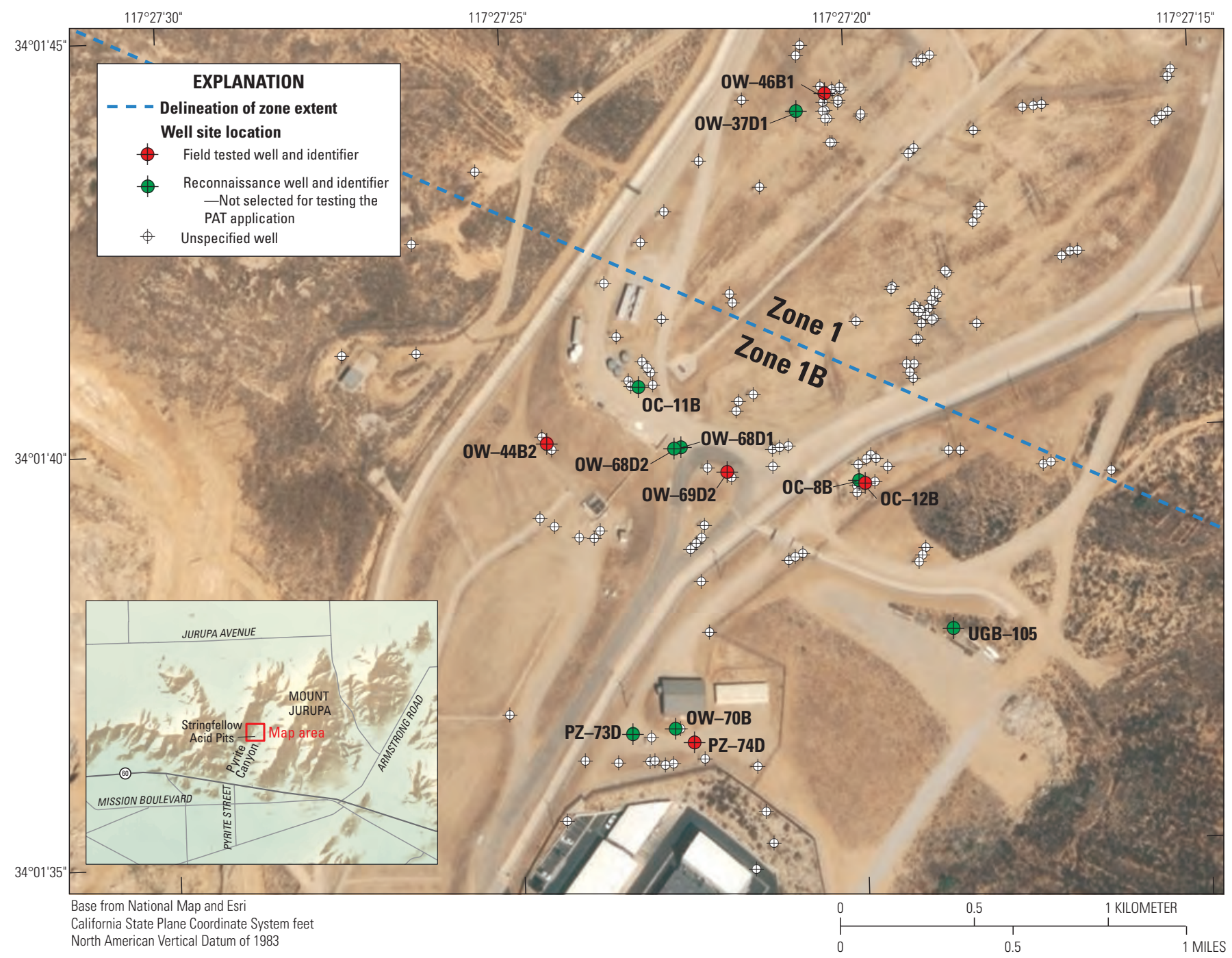

Figure 3. Map showing wells tested near zone 1B at the Stringfellow Superfund site in Jurupa Valley, California. PAT, Purge Analyzer Tool.

were used to evaluate in-well vertical travel times computed by the PAT and to identify wellbore processes where the PAT could be further enhanced.

Hydraulic testing during sampling was used to ascertain aquifer hydraulic properties, in-well flow, travel times, and time-dependent capture intervals of samples from wells. Hydraulic properties of the wells were analyzed using an inverse analysis by fitting the model-computed drawdowns to the observed drawdown with a Markov-chain Monte Carlo simulation embedded within the general well function (GWF; Perina and Lee, 2006; Perina, 2020). Solution using a Markovchain is based on the premise that the future estimate of the hydraulic property is dependent on the present estimate. The GWF includes transient-hydraulic processes such as aquifer storage. Results were compared with the hydraulic analysis embedded in the PAT to guide the computation of in-well travel times. The PAT assumes an adjusted steady-state radial inflow after factoring in well storage.
Water chemistry data were collected to identify differences associated with the different flow zones that were captured. Water chemistry was monitored for selected physicochemical parameters (specific conductance, temperature, and dissolved oxygen) and analyzed for TCE and other volatile organic compounds and for perchlorate. Samples of ambient water chemistry were collected along a vertical profile using a series of passive samplers at the five wells. After deployment and retrieval of passive samplers, two types of active purge samples were collected: a standard purge and an extended purge. At many monitoring wells at the Superfund site, samples were typically collected using bailers. Therefore, bailed samples were collected in addition to standard and extended purge samples. The standard purge includes collection of samples at one time after a predetermined purge duration; purge duration often is less than 45 minutes at low flow rates (less than 0.3 liter per minute [L/min]). Extended purge included collection of up to four temporal samples to 
investigate spatiotemporal variations in water chemistry and inferred travel times. The timing of the sample collections was informed by the PAT computations of time-of-travel and aquifer capture and occurred after the standard purge samples were collected.

Before and after purging, well profiles of water temperature and conductivity were collected to help delineate capture intervals during purging by comparing the changes in water temperature and conductivity of the purge water to the profile results. Further, examination of changes of prepumped and postpumped profiles help delineate where wellbore water movement and groundwater inflow occurred.

\section{Reconnaissance Survey}

A reconnaissance was performed of 13 wells near zone $1 \mathrm{~B}$ to ensure accessibility and confirm that well data recorded in the field matched reported well construction data (table 1). The reconnaissance required measurements of casing dimensions, depth to water level from top of casing, and well depth (sounding). Most wells were set in fractured rock. Well OW-37D1 was not accessible because it had an installed pump, and no data could be collected from it. Well OW-68D1 was dry. The reconnaissance results were used, along with well construction and information such as reported historical well concentrations, well hydraulics, lithology, and fracture characteristics, to help select wells for more comprehensive testing. Wells were visited in order from low to high TCE concentrations to reduce the likelihood of cross-contamination from equipment usage although all equipment was decontaminated between wells. Wells near zone 1B were selected (fig. 3) rather than wells from the other zones because the wells near zone 1B were secure from vandalism, accessible, and concentrations of constituents of interest (TCE and perchlorate) in these wells ranged from medium to high.

Ambient vertical chemistry profiles for specific conductance and temperature were measured at 11 wells as a screening tool to assess the degree of mixing in the well and the potential for differences in vertical chemistry. Six to eight measurements of the specific conductance and temperature of water were made at equally spaced depths within the water column of each well.

\section{Borehole Geophysical Logging}

All borehole geophysical data were collected using a Century Geophysical LLC system VI logging system. Limitations, calibration procedures, and algorithms used by the geophysical probes during logging are available from the manufacturers (Century Geophysical LLC, 2018; Mount Sopris Instruments, 2018).

All logs were collected according to the American Society of Testing and Materials borehole geophysical standard procedures (American Society of Testing and Materials, 2004, 2007, 2010). Geophysical logs were collected in digital format and were recorded in the proprietary format of the data acquisition equipment used to collect the logs. These proprietary data formats were converted to and stored as log ASCII standard format (Canadian Well Logging Society, 2013) for tabular data.

The natural gamma-ray logs provide a record of gamma radiation detected at depth in a borehole and are unaffected by well fluids. A scintillation detector is used in natural gamma radioactivity tools to measure the natural gammaray emission from radioactive material in the rock. The primary isotopes that emit gamma radiation are potassium $\left(\mathrm{K}^{40}\right)$, uranium $\left(\mathrm{U}^{238}\right)$, and thorium $\left(\mathrm{Th}^{232}\right)$. As each of these isotopes decay, the energy released contributes to the total natural gamma radioactivity. Typically, fine-grained sediments that contain abundant clay tend to be more radioactive than coarse-grained sediments, quartz sandstones, or carbonates (Keys, 1990). These logs are useful, in part, because of their versatility to function in polyvinyl chloride (PVC)- or steelcased wells with fluid- or air-filled boreholes and because they typically provide a good indication of layering or contacts between bedding.

EM-induction probes measure electrical conductivity in air- or water-filled boreholes and perform well in open or PVC-cased wells. The measurement of conductivity commonly is reciprocated to provide logs with curves of both resistivity and conductivity (Keys, 1990). Conductivity is affected by the salinity of borehole fluids, rock fluids, and the type of lithology encountered. Material in the annular space and metal centralizers used to center the well in the borehole can affect EM logs. Generally, pure carbonates, sands, and gravels have lower conductivity (thus higher resistivity) than clays or shales (Keys, 1990).

The EM flowmeter logs, collected at wells OC-12B and PZ-74D, measure the rate and direction of vertical flow in a well or borehole by using the principle of Faraday's law of induction. The EM flowmeter probe consists of an electromagnet and two electrodes 180 degrees $\left(^{\circ}\right.$ ) apart and $90^{\circ}$ to the magnetic field inside a 1.65-inch (in.) diameter hollow cylinder or tube. The voltage induced by a conductor (in this case, water) moving at right angles through the magnetic field is directly proportional to the velocity of the conductor through the field (Keys, 1990). The EM flowmeter logs collect information on vertical flow traversing past the tool sensor, and differences in vertical flow are indicative of horizontal inflow and outflow between the well and the aquifer with depth. EM flowmeter logs were run in trolling mode with the tool moving down and in stationary mode with the tool fixed at a constant depth.

Fluid logs (specific conductance and temperature) are best recorded in boreholes containing ambient fluid that have had sufficient time to stabilize. Fluid logs were the first logs collected and were recorded as the probes moved downward, recording ambient conditions before other probes passed through the borehole to avoid vertically mixing the borehole fluid. Curve deflections on the specific-conductance and temperature logs can indicate horizontal or vertical flow, stratification of borehole fluid, or well openings (Keys, 1990). Subsurface temperature data can provide information about 


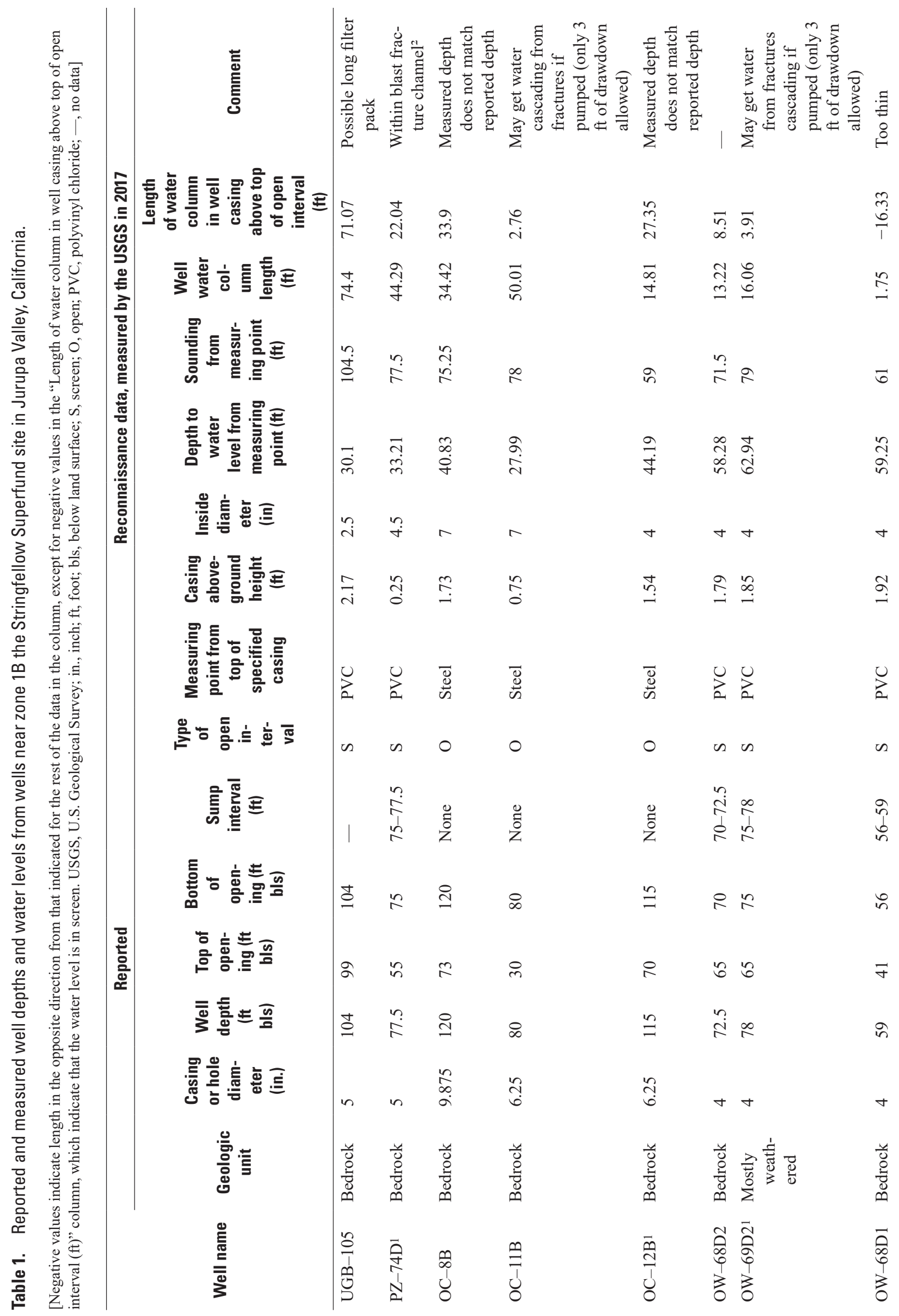




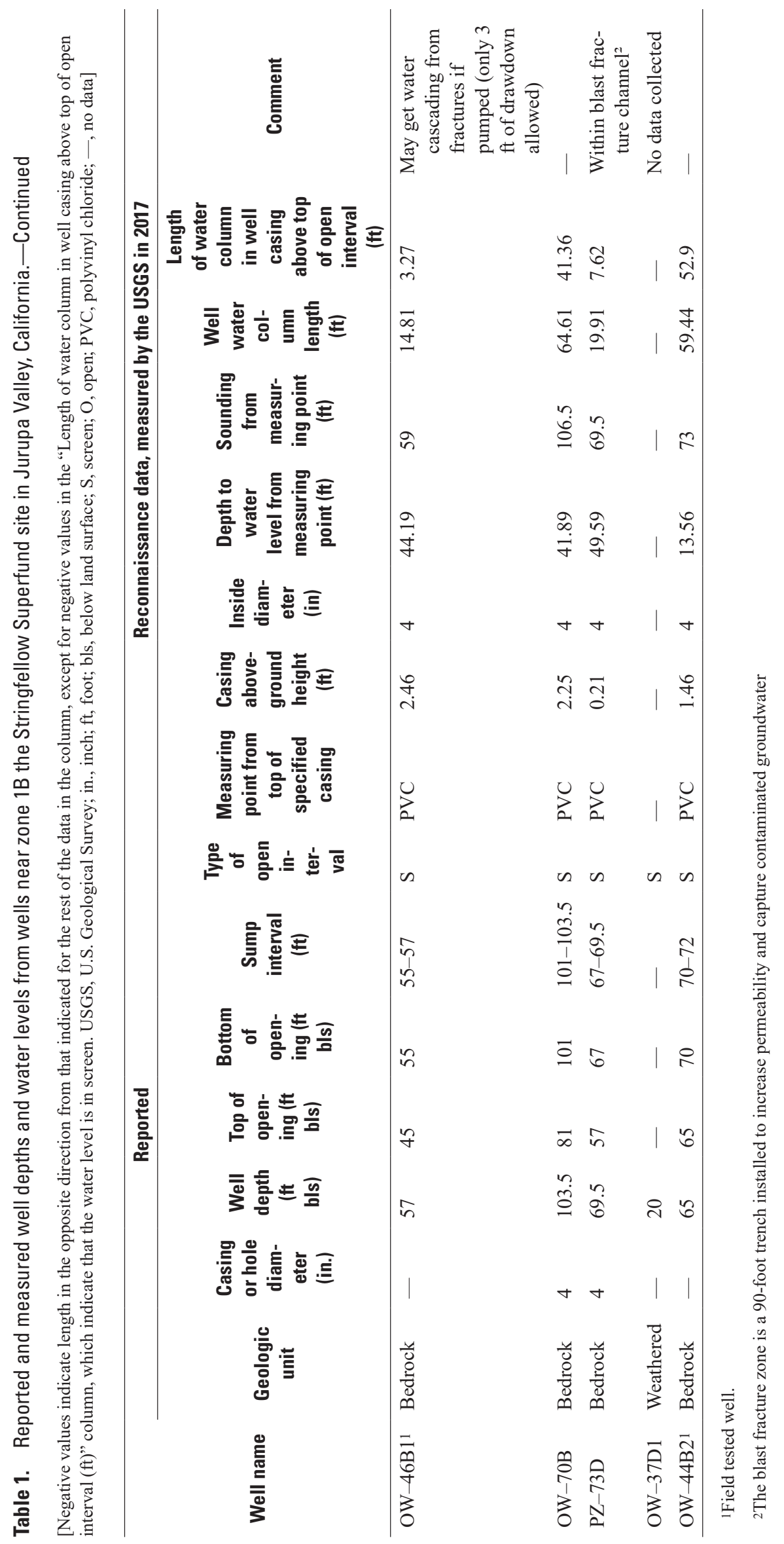


groundwater flow rates. In the absence of appreciable groundwater flow, conduction is the only heat-transport mechanism and results in a conductive geothermal gradient, or simply, "conductive thermal gradient" (Anderson and others, 2004).

An MSI model ABI-40, multi-echo, acoustic televiewer $\log$ was used. The ABI-40 can collect logs at speeds up to 3 feet per minute ( $\mathrm{ft} / \mathrm{min}$ ) and can log boreholes with diameters of up to $20 \mathrm{in}$. The ABI-40 tool uses a fixed head (source) and rotating mirror to direct the acoustic beam to the borehole wall and back to the transducer, producing higher-resolution images than the tools that have a rotating source and receiver (Williams and Johnson, 2004). The tool produces oriented images of the acoustic travel time and reflectivity of the borehole wall.

A video log was recorded for well OC-12B to examine features in the open borehole. The video log used two R-Cam 1000 XLT cameras in a single housing, each with a wide-angle lens, for viewing downhole and side view images in water wells or boreholes (Laval Underground Surveys, 2018). Low light level charge-coupled device sensors allow the cameras to detect images with minimal lighting power. Adjustable lighting with light-emitting diodes (LEDs) allows for optimal imagery. Data are stored as MPEG (.mp4) movie files (U.S. Geological Survey, 2020).

\section{Groundwater Sampling}

Groundwater sampling was done under passive and active sampling methods. Active sampling includes collection with a bailer and pumped samples. The passive samples included a profile of samplers, the bailer sample included just one collection point, and the pumped samples included timeseries collection.

\section{Passive}

Multiple passive samplers were installed to vertically profile concentrations in the five wells that were targeted for extensive field testing. The ability to associate contaminant concentrations to specific intervals of a well allows for improved estimation of travel times during purging of a well. For example, if the initial ambient concentrations of a contaminant show stratification in the well, then the arrival time of those concentrations can be used to refine in-well travel times and the distribution of well inflows (Harte, 2017). Further, TCE and perchlorate have unique chemical properties that can behave differently in the well water column; those differences can be exploited to identify capture intervals during pumping of wells.

The results of the borehole geophysical logging were used to identify where to deploy the passive samples. Samplers were deployed to coincide with known fractures, geologic contacts, inflow and outflow zones, and inflection points from fluid profiles. The location of samplers was further constrained to the open interval of the well and to the water column in the well casing (if present). One sampler per well was installed in the casing above the open interval (if saturated) to identify if there was degassing of TCE based on relative concentration differences between the water chemistry of water in the well casing and that of water in the screen/ open interval. Samplers were numbered from the bottom up. All samplers were fully submerged during deployment. The number of samplers deployed was well-specific but ranged between 3 and 10 per well.

Two types of passive samplers were used to accommodate the types of contaminants of concern present: rigid porous polyethylene (RPP) and polyethylene diffusion bag (PDB) samplers. Both samplers rely on diffusion of the dissolved chemical in the well water to come to equilibrium with contaminant-free water inside the sampler. Samplers consisted of laboratory-grade deionized water as the chemical uptake medium. Membranes differed for the two types of samplers. The RPP samplers were used to collect perchlorate samples; perchlorate is a large anion and can diffuse or transport through the RPP sampler (Parsons Engineering Science, Inc., 2005; Interstate Technology and Regulatory Council, 2006, 2007; Imbrigiotta and Harte, 2020). PDB samplers were used to collect volatile organic compounds (VOCs) such as TCE (Vroblesky, 2001a, b). The PDB sampler consisted of a 2-millimeter ( $\mathrm{mm}$ ), lay-flat polyethylene tubing. Lay-flat tubing is filled with laboratory-grade deionized water and sealed with a heat sealer during construction of the PDB. Many VOCs have a high diffusion coefficient and can diffuse through the lay-flat tubing. When deployed, the concentration of VOCs in the sampler slowly reaches equilibrium with the concentration in the surrounding well water. The PDB length selected for use on this project was $18 \mathrm{in}$. long, and the RPP length was 6 in. long. There was a 250 -milliliter $(\mathrm{mL})$-bottle requirement for the perchlorate; three RPP samplers were needed per sample to achieve the minimum $250-\mathrm{mL}$ volume. The RPP were submerged in a deionized water bath prior to deployment to prevent leakage of water through the membrane. All passive samplers were deployed in a protective mesh.

The laboratory-grade deionized water was sampled in a bottle and preserved prior to construction of samplers, and the sample served as a source solution blank. Laboratory-grade deionized water was provided by the San Diego field office of the California Water Science Center, USGS. The first PDB and RPP samplers constructed served as dedicated equipment blanks. The equipment blank samplers were stored with the other samplers in a deionized water bath and held until all other samplers were deployed. After deployment of all other samplers, water from the equipment blank samplers was bottled and submitted for TCE and perchlorate analyses. The equipment blank served multiple purposes: as a blank of the deionized water and to test for contamination of the samples before deployment. If TCE or perchlorate concentrations had been measured above reporting levels (they were not) from the submitted samples of the equipment blank, then the source solution blanks would have also been submitted for analyses to ascertain if the contamination was present in the source water itself or was introduced later in the sampling process. 
Sample duplicates were collected at each well by doubling the samplers at one fixed depth (slightly vertically offset by less than 0.5 foot [ft]) location per well.

Samplers were attached to a weighted line and lowered into the well to the desired depths. The passive samplers were left in place in the wells for 2 weeks to 1 month. Samplers were retrieved on the same day that the bailer samples were collected to allow for a contemporaneous comparison. Several VOCs quickly equilibrate with water in the PDB sampler in a relatively short (3 to 5 days) time frame (Harte, 2002). The RPP samplers also equilibrate relatively quickly, in about 14 days (Parsons Engineering Science, Inc., 2005).

Prior to collection of purged samples, passive samplers were retrieved by removing the weighted line and samplers. The condition of the samplers was noted to ensure the samplers were intact and whether iron-staining or other fouling may have inhibited diffusion during deployment. Iron-staining denotes redox reactions from mixing of different waters, such as oxygenated water from the sampler with reduced water from the well. During retrieval of the PDBs, the samplers were placed on clean aluminum foil until samples could be transferred to vials. Immediately after retrieval of the entire sample string, the water from inside the samplers was transferred to sample bottles (40-mL vials). No filtering was required for TCE. For the PDB, the lay-flat tubing was cut with a clean pair of scissors and the water was poured into a pretreated $40-\mathrm{mL}$ vial. The vials were pretreated with three drops of hydrochloric acid to ensure a water sample with a pH below 2 . Filtering for perchlorate through a 0.2 -micrometer $(\mu \mathrm{m})$ filter was needed because the membrane of the RPP is $7 \mu \mathrm{m}$. For the RPP, an end cap was removed, and the water was transferred from the RPP through a new dedicated syringe and filtered through a new dedicated $0.2-\mu \mathrm{m}$ filter into a $250-\mathrm{ml}$ polyurethane sample bottle.

Samples were shipped to the EPA Region 9 laboratory for analysis. The samples were analyzed for chlorinated VOCs by EPA method 8260 and for perchlorate by EPA method 331.0 (U.S. Environmental Protection Agency, 2005, 2006).

\section{Active}

Bailer samples were collected at five test wells. Previous site reports do not specify a depth of collection for the bailer samples and it is unknown at what depths the historical samples were collected (GeoLogic Associates, 2015, 2016). For the study in this report, the bailer samples were collected at the middle of the open or screen interval of the well by descending slightly past the middle of the interval. The wells were not purged before bailer collection so as to follow similar procedures as those used at the site for the sampled wells (GeoLogic Associates, 2014). The 3-ft-long, 1.5-in.-wide Teflon bailer (Aqua Bailers, 2020) feeds from the bottom during descension into the saturated water column of the well and stops filling when ascending because the ball valve plugs the bottom hole. After retrieval, samples were collected at the bottom of the bailer by inserting a device to push up against the ball valve to release the trapped fluid. The bailer was decontaminated before and after each use using a three-step cleaning process that included using a (1) cleaning with a nonphosphate, laboratory-grade detergent, (2) rinse that contains a deionizing solution, and (3) lastly a methanol rinse.

Active samples that were pumped are called purge samples in this report. Two types of purging were done. Standard purging was done following a modified low-flow protocol (Puls and Barcelona, 1996), and extended purging continued afterwards following the same protocols to assess spatiotemporal variability of contaminants of concern. The modified low-flow protocol approach allowed for water-level drawdown in the well casing but not the well opening (screen or open borehole). In fractured rock, dewatering of the open borehole can lead to cascading of groundwater via fractures into the well. For the extended purging, two or three additional samples were collected, depending on the well and pumping capacity. Temporal trends in contaminants of concern were compared with the vertical distribution of contaminants of concern from passive sampling and to the distribution of known fractures to develop insight into in-well travel time and chemical-mixing models.

Initially, four of the five test wells were pumped for purge samples. Wells OW-46B1 and OW-69D2 had only short (less than 5-ft-long) water columns (table 1) in the well casing, which was problematic when pumping the well because of the limitations associated with drawdowns in the well opening. Well OW-46B1 was pumped but experienced quick drawdowns, and pumping was stopped prior to dewatering of the well screen; no purge samples were collected at well OW-46B1. Well OW-69D2 was not pumped because of the experience at well OW-46B1. Only bailer samplers were collected at wells OW-46B1 and OW-69D2.

During purging, purge wastewater was discarded according to site protocols (GeoLogic Associates, 2015). All water except sampled water was discharged to waste containers and properly discarded according to site protocols.

Sampling was done via a sample line using a t-valvejunction. The flow rate off the junction was approximately 300 milliliters per minute $(\mathrm{mL} / \mathrm{min})$ to minimize turbulence. At each well, samples were collected from the sample line in the prescribed sequence to maintain consistency. New sampling tubing was used at each well to avoid cross-contamination between wells. A downhole Geosub SS submersible pump was used. The pump was decontaminated after each well following standard decontamination procedures (U.S. Geological Survey, 2019).

An inline flowmeter was used to track the purge volume and allow better tracking of the response of field parameters to purging. Water levels were measured periodically to determine pre-pumped and pumping water levels. A portable multiparameter YSI sonde with a flow through chamber was calibrated daily and used to measure temperature, dissolved oxygen, $\mathrm{pH}$, and specific conductance. Calibration checks were done daily to identify potential drift. 
The extended purge groundwater samples were collected following similar purge procedures, but the timing of the collection was informed by predictive PAT simulations and corresponding capture sequences based on in-well time of travel computations (Harte, 2017; Harte and others, 2019). Specifically, the pump time associated with the capture of pumped water that represents approximately the 60,80 , and 90 percent mark of the total capture of recent inflowing aquifer water, as determined from the PAT, was used to time the collection of the extended purge samples. These capture percentages are determined from the in-well time of travel to the pump intake whereas the remaining capture percent represents in-place well water prior to pumping of the well.

The procedure for groundwater sampling at the test wells included these steps:

1. Measure water level and record location of measurement point.

2. Configure new tubing length and attach to pump.

3. Hook up flow through cell to sonde.

4. Attach frozen dyes to pump string (pump hose or electrical line) at selected distances from the pump intake.

5. Lower pump to desired depth (typically at the midpoint of the well open interval).

6. Install pressure transducers and remeasure water level.

7. Turn on pump.

8. Record start time and flow rate.

9. Purge according to standard operating procedures (typically involves a purge duration of 40 to 50 minutes).

10. Prepare bottles and labels.

11. Measure water levels periodically.

12. Record six parameter values each measurement period (pressure, water temperature, water specific conductance, and three dyes).

13. At prescribed sample times, open sample t-valve.

14. Allow sample line to flush for 5 minutes.

15. Sample for VOCs then perchlorate.

16. Continue purging for extended purge samples.

17. Repeat sampling steps for extended purge.

18. After sampling, switch off sample port and record final parameters through waste line.

19. Document chain of custody.

20. Ship samples to the EPA Region 9 laboratory for analysis.
21. Analyze samples for chlorinated VOCs by EPA method 8260 and for perchlorate by EPA method 331.0 (U.S. Environmental Protection Agency, 2005, 2006).

\section{Dye Testing}

During deployment of the pump string, the rhodamine, fluorescein, and food-grade blue dyes were lowered into the well. The rhodamine was placed above the pump intake at distances of 2.5 to $5 \mathrm{ft}$. The fluorescein was placed below the pump intake equidistant from the rhodamine. The food grade dye was placed with the fluorescein to check velocity rates of the fluorescein dye. The dyes were deployed frozen, according to methods described by Harte (2013). The frozen dyes were placed in a modified, 4-in.-long, 250-mL polyurethane bottle, nylon screen sampler with a coarse-size, 255- $\mu \mathrm{m}$ mesh to allow for rapid disbursement downhole. The dyes were lowered with the pump string, and the pump was turned on within a few minutes of deployment to reduce the effect of inwell dye mixing due to ambient flow patterns before the start of pumping.

Dye tracers were monitored in the pump discharge line at the surface with calibrated Turner Designs Cyclops sensors (Turner Designs Inc., 2018) for rhodamine and fluorescein. The sensors were hooked to CR-1000 and CR-10X data loggers for recording and display, and values were recorded every minute. The food-grade blue dye was measured manually, every 10 minutes, with a hand-held Hach colorimeter that measured at a $600-\mu \mathrm{m}$ wavelength.

Dye placement distances from the pump intake were located based on predictive PAT simulations (pretest) of potential vertical flow velocities and travel times in the test wells given potential pump position, rates, and duration. Dyes were positioned close enough to the pump intake (typically 2.5 to 5 $\mathrm{ft}$ apart) such that dye mobilization was expected within a 1to 2-hour window.

\section{Hydraulic Analysis and Simulation}

For the test wells that were pumped for an extended duration (wells PZ-74D, OC-44B2, and OC-12B), pump rates and water levels were measured to allow for single well hydraulic analysis. Pressure heads were measured continuously with a Druck 0 - to 10 -pound per square inch $\left(\mathrm{lb} / \mathrm{in}^{2}\right)$ downhole pressure transducer connected to a $\mathrm{CR}-10 \mathrm{X}$ data logger recording at 1-minute intervals. Manual water levels were measured periodically with an electric tape as backup and used to calibrate continuous measurements. The pressure head data were converted to water levels from the relation between the manual measurements and the pound-per-squareinch value following methods described by Harte (2005). An inline flowmeter, which uses ultrasonic principles to measure flow, was used to track pump rates. 
Water levels recorded during purge-testing of wells PZ-74D, OC-44B2, and OC-12B were analyzed as timedrawdown pumping test data using the general well function (GWF) of Perina and Lee (2006). Estimated aquifer properties included hydraulic conductivities in the radial and vertical direction and specific storage. The GWF also calculates the flow from the aquifer into the well as part of the solution to accommodate temporal inflow changes during the early times of pumping. For low-permeability aquifers, at the start of pumping, most of the extracted water is from the storage within the well casing and inflow from the aquifer is a small fraction of the extraction rate. Before the groundwater inflow from the aquifer becomes equal to the pumping rate, the extracted water is a mix of water in the casing and inflowing groundwater from the aquifer. The time duration required for aquifer inflow rate to equilibrate with the pumping rate can be considered a minimum purge time required before sampling.

For the GWF simulations, purge rates were approximated by a constant (average) rate for well PZ-74D, five pumping steps for well OC-44B2, and two pumping steps for well OC $-12 \mathrm{~B}$, based on purge records. The aquifer thickness was assumed to be from the water table to the bottom of the well screen; more accurate information was not available. Well skin effects, with and without, were simulated but the hydraulic conductivity estimates of the skin have large uncertainty because the properties of these skins cannot be uniquely determined from single-well tests. For purposes of comparisons with the PAT estimates, the simulation with no well skin is applicable because both aquifer and skin hydraulic conductivities are implicitly coupled by the PAT solution. Further information on well skin effects can be found in Cooley and Cunningham (1979).

All the estimated aquifer properties assume an equivalent porous medium even though the actual aquifer is fractured bedrock or decomposed bedrock that may contain weathering residues in various combinations with intact rock in addition to fractures resulting in channeled flow. Therefore, estimated parameters represent an average of the bulk flow for the entire saturated aquifer. At that scale, an equivalent porous medium is a reasonable approximation.

The purge records (information from the pumping and sampling of wells) from wells OC-12B, OW-44B2, and PZ-74D (table 2) were converted to time-drawdown and time-flowrate data and evaluated as pumping tests. The purge record from well OC-46B1 did not contain a sufficient number of water level measurements to allow curve fitting. Purge (pumping) rates were approximated by a constant (average) rate for well $\mathrm{PZ}-74 \mathrm{D}$, five pumping steps (with purge rate constant within each step) for well OW-44B2, and two pumping steps for well OC-12B (table 3).

The observations for the time-drawdown response were curve fitted in a Markov chain simulation (see for example, Tarantola, 2005; Robert and Casella, 2010). The starting parameters for the Markov chain were determined by a genetic algorithm and three Markov chains were executed sequentially to improve proposal distributions (Perina, 2020).
Table 2. Well construction information for the general well function model analysis, Stringfellow Superfund site in Jurupa Valley, California.

[Some values are listed in meters, which are converted to feet by multiplying meters by 3.28. General well function model is from Perina and Lee (2006). in., inch; ft, foot; bls, below land surface; m, meter; S, screen; O, open borehole]

\begin{tabular}{|c|c|c|c|}
\hline Information & PZ-74D & OC-12B & OW-44B2 \\
\hline $\begin{array}{l}\text { Casing or borehole diameter } \\
\text { (in.) }\end{array}$ & 4 & 6.25 & 4 \\
\hline Screen type & S & $\mathrm{O}$ & $\mathrm{S}$ \\
\hline Geologic unit material & $\begin{array}{r}\text { Weathered } \\
\text { bedrock }\end{array}$ & Bedrock & Bedrock \\
\hline Depth to water level (ft bls) & 33.21 & 44.19 & 13.56 \\
\hline Depth to top of screen ( $\mathrm{ft}$ bls) & 55 & 70 & 65 \\
\hline $\begin{array}{l}\text { Depth to bottom of screen } \\
\text { (ft bls) }\end{array}$ & 75 & 115 & 70 \\
\hline Aquifer thickness (ft) & 41.79 & 70.81 & 56.44 \\
\hline Well casing inner radius (in.) & 0.0508 & 0.0794 & 0.0508 \\
\hline $\begin{array}{l}\text { Height of water level above } \\
\text { top of screen (ft) }\end{array}$ & 21.7792 & 25.8136 & 51.4304 \\
\hline $\begin{array}{l}\text { Height of water level above } \\
\text { bottom of screen (ft) }\end{array}$ & 41.7872 & 70.7824 & 56.416 \\
\hline Aquifer thickness (m) & 12.74 & 21.58 & 17.2 \\
\hline Well casing inner radius (m) & 0.0508 & 0.0794 & 0.0508 \\
\hline $\begin{array}{l}\text { Height of water level above } \\
\text { top of screen }(\mathrm{m})\end{array}$ & 6.64 & 7.87 & 15.68 \\
\hline $\begin{array}{l}\text { Height of water level above } \\
\text { bottom of screen (m) }\end{array}$ & 12.74 & 21.58 & 17.2 \\
\hline
\end{tabular}

Table 3. Estimated pumping rates for wells used in calculations for the general well function model, Stringfellow Superfund site in Jurupa Valley, California.

[General well function model is from Perina and Lee (2006) and Perina (2020). Q, pump rate recorded as stepwise change; min, minute; L/min, liter per minute; $\mathrm{Q}_{\text {ave }}$, time-weighted average pump rate; NE, not estimated; - , no data]

\begin{tabular}{llllll}
\hline \multicolumn{2}{c}{ PZ-74D } & \multicolumn{2}{c}{ OW-44B2 } & \multicolumn{2}{c}{ OC-12B } \\
\hline Time & $\mathbf{0}$ (L/min) & Time (min) & $\mathbf{0}$ (L/min) & Time (min) & $\mathbf{0 ~ ( L / m i n ) ~}$ \\
\hline- & $\mathrm{NE}$ & 0 & 2.49 & 0 & 2.45 \\
- & $\mathrm{NE}$ & 19 & 2.26 & 12 & 1.91 \\
- & $\mathrm{NE}$ & 38 & 1.19 & - & - \\
- & $\mathrm{NE}$ & 43 & 0.87 & - & - \\
- & $\mathrm{NE}$ & 70 & 0.39 & - & - \\
$\mathrm{Q}_{\mathrm{ave}}$ & 2.741 & - & 1.56 & - & 2.00 \\
\hline
\end{tabular}

${ }^{1}$ Measured once. 
The GWF accounts for partial penetration and casing storage in both the pumping and observation wells and represents pumping from confined, unconfined, or leaky aquifers. The aquifer was analyzed primarily as confined. The estimated aquifer properties included hydraulic conductivity in the radial direction $\left(K_{r}\right.$, the subscript $r$ is used to indicate that $K_{r}$ is horizontal hydraulic conductivity in the radial direction according to the cylindrical coordinate system with radial symmetry used in the model), vertical-to-horizontal anisotropy in hydraulic conductivity $\left(K_{z}: K_{r}\right)$, and specific storage $\left(S_{s}\right)$.

The GWF can simulate different aquifer types; the analysis for this study used a confined aquifer model (the simplest aquifer type) because it is much faster to execute, and the results are not expected to be very different from an unconfined model. The tested aquifer may be considered unconfined, but due to the relatively short duration of pumping, the time-drawdown response in the pumping wells was expected to be nearly identical to the response of a confined aquifer. To confirm this expectation, the observations for well PZ-74D were analyzed by fitting both confined and unconfined aquifer models, and the model-computed values for $K_{r}, K_{z}: K_{r}$, and $S_{s}$ compared. For the simulation of the unconfined condition, a specific yield parameter was included. The other two wells were not selected for fitting the unconfined aquifer model because of the long computational time that would be required due to the multiple pumping steps.

The PAT was used in predictive mode to simulate inwell time of travel at the reconnaissance wells under simple homogeneous conditions. The selection of homogeneous conditions was partly necessitated by not knowing the fracture or fracture locations relative to the well screen or open interval for each well. If prior hydraulic conductivity estimates were available, those hydraulic conductivity values were simulated to compute the in-well time of travel required for purging of the well. If no hydraulic conductivity values were available, a uniform value of 0.1 foot per day (ft/d) based on reported ranges between 0.0024 and $1.81 \mathrm{ft} / \mathrm{d}$, with a calculated geometric mean of $0.071 \mathrm{ft} / \mathrm{d}$, of slug tests in 26 unweathered bedrock wells in zone 1B (Environ International Corp., 2012) was used.

The PAT was also used in calibration mode after testing to attempt to match the measured dye travel. The first large concentration increase (peak or near peak) was used as an arrival time of the dye as a marker of travel time. PAT simulations were used to help match the computed velocities from the dye arrival by adjusting two user assigned parameters for a given bulk hydraulic conductivity: the heterogeneity factor (HF) and the length of the mixing zone $\left(\mathrm{M}_{\mathrm{z}}\right)$. The HF affects flow patterns and travel times to the pump intake by influencing the distribution of inflowing groundwater across the well opening. In some cases, the pump intake was placed in the midpoint of the well opening; asymmetric arrival of dyes indicates asymmetric directional velocities in the well. Changing the vertical extent of the $\mathrm{M}_{\mathrm{z}}$ also influences computed vertical travel times (Harte and others, 2019). The $M_{z}$ is the zone where well water mixes near the pump and vertical flow is not calculated. Therefore, for a large $\mathrm{M}_{\mathrm{z}}$, the distance of vertical travel is shorter than for a small $\mathrm{M}_{\mathrm{z} \text {, }}$ and the simulated vertical velocities are lower because the $\mathrm{M}_{\mathrm{z}}$ length affects horizontal inflow directly and vertical flow inversely (fig. 2).

\section{Additional Vertical Profiles of Pumped Wells}

Well profiles of fluid water temperature and specific conductance were also collected, after purging, to help identify sample capture intervals, using an InSitu Inc. Aqua TROLL multiparameter handheld probe. Profiles were compared to ambient well profiles and differences noted as an indicator of potential inflow or outflow zones.

The probe was lowered down the well at a slow, steady rate to minimize water disturbance; stops were made before each reading to allow the probe adequate time to equilibrate and record each parameter. The depth of each reading was recorded by the pressure sensor on the probe and was referenced to depth below ground surface for graphical display. Readings were taken at varying depths from just below the water surface to the total depth of the well.

\section{Results of the Evaluation and Application of the PAT}

Additional data for this project are available at Harte (2020). The discussion of the study results in this report is divided into several sections including findings from the reconnaissance survey, findings from the data collected at the field-tested wells, and results of hydraulic analysis of pumping conditions during active sampling. The discussion of field testing includes results from the borehole geophysical logs, groundwater sampling, vertical profiling of physicochemical properties, and analysis of simulations with the PAT.

\section{Findings From Reconnaissance Survey}

The vertical variability in specific conductance and temperature, as determined by the standard deviation of the values collected from the vertical physicochemical profiles, is graphically plotted against the water column length (fig. $4 \mathrm{~A}$ and $C$ ) and the screen or open interval length (fig. $4 B$ and $D$ ). Wells that exhibit high variability for an associated water column length or screen length are plotted in the upper left quadrant of the graphs; wells that exhibit low variability are plotted in the lower right quadrant of the graphs. The standard deviation should theoretically increase with an increase in the screen length unless mixing occurs in the water column of the well or the groundwater chemistry of the aquifer is relatively homogeneous.

Relatively high vertical variability (high standard deviation) in specific conductance of well water is seen at wells PZ-73, OW-46B1, and PZ-74D, indicating a high potential for identifying groundwater chemistry that varies in the aquifer with depth. Moderate vertical variability in specific 
A. Specific conductance relative to water column length

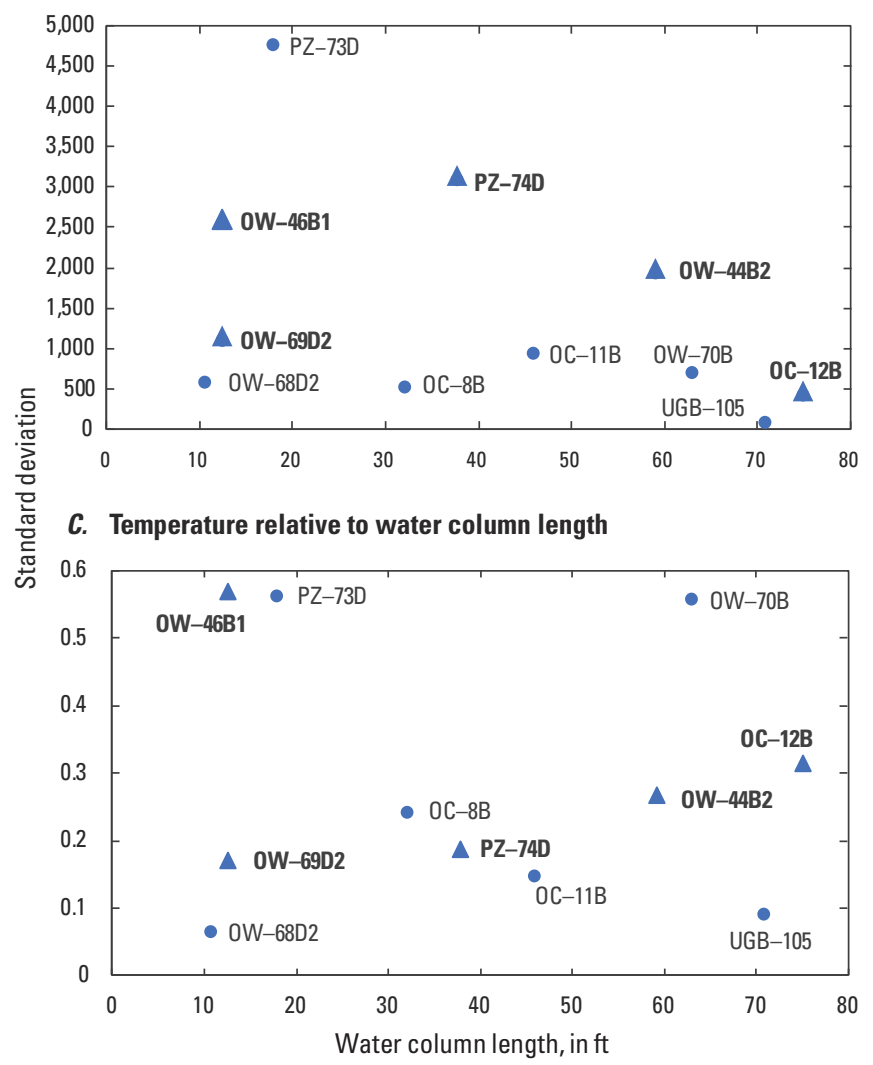

$B$. Specific conductance relative to screen length

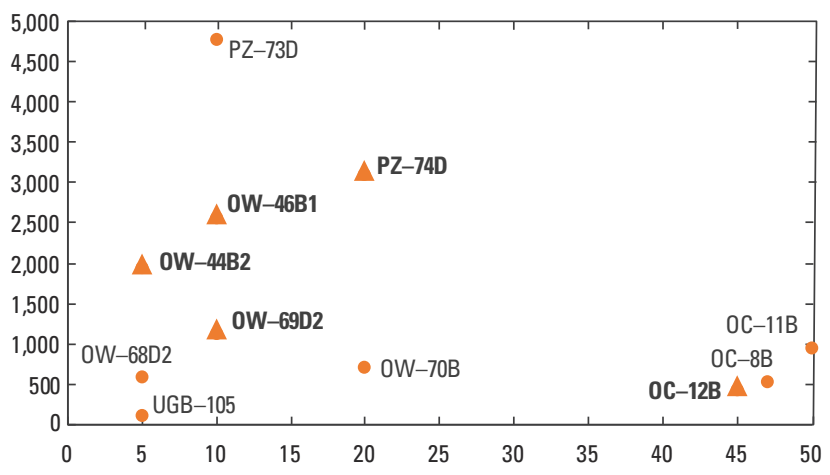

D. Temperature relative to screen length

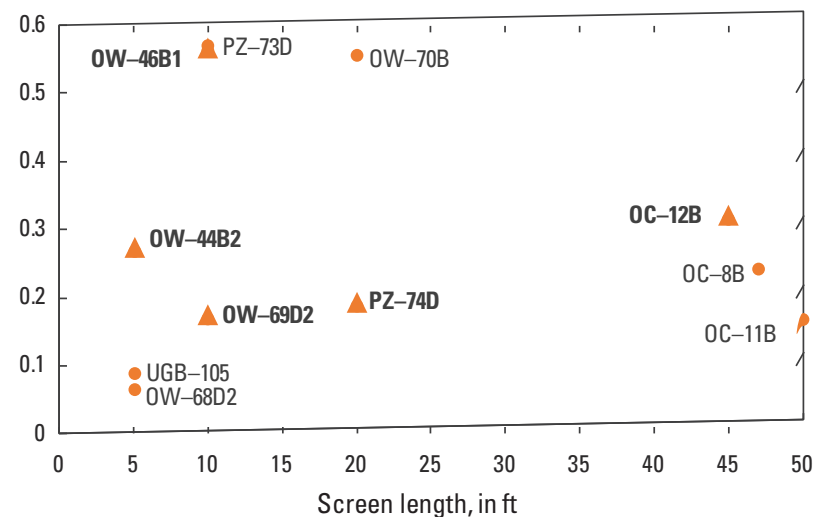

\section{EXPLANATION}

Reconnaissance well-Relative to water column length, relative to screen length

- Water column (blue color)

- Screen length (orange color)

Test well-Relative to water column length, relative to screen length

A Water column (blue color)

A Screen length (orange color)

Figure 4. Graphs of standard deviation from values measured during vertical profiles of wells for $A$ and $B$, water specific conductance and $C$ and $D$, water temperature relative to water column length and screen length at the Stringfellow Superfund site in Jurupa Valley, California. Well identifiers in bold typeface indicate the test wells used in the general well function analysis. $\mathrm{mS} / \mathrm{cm}$, microsiemens per centimeter; $\mathrm{ft}$, foot; ${ }^{\circ} \mathrm{C}$, degree Celsius.

conductance is seen at wells OW-69D2 and OW-44B2. Less vertical variability is seen in specific conductance at wells OW-68D2, OC-8B, and OC-11B, and little vertical variability (low standard deviation) is seen at wells OW-70B, OC-12B and UGB-105. Well UGB-105 showed the least variability in vertical water temperature and specific conductance; this suggests that the well is poorly connected to the aquifer.

For the vertical water-temperature profiles, most wells show little vertical temperature variation other than that likely caused by the natural geothermal gradient and annual (seasonal) temperature variations in the shallow subsurface (fig. $4 C$ and $D$ ). The exceptions are wells OW-46B1, OW-70B, and PZ-73, which show the greatest vertical variability in temperature that could be caused by horizontal groundwater flow with nonuniform and distinct water temperatures.

\section{Borehole Geophysical Logs}

Based on the natural gamma-ray logs, weathering in the rock and the vertical location of contacts between more weathered and less weathered rock for wells PZ-74D, OW-69D2, and OC-12B were delineated (figs. 5 to 8). Wells OW-46B1 and $\mathrm{OW}-44 \mathrm{~B} 2$ have short screens and likely do not intersect the contact. 
All five wells logged contain metal centralizers that affect the responses of the EM-induction tool. The metal centralizers are used during well installation to center the well within the borehole. Interference from the metal centralizers are reduced if the centralizers are spaced far enough apart as they were at wells PZ-74D (fig. 5) and OW-69D2 (fig. 7). The EM-induction $\log$ for well OC-12B is not shown because of interference from the centralizers.

Some fluid logs under ambient flow conditions show changes with depth such as at well PZ-74D at a depth of 72.5 $\mathrm{ft}$ depth (fig. 6). At that depth, a small inflection in the fluid resistivity log is visible indicating the presence of a hydraulically active flow zone. Ambient fluid logs from the other wells show small changes within the well opening; most changes in fluid logs occur between the well water in the casing and water within the well opening (figs. 8 to 11). This indicates differences in well water chemistry between the casing and opening part of the well.

Well OC-12B is an open borehole, which allowed for the collection of an acoustic televiewer log (fig. 12), and EM-flow measurements. For the most part, travel times from the acoustic signal do not show appreciable fracturing in the borehole and it is likely the hydrogeologic unit is uniformly weathered.

The fluid logs for well OC-12B were run under ambient and pumped conditions where the pump was placed above the open borehole interval (figs. 13). The differences in fluid resistivity between ambient (unpumped) and pumped conditions denote changes that result from either inducement of inflow into the borehole or redistribution of water in the borehole from convergence of flow toward the pump. For well OC-12B, pumping induces mixing of casing water (above a depth of $70 \mathrm{ft}$ ) with water within the open borehole (below a depth of $70 \mathrm{ft}$ ). There appears to be little inflow of groundwater from the aquifer from pumping as denoted by the absence of inflection points (changes in fluid resistivity log) within the well opening.

The EM-flow logs for stationary readings under unpumped conditions for well OC-12B show differences in vertical flow between readings at 60 to $75 \mathrm{ft}$ and 104 to $112 \mathrm{ft}$ (fig. 14). Because of the shift between flows, it is likely that some inflow occurs between 75 and $104 \mathrm{ft}$ below land surface despite little differences in the fluid resistivity logs under unpumped and pumped conditions.

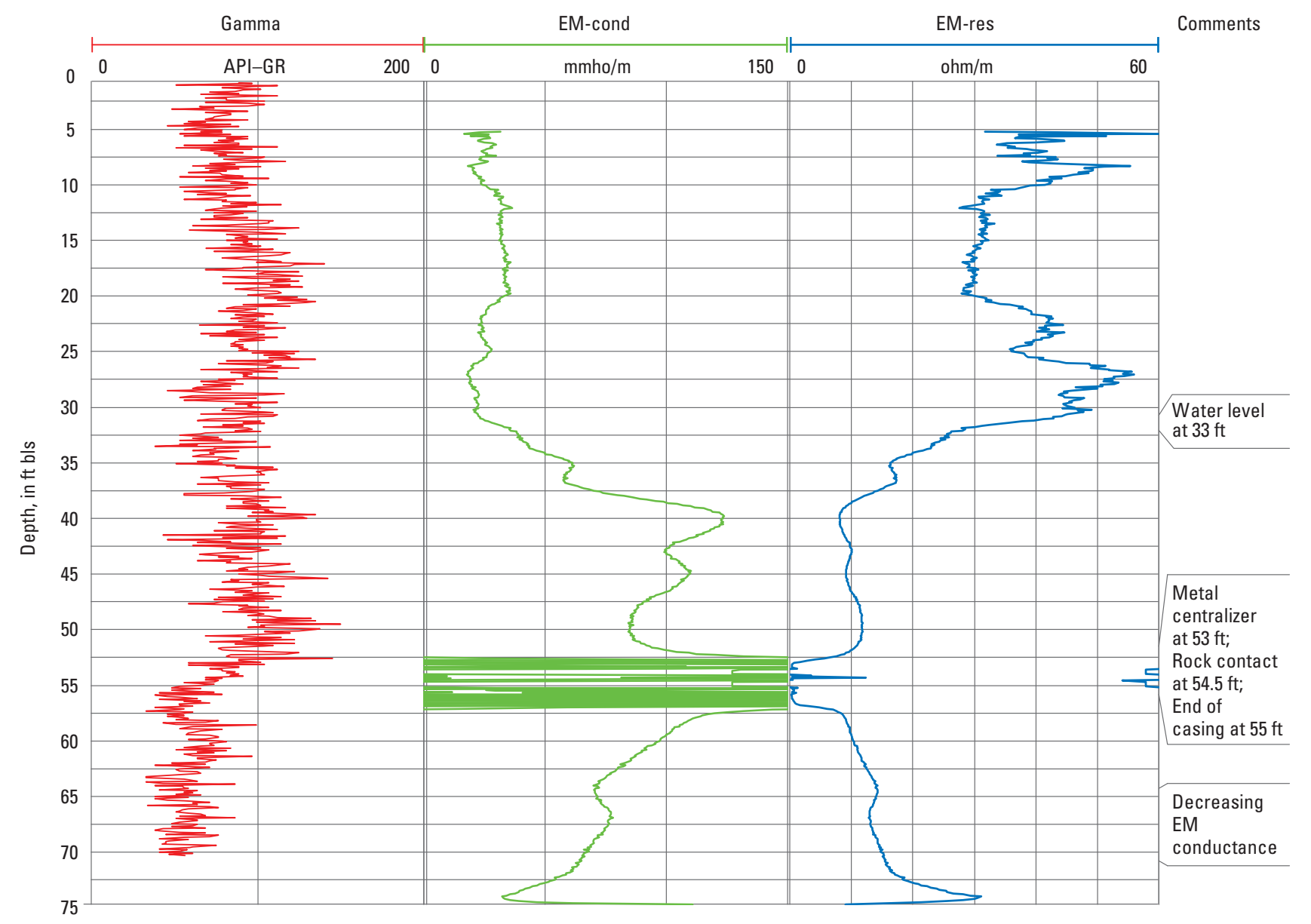

Figure 5. Logs of natural gamma radioactivity and electromagnetic (EM) induction for well PZ-74D at the Stringfellow Superfund site in Jurupa Valley, California. Resistivity is the inverse of conductivity. API-GR, American Petroleum Institute gamma ray unit; $\mathrm{mS} / \mathrm{m}$, millisiemens per meter; ohm/m, ohm per meter; bls, below land surface; ft, foot. 


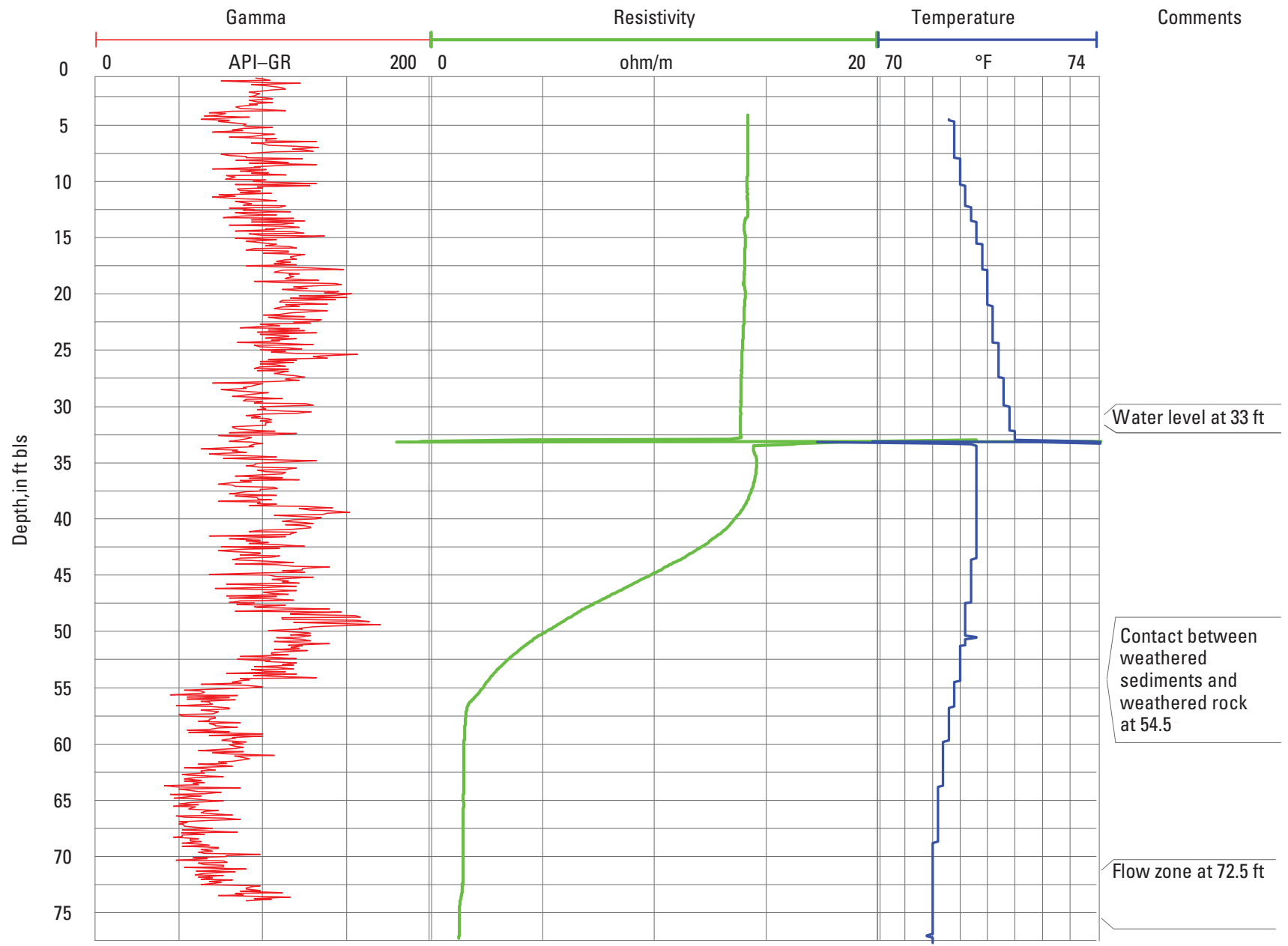

Figure 6. Logs of natural gamma radioactivity, fluid resistivity, and fluid temperature for well PZ-74D at the Stringfellow Superfund site in Jurupa Valley, California. API-GR, American Petroleum Institute gamma ray unit; ohm/m, ohm per meter; ${ }^{\circ}$, degree Fahrenheit; bls, below land surface; $\mathrm{ft}$, foot. 


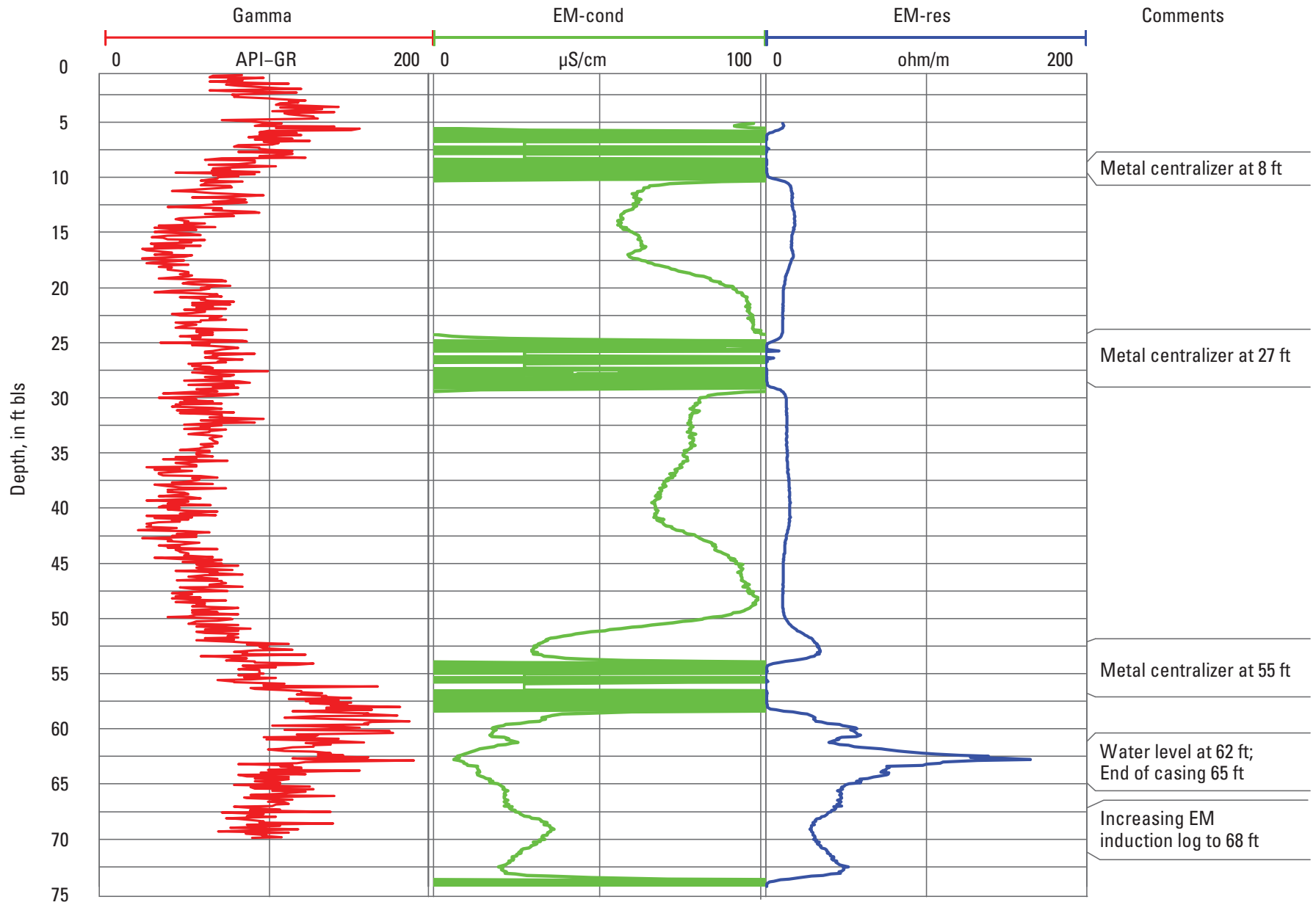

Figure 7. Logs of natural gamma radioactivity and electromagnetic (EM) induction for well OW-69D2 at the Stringfellow Superfund site in Jurupa Valley, California. Resistivity is the inverse of conductivity. API-GR, American Petroleum Institute gamma ray unit; $\mathrm{mS} / \mathrm{m}$, millisiemens per meter; ohm/m, ohm per meter; bls, below land surface; $\mathrm{ft}$, foot. 


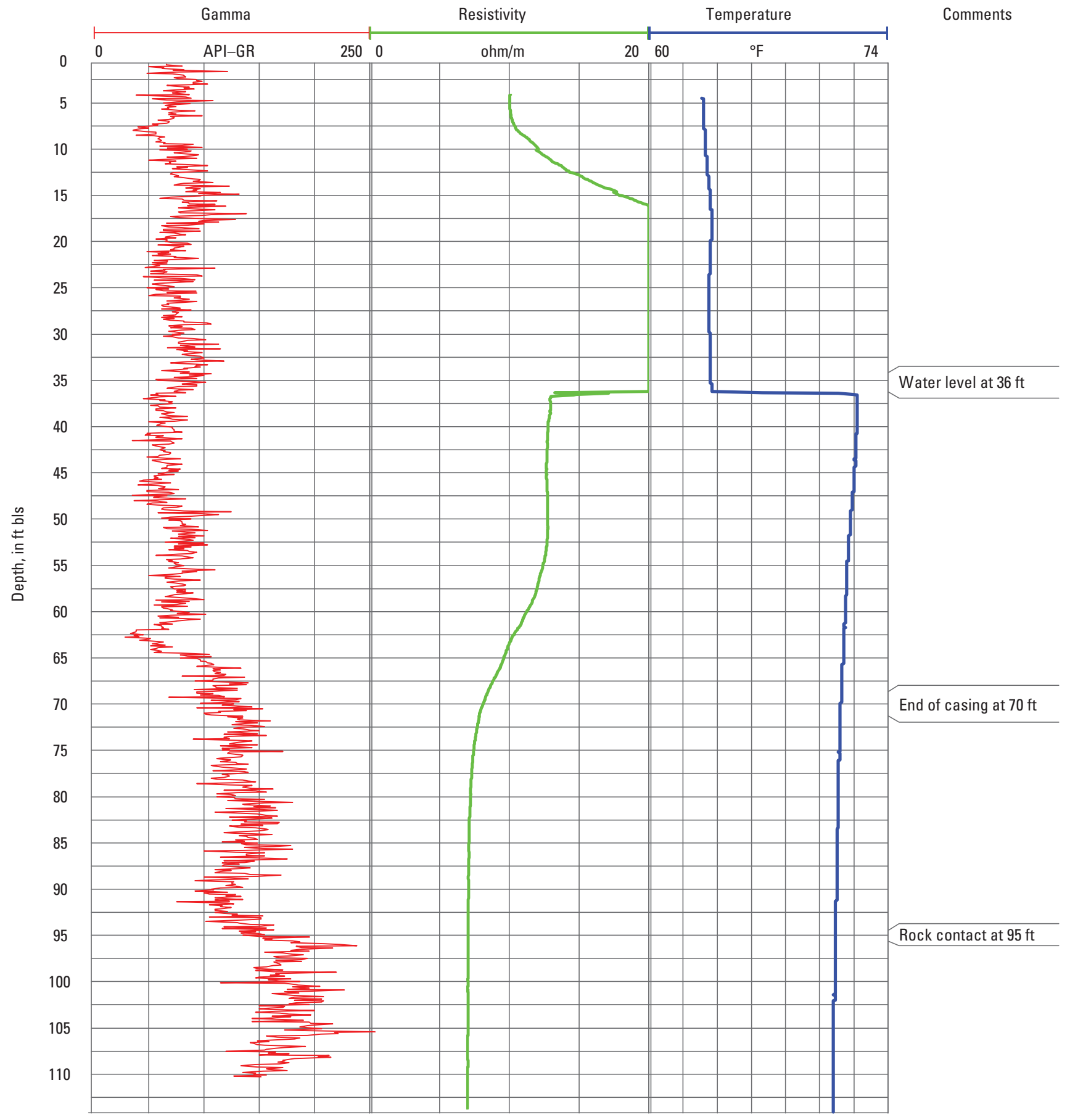

Figure 8. Logs of natural gamma radioactivity, fluid resistivity, and fluid temperature for well OC-12B at the Stringfellow Superfund site in Jurupa Valley, California. API-GR, American Petroleum Institute gamma ray unit; ohm/m, ohm per meter; ${ }^{\circ}$, degree Fahrenheit; bls, below land surface; ft, foot. 


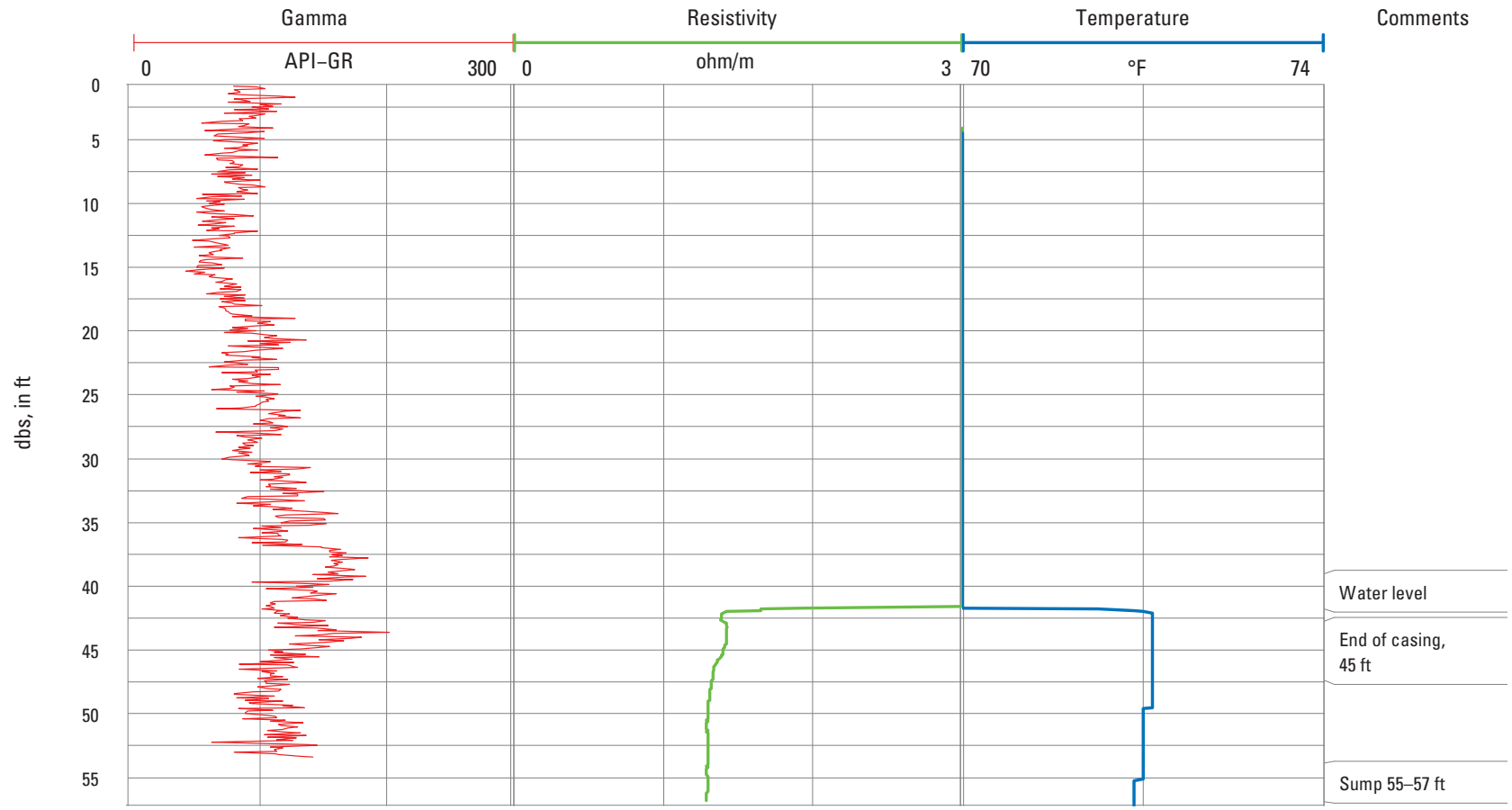

Figure 9. Logs of natural gamma ray, fluid resistivity, and temperature logs for well OW-46B1 at the Stringfellow Superfund site in Jurupa Valley, California. API-GR, American Petroleum Institute gamma radioactivity unit; ohm $/ \mathrm{m}$, ohm per meter; ${ }^{\circ}$, degree Fahrenheit; bls, below land surface; ft, foot.

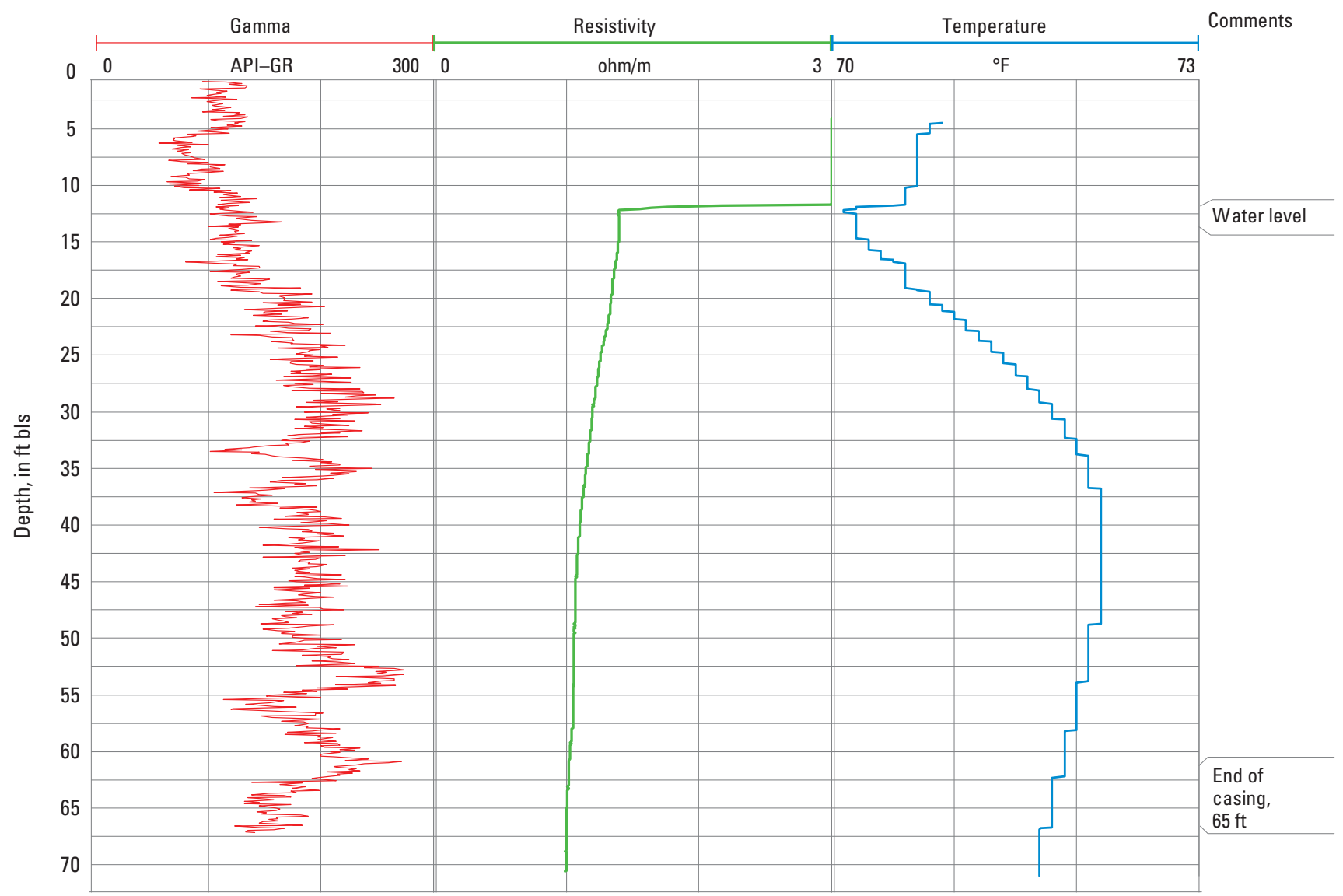

Figure 10. Logs of natural gamma ray, fluid resistivity, and temperature for well OW-44B2 at the Stringfellow Superfund site in Jurupa Valley, California. API-GR, American Petroleum Institute gamma radioactivity; ohm $/ \mathrm{m}$, ohm per meter; ${ }^{\circ}$, degree Fahrenheit; bls, below land surface; ft, foot. 


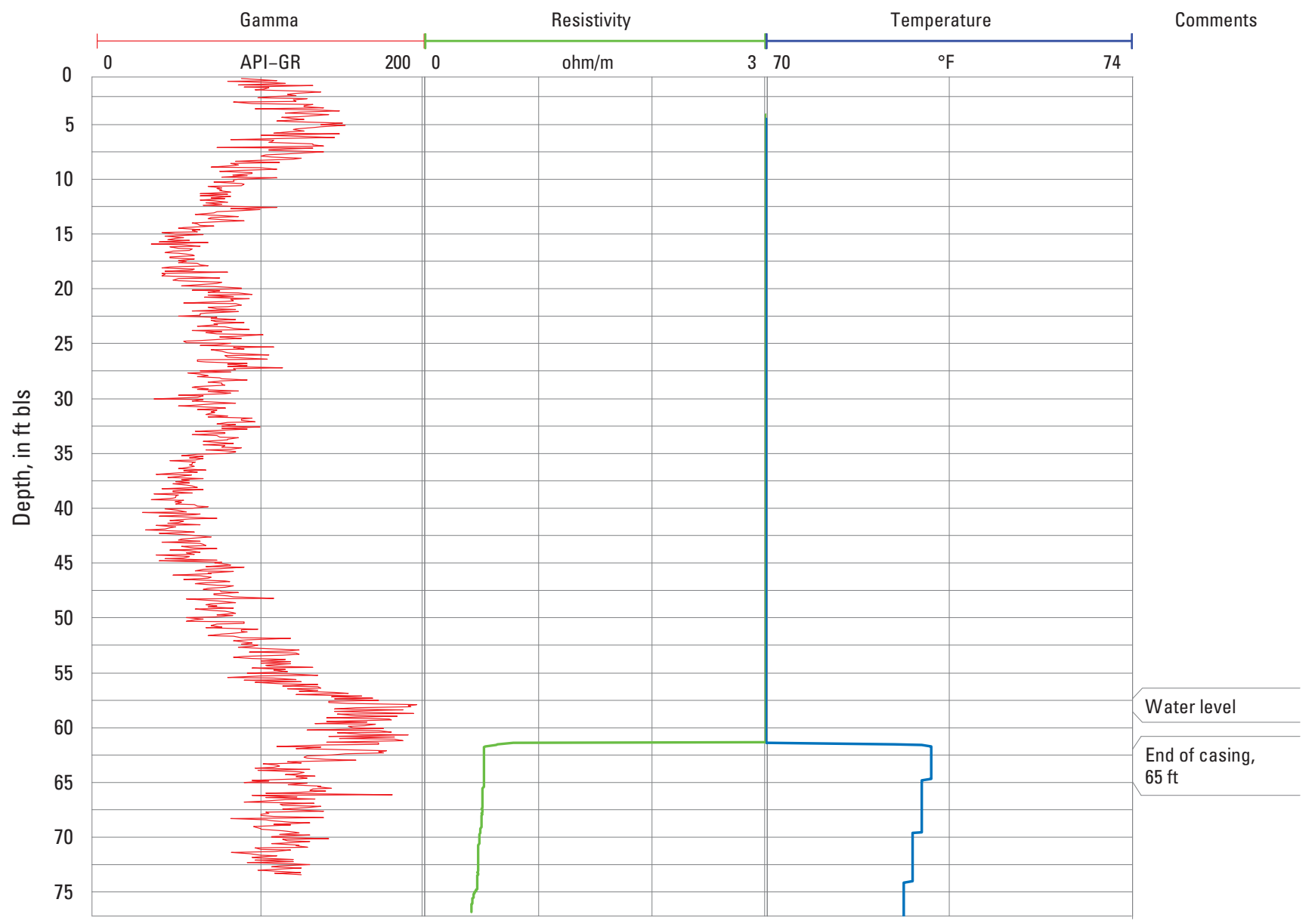

Figure 11. Logs of natural gamma ray, fluid resistivity, and temperature for well OW-69D2 at the Stringfellow Superfund site in Jurupa Valley, California. API-GR, American Petroleum Institute gamma radioactivity unit; ohm/m, ohm per meter; ${ }^{\circ} \mathrm{F}$, degree Fahrenheit; bls, below land surface; ft, foot. 


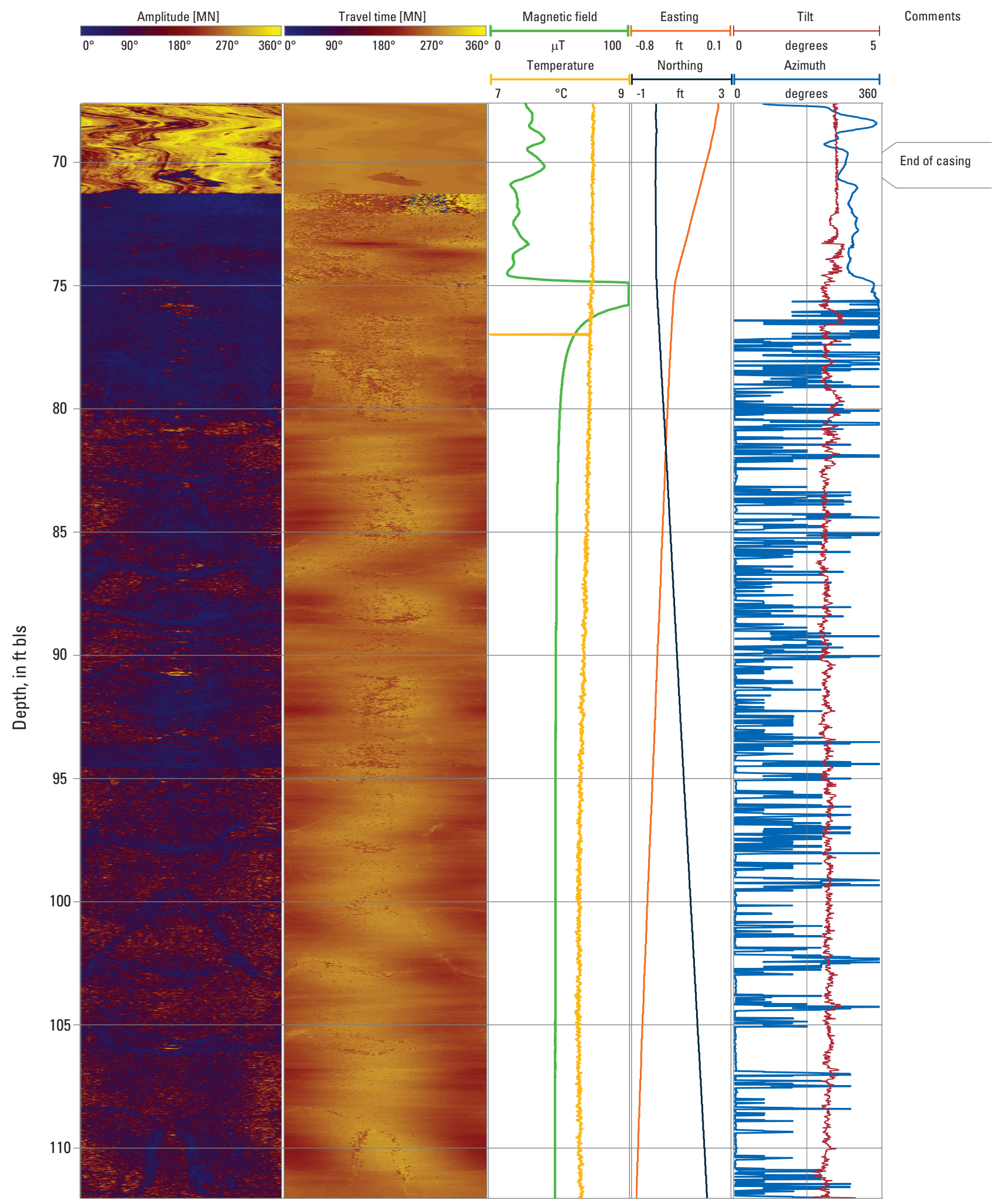

Figure 12. Acoustic televiewer log for well $\mathrm{OC}-12 \mathrm{~B}$ at the Stringfellow Superfund site in Jurupa Valley, California. MN, magnetic north; ft, foot; bls, below land surface; ${ }^{\circ}$, degree; $\mu \mathrm{T}$, microtesla; ${ }^{\circ} \mathrm{C}$, degree Celsius. 


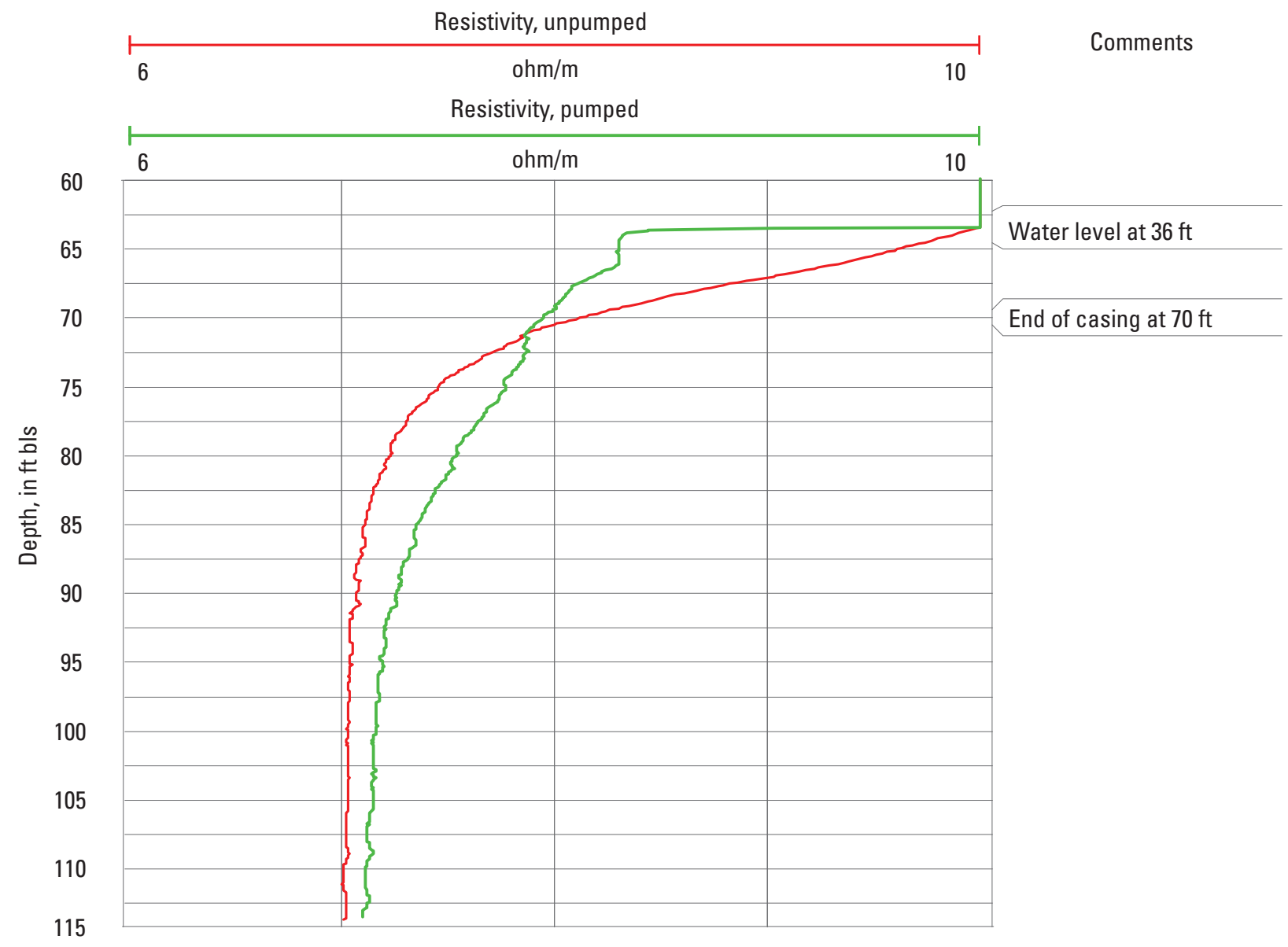

Figure 13. Fluid resistivity logs for well OC-12B at the Stringfellow Superfund site in Jurupa Valley, California under ambient (red line) and post pumped (green line) conditions. bls, below land surface, $\mathrm{ft}$, feet; ohm/m, ohm per meter. 


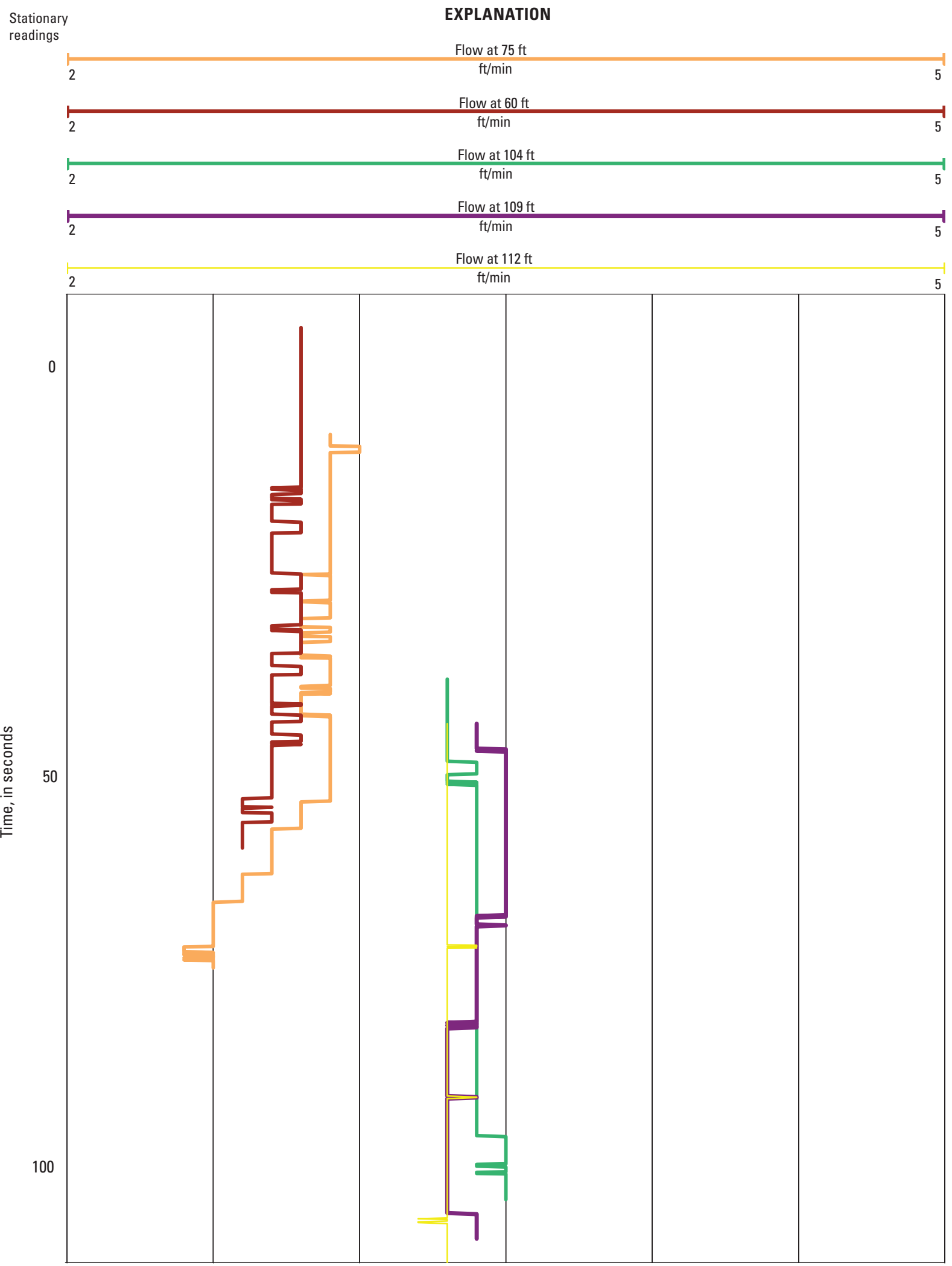

Figure 14. Stationary electromagnetic (EM) flowmeter logs for well OC-12B at the Stringfellow Superfund site in Jurupa Valley, California. $\mathrm{ft}$, foot; $\mathrm{ft} / \mathrm{min}$, foot per minute. 


\section{Analysis of Aquifer Hydraulic Properties With the GWF}

The GWF results (figs. 15 to 21 ; table 4) are shown for the mean parameters from 1,000 simulations in the last of three sequential Markov chains for the three pumped wells where groundwater purge sampling occurred. Table 4 includes results with and without computation of a skin effect, and a comparison of results under confined and unconfined conditions for well PZ-74D.

Linear graphs of model fit to observations show that, for well PZ-74D (figs. 15 and 16), the actual pumping rate was not constant but varied around the average rate used for fitting. For well OC-12B, there was a systematic misfit (a substantial and consistent discrepancy) between modelcomputed and observed water levels after 12 minutes; fitting with a model accounting for a possible skin zone around the well did not decrease this misfit, suggesting that some other conditions of the well construction or aquifer affected the drawdown response, such as, for example, fracture flow (figs. 17 and 18). The fit to the observations from well OW-44B2 is without any systematic misfit (figs. 19 and 20). The data in table 4 show that the quality of fit measured by the square of Pearson's coefficient $\left(\mathrm{R}^{2}\right)$ is similar for all fittings, with $\mathrm{R}^{2}$ ranging from 0.995 to 0.999 . The square root of the mean square error between observations and model fit ranged from 1.57 to $1.69 \mathrm{ft}$.

The main aquifer property of interest is the radial hydraulic conductivity $\left(K_{r}\right)$; the remaining aquifer properties are less relevant to the use of the PAT, but their estimation is necessary for the fitting process. The fitting for well OC-12B with a model accounting for a skin zone surrounding the well shows that the estimated $K_{r}$ values are subject to considerable (and unavoidable) uncertainty when data for time-drawdown response are available from the pumping well only. However, when using the PAT, the effective $K_{r}$ that combines the effects of the conductivity of both the aquifer $\left(K_{r}\right)$ and the skin zone $\left(K_{r s}\right)$ should be used; thus, the results from fitting without estimation of $K_{r s}$ are applicable.
The fitting for an unconfined aquifer resulted in negligible change in the estimated values for $K_{r}, K_{z}: K_{r}$, and $S_{s}$ for observations from well PZ-74D. Thus, accounting for the unconfined aquifer condition is not necessary for the use of the PAT to analyze well PZ-74D purge records. The same is expected for the other tested wells.

The $K_{r}$ results from our study in 2017 for wells OC-12B (no skin; table 4; $0.0000904 \mathrm{ft} / \mathrm{d}$ ) and OW-44B2 (no skin; table $4 ; 0.000277 \mathrm{ft} / \mathrm{d}$ ) are lower by a factor of approximately 30 than the 0.0024 and $0.0087 \mathrm{ft} / \mathrm{d} K_{r}$ values, respectively, estimated from slug tests conducted in 2012 (Environ International Corp., 2012, table 4). Differences in $K_{r}$ from earlier slug tests (in 2012) to later single-well pump tests (in 2017) may be an indication of biofouling of the well screens and surrounding zones affecting hydraulic tests. In contrast, the $K_{r}$ results (no skin; table 4) for well PZ-74D $(0.1360 \mathrm{ft} / \mathrm{d}$ ) is higher by a factor of 3 than the slug test results in 2015 (table 5; Environ International Corp., 2015).

The inflow from the aquifer into the tested well during purging, as well as the purge rate, varied over time (figs. 16, 18, and 20). Theoretically, at the start of pumping, most of the extracted water is from the storage within the well casing, and inflow from the aquifer is a small fraction of the extraction rate. Before the inflow becomes equal to the pumping rate, the extracted water is a mix of borehole water in the casing and inflowing groundwater from the aquifer. The portion of the well-casing water decreases over time until only aquifer water is pumped out. The time when the inflow becomes equal to the pumping rate can be considered a minimum required purge time for sampling.

For well PZ-74D, the inflow equals the purge rate after about 2 hours of purging; this is the time when all pumped water is from the aquifer. During the first 2 hours, a part of the pumped water was from the well casing. Compared with well PZ-74D, wells OC-12B and OC-44B2 were going dry during purging considering that the inflow from the aquifer was considerably smaller in magnitude compared with the purge rate. The pumped water was a mix of casing and aquifer water, with the aquifer fraction being relatively small (figs. 18 and 20). 


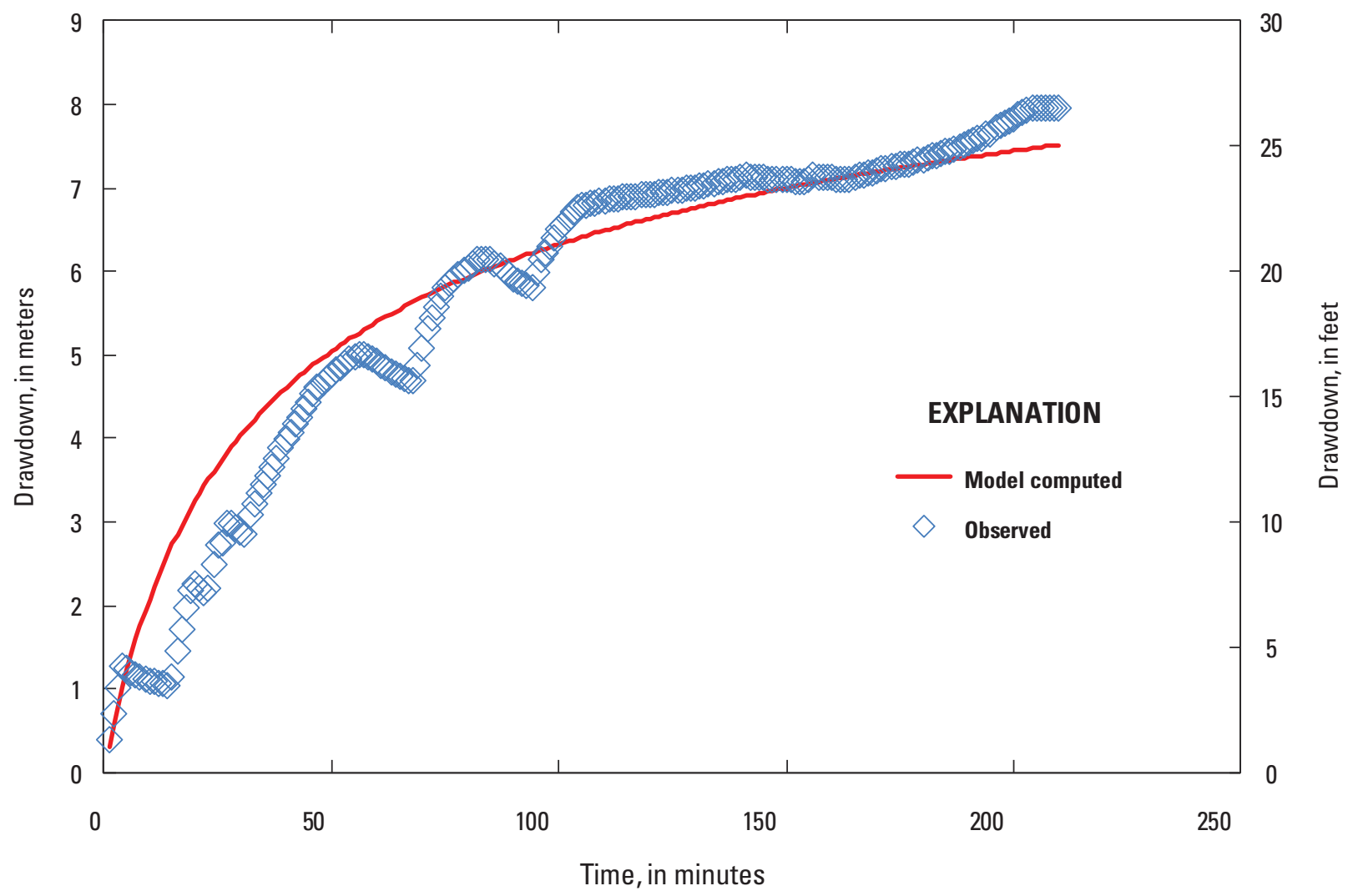

Figure 15. Graph showing model-computed and observed drawdown from initial static water levels for well PZ-74D at the Stringfellow Superfund site in Jurupa Valley, California. Simulated drawdown is from the general well function model by Perina and Lee (2006), and Perina (2020). m, meter; ft, foot; min, minute.

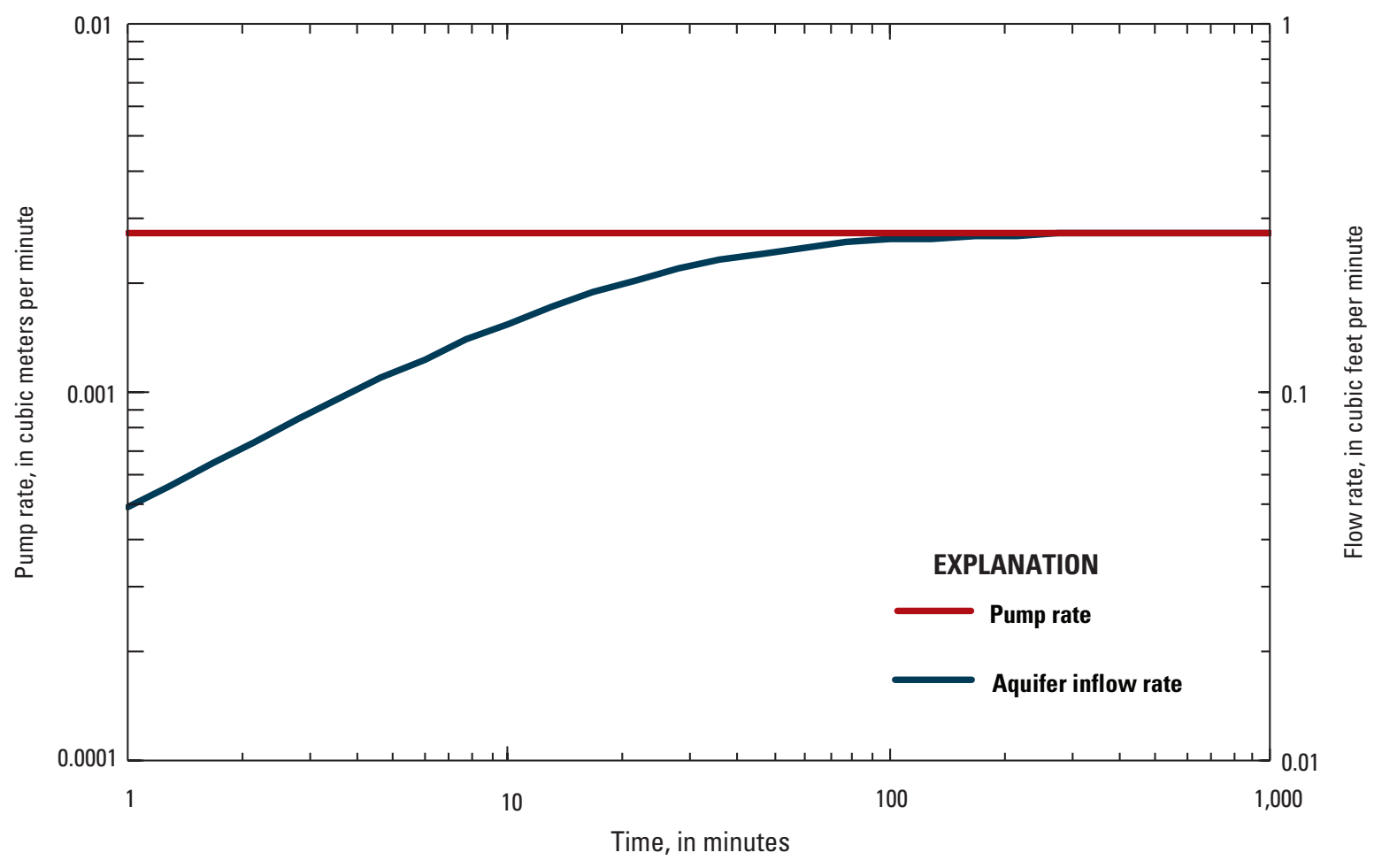

Figure 16. Graph showing model-computed inflow from aquifer (blue line) and pumping rate (red line) for well PZ-74D at the Stringfellow Superfund site in Jurupa Valley, California. Simulated inflow is from the general well function model by Perina and Lee (2006), and Perina (2020). $\mathrm{m} 3 / \mathrm{min}$, cubic meter per minute; $\mathrm{ft} 3 / \mathrm{min}$, cubic foot per minute; min, minute. 


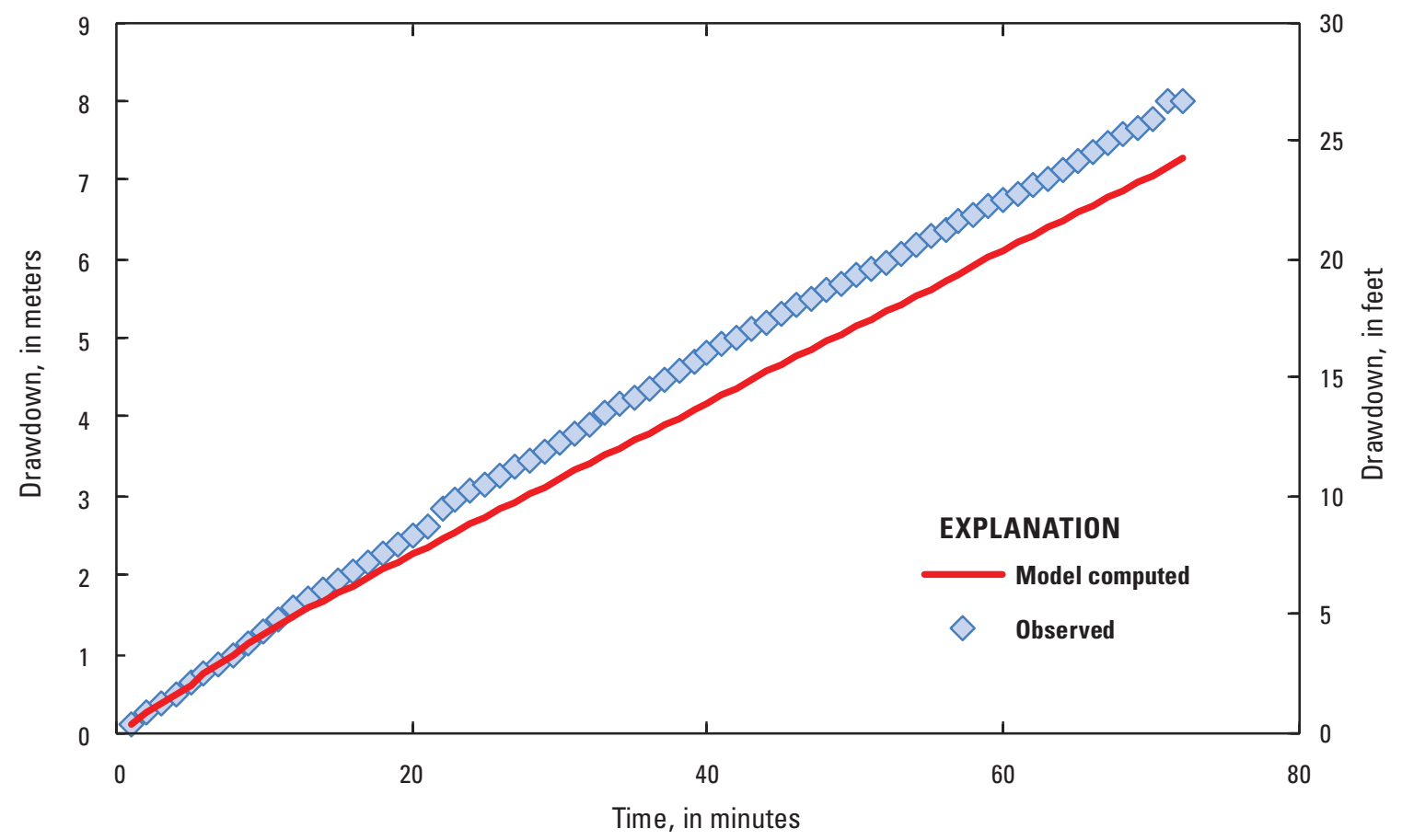

Figure 17. Graph showing model-computed and observed drawdown from initial static water levels for well OC-12B at the Stringfellow Superfund site in Jurupa Valley, California. Simulated drawdown is from general well function model by Perina and Lee (2006), and Perina (2020). $\mathrm{m}$, meter; $\mathrm{ft}$, foot; min, minute.

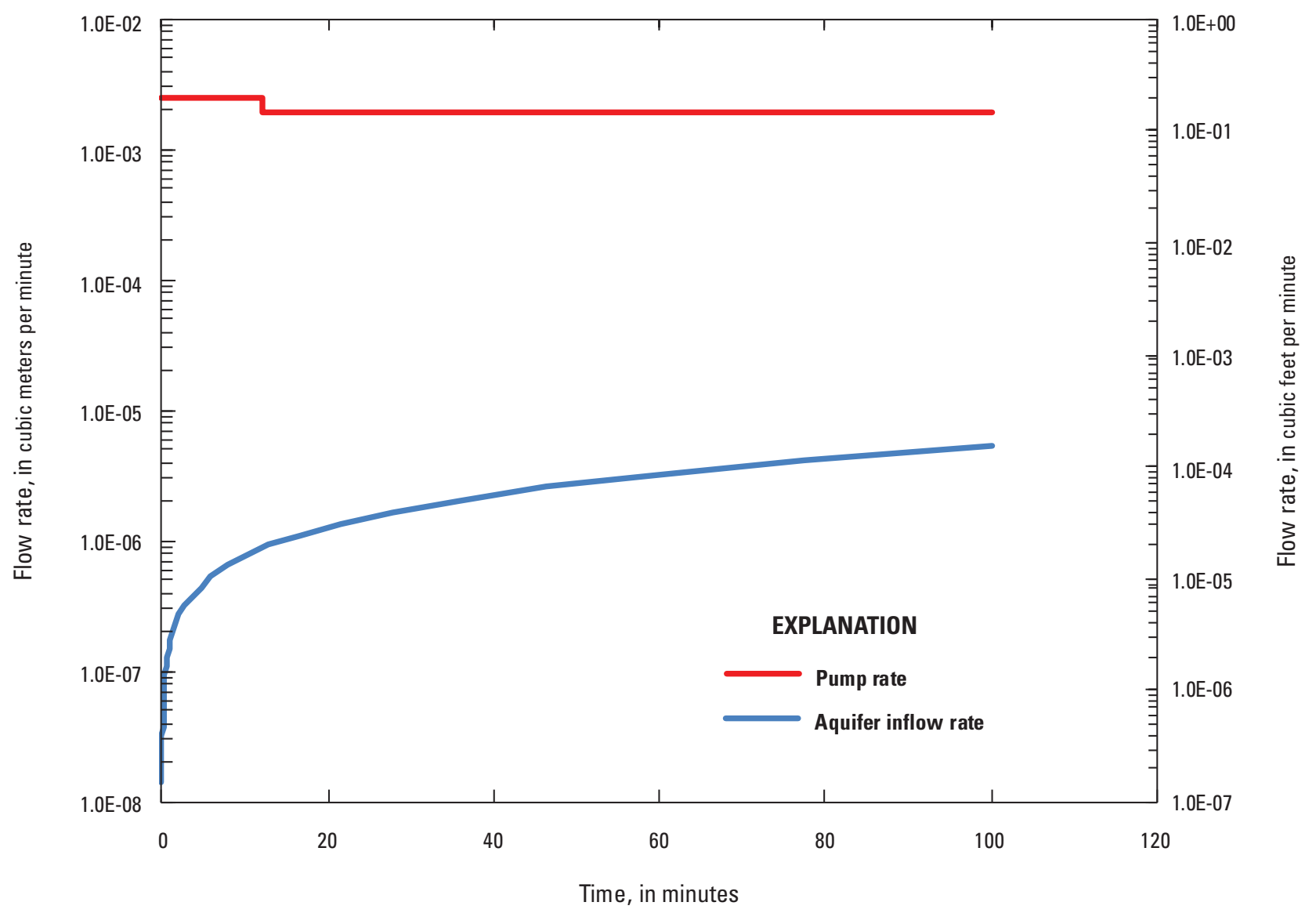

Figure 18. Graph showing model-computed inflow from aquifer (blue line) and pumping rate (red line) for well OC-12B at the Stringfellow Superfund site in Jurupa Valley, California. Simulated inflow is from the general well function model by Perina and Lee (2006), and Perina (2020). $\mathrm{m} 3 / \mathrm{min}$, cubic meter per minute; $\mathrm{ft} 3 / \mathrm{min}$, cubic foot per minute; min, minute. 


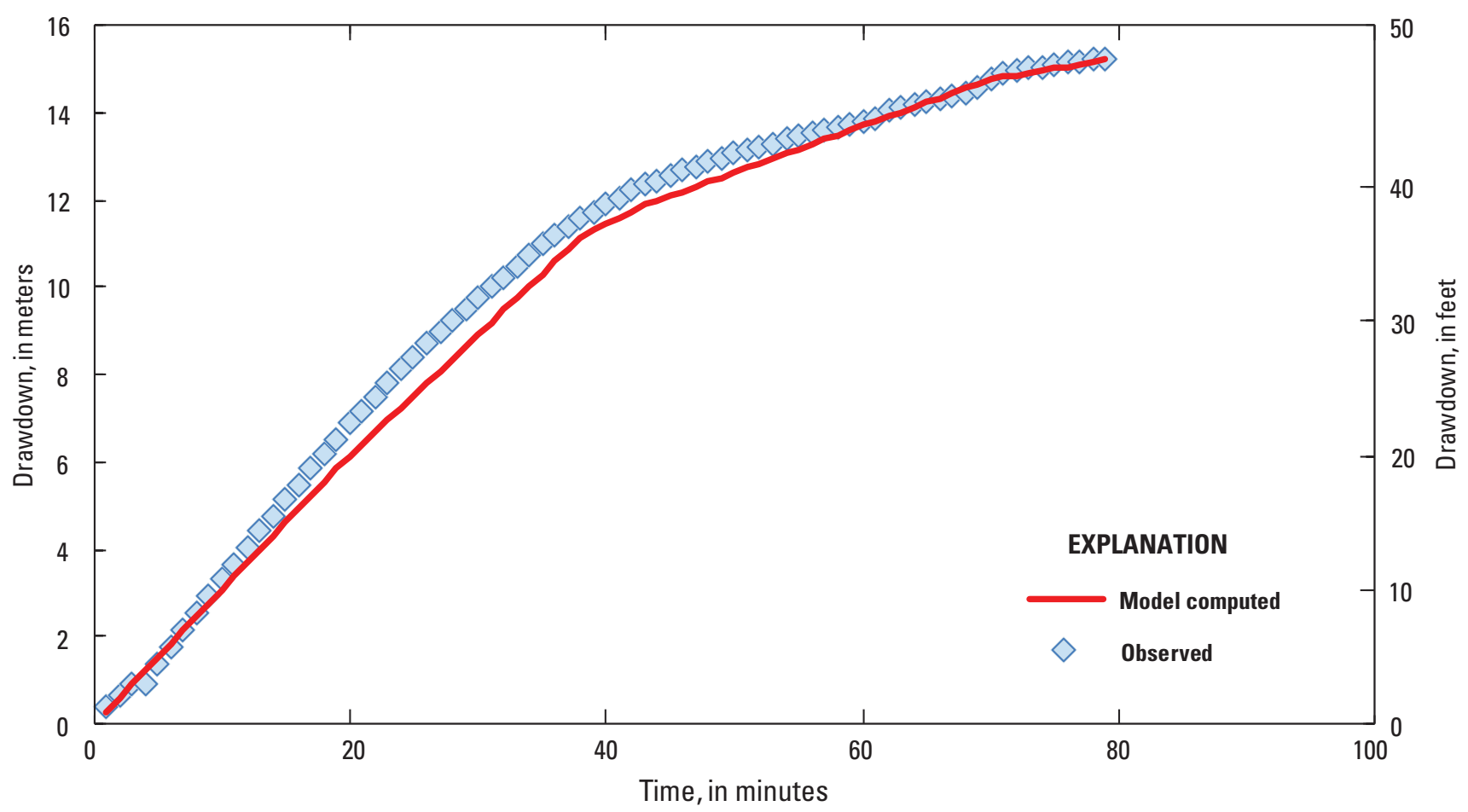

Figure 19. Graph showing model-computed and observed drawdown from initial static water levels for well OW-44B2 at the Stringfellow Superfund site in Jurupa Valley, California. Simulated drawdown is from general well function model by Perina and Lee (2006), and Perina (2020). m, meter; ft, foot; min, minute.

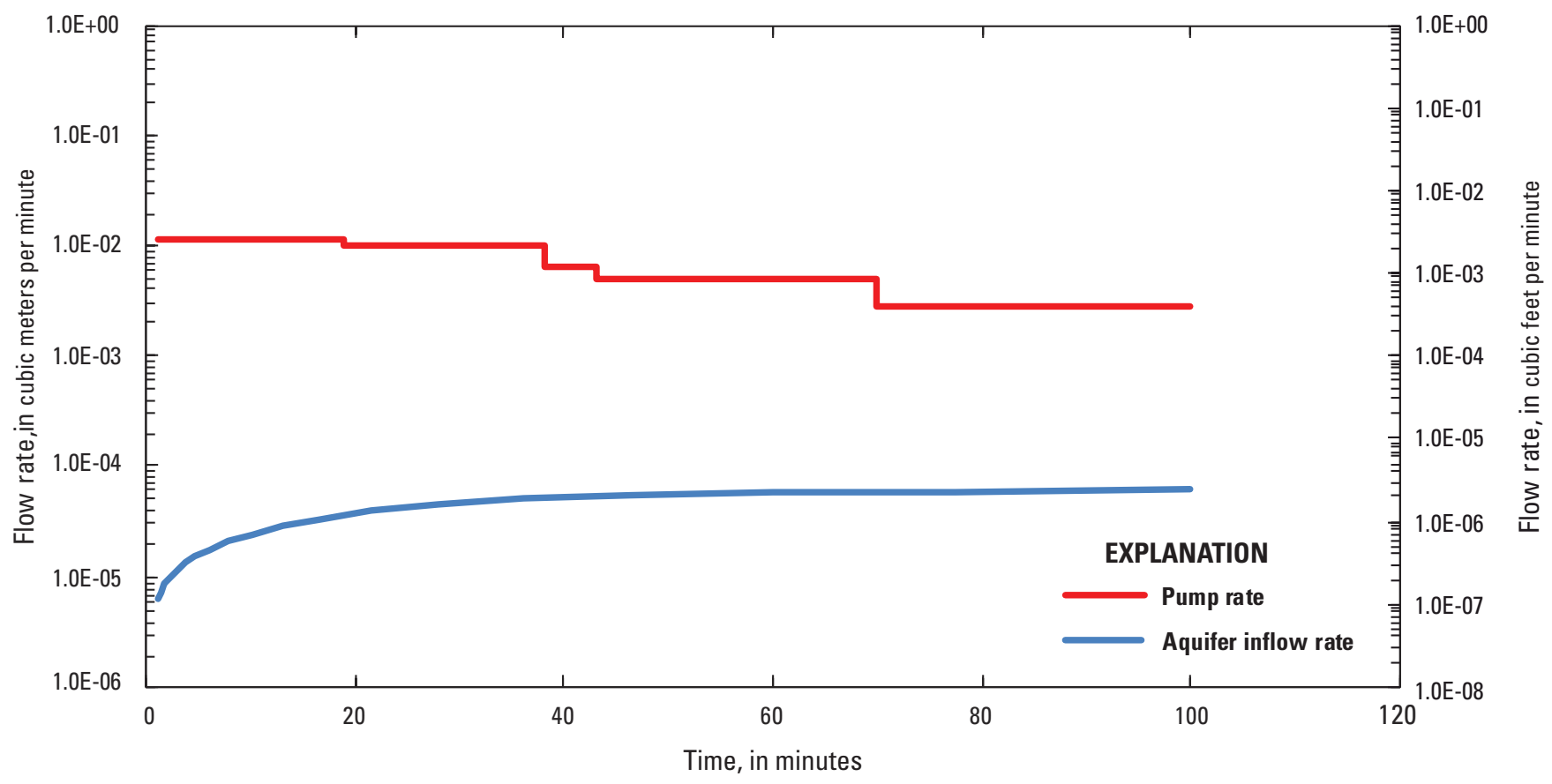

Figure 20. Graph showing model-computed inflow from aquifer (blue line) and pumping rate (red line) for well OW-44B2 at the Stringfellow Superfund site in Jurupa Valley, California. Simulated inflow is from the general well function model by Perina and Lee (2006), and Perina (2020). $\mathrm{m} 3 / \mathrm{min}$, cubic meter per minute; $\mathrm{ft} 3 / \mathrm{min}$, cubic foot per minute; min, minute. 


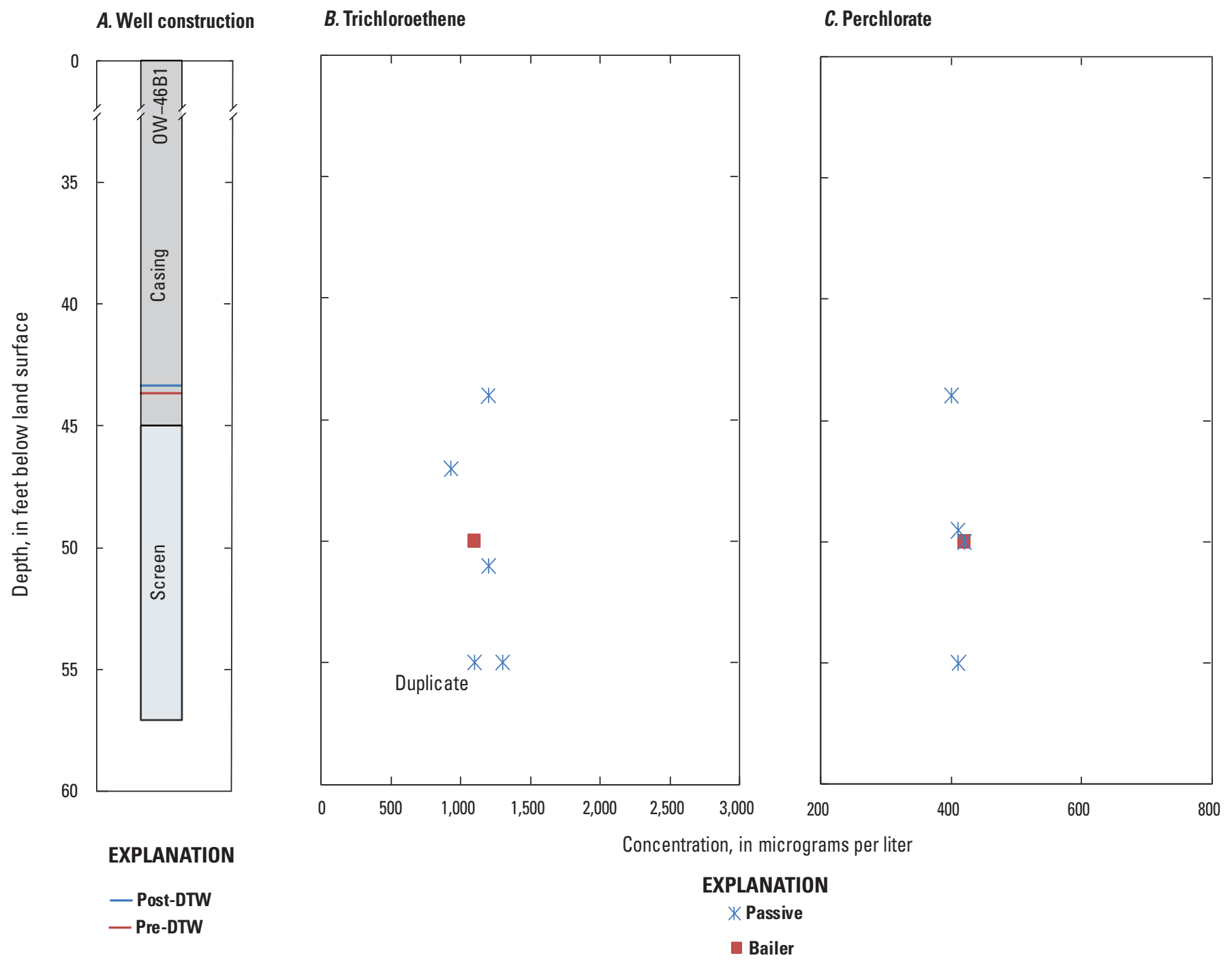

Figure 21. Graphs showing well construction information and plots of trichloroethylene and perchlorate vertical chemical profiles derived from passive and bailer samples for well OW-46B1 at the Stringfellow Superfund site in Jurupa Valley, California. Additional description on samples provided in table 5. Pre-DTW, water level before passive deployment; post-DTW, water level before retrieval; $\mu \mathrm{g} / \mathrm{L}$, microgram per liter. 
Table 4. Parameters calculated by the general well function model for confined and unconfined conditions for the test wells at the Stringfellow Superfund site in Jurupa Valley, California.

[General well function (GWF) model is from Perina and Lee (2006), and Perina (2020). $\mathrm{R}^{2}$, square of Pearson correlation coefficient; ft/d, foot per day; $\mathrm{ft}^{-1}$, 1 / foot; - , no data or not estimated; skin, well skin effect calculated; no-skin, well skin effect not accounted for]

\begin{tabular}{|c|c|c|c|c|c|c|c|}
\hline \multirow{3}{*}{$\begin{array}{c}\text { Parameter } \\
\text { Well }\end{array}$} & \multicolumn{6}{|c|}{ Confined aquifer } & \multirow{3}{*}{$\begin{array}{l}\text { Unconfined } \\
\text { aquifer, no } \\
\text { skin, well } \\
\text { PZ-74D }\end{array}$} \\
\hline & \multicolumn{3}{|c|}{ No skin } & \multicolumn{3}{|c|}{ Skin } & \\
\hline & PZ-74D & OC-12B & OW-44B2 & PZ-74D & OC-12B & OW-44B2 & \\
\hline $\begin{array}{l}\text { Vertical-to-radial hydraulic } \\
\text { conductivity }\left(K_{z} / K_{r}\right)\end{array}$ & $8.85 \times 10^{-3}$ & $9.97 \times 10^{-3}$ & $9.74 \times 10^{-3}$ & $8.40 \times 10^{-3}$ & $7.27 \times 10^{-3}$ & $4.09 \times 10^{-3}$ & $8.73 \times 10^{-3}$ \\
\hline $\begin{array}{l}\text { Hydraulic conductivity of the } \\
\text { skin zone in radial direction } \\
(\mathrm{ft} / \mathrm{d})\end{array}$ & - & - & - & $3.63 \times 10^{-4}$ & $2.46 \times 10^{-5}$ & $1.90 \times 10^{-8}$ & - \\
\hline Specific yield & NA & NA & NA & NA & NA & NA & 0.197 \\
\hline
\end{tabular}




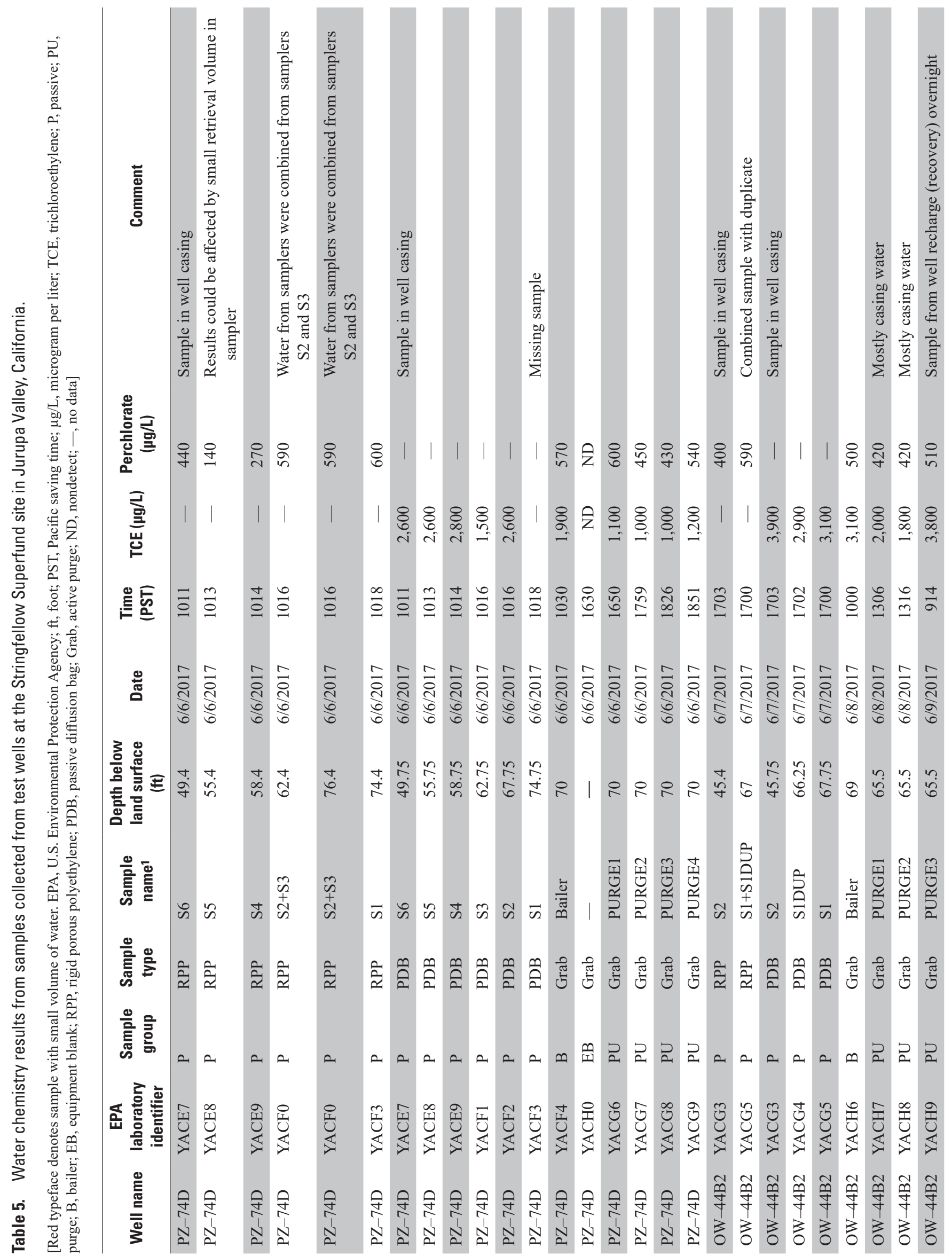




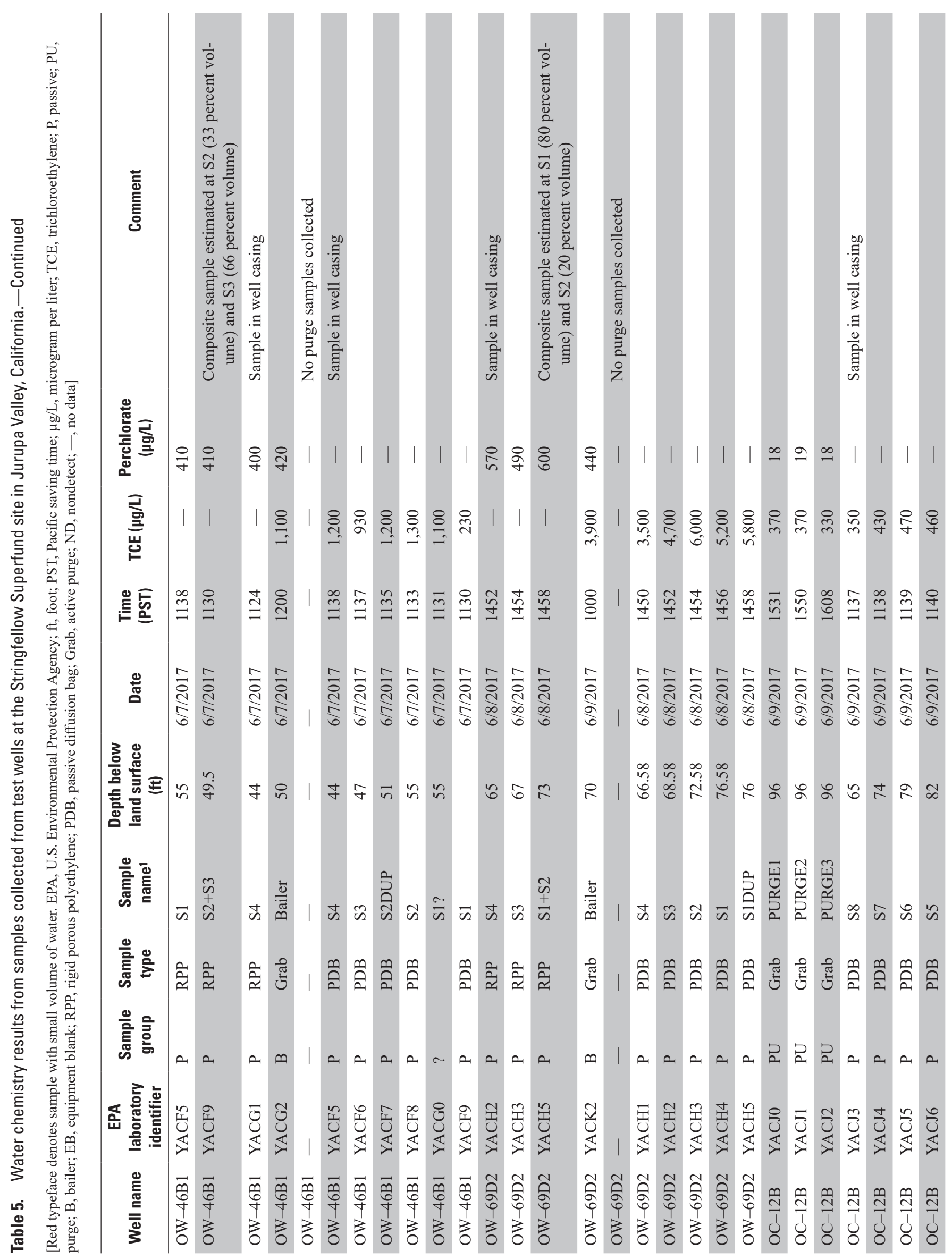




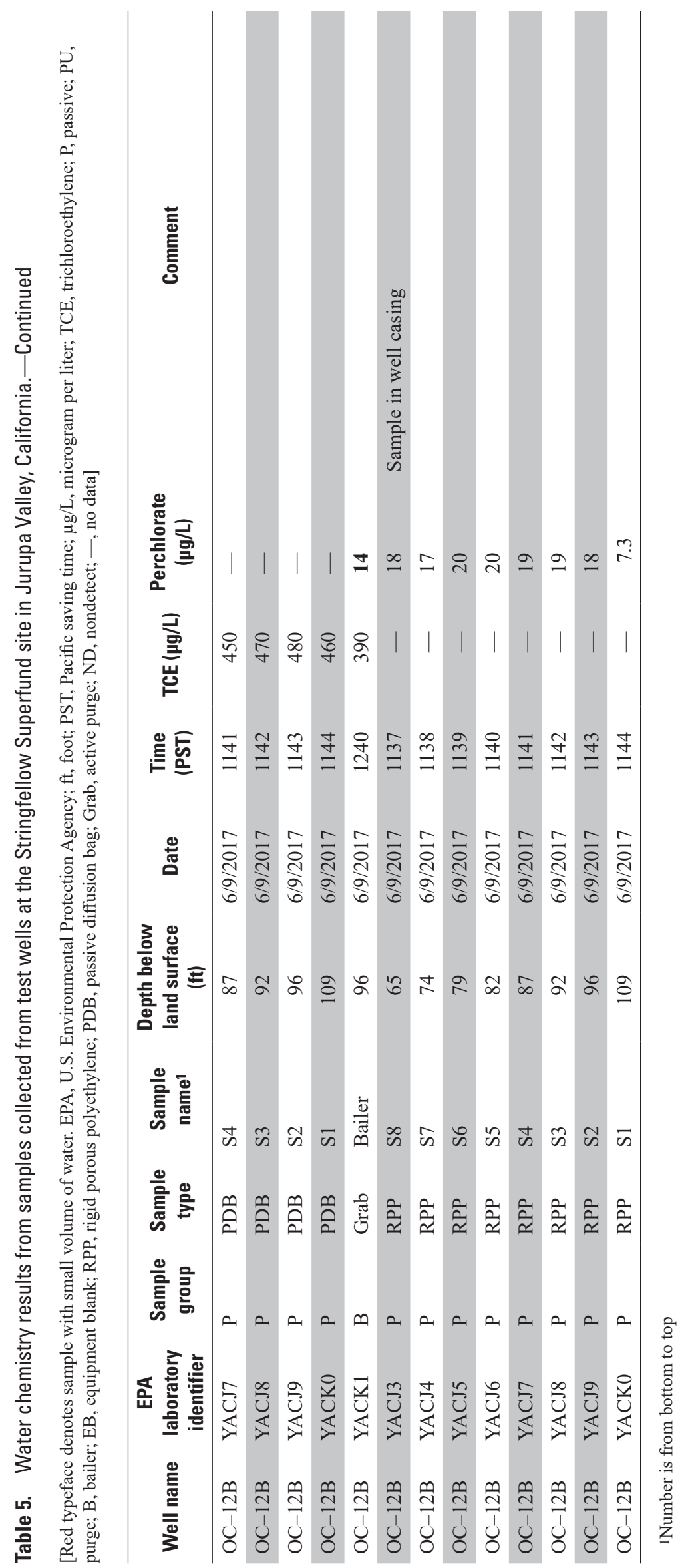




\section{Groundwater Chemistry}

Results of the vertical chemistry profiles for TCE and perchlorate from passive samplers are shown in figures 21 through 25 . The profiles are referenced to the sample results from the bailer and purge samples at the corresponding depth of sample collection.

At well OW-46B1, the profile of TCE concentrations shows a greater variation with depth than perchlorate concentrations (relative percent difference of approximately 20 percent for TCE and 5 percent for perchlorate; fig. 21). At well OW-69D2, the profile of TCE concentrations shows a large vertical difference in TCE concentrations (relative percent difference of approximately 50 percent; fig. 22). The highest TCE concentration, at a depth of approximately $73 \mathrm{ft}$ below land surface, coincides with the contact between weathered and unweathered granodiorite based on the lithologic log (Tetra Tech, Inc., 2000); the profile of perchlorate concentrations also shows the highest concentration at a similar depth. At shallow depths closer to the water-level surface and atmospheric/water interface, TCE concentrations are lowest, but perchlorate concentrations show no such pattern (fig. 22). These differences in profile concentrations between TCE and perchlorate at shallow depths nearer to the water surface likely reflect the differences in volatilization losses between TCE and perchlorate; the vapor pressure for TCE is relatively high but negligible for perchlorate (GSI Environmental, 2019).

At well OW-44B2, the profile of TCE concentrations shows highest concentrations within the casing water, whereas perchlorate concentrations show the lowest in the casing water at a similar depth (fig. 23). One possibility for why high TCE concentrations exist in the casing water relative to the screen water is that residual groundwater is present in the casing from a previous time (essentially, remnant water left over in the casing from a period where TCE concentrations were higher than the current period). A hydrogeologic condition of relatively high TCE concentrations and a corresponding low water level followed by a period of low TCE concentrations and a corresponding high-water level could promote such a concentration profile. Conversely, the water within the screen would be contemporaneous to current conditions, reflecting the low TCE concentrations.

At well PZ-74D, the profile of TCE concentrations show a fairly uniform concentration range between 2,600 and 2,800 $\mu \mathrm{g} / \mathrm{L}$ except at a depth of about $62.5 \mathrm{ft}$, where the TCE concentration drops to about $1,500 \mu \mathrm{g} / \mathrm{L}$ (fig. 24). At that depth, the EM-induction log shows a decrease indicating a zone of less weathered rock (fig. 5) suggesting relatively low TCE concentration groundwater being present in the less weathered rock. In contrast, TCE concentrations are higher near the contact between weathered sediments and weathered bedrock at a depth of approximately $55 \mathrm{ft}$ (fig. 5).
At well OC-12B, the profile of TCE concentrations shows the lowest concentrations in the casing and near the top of the screen. Conversely, perchlorate concentrations are high in the casing and likely reflect differences in volatilization between the two compounds (fig. 25).

Results from the purge samples provide insight into timevarying capture of pumped water. The differences in purge sample concentration over time at the three wells supports corresponding information on the relative amounts of groundwater from the aquifer and water from borehole storage that is being captured during pumping.

At well PZ-74D, differences in concentrations were found between the four time-varying purge samples collected between 69 and 131 minutes after pumping started. The relative percent difference for time-varying chemistry during pumping varied by 18 percent for TCE and 33 percent for perchlorate (table 5). Hydraulic analysis of samples from well PZ-74D indicated almost 100-percent capture of groundwater from the aquifer during the sampling period (69 to $131 \mathrm{~min}-$ utes after start of pumping; fig. 16), indicating little capture of casing water.

At well OC-12B, based on differences between three samples collected between 35 and 71 minutes after pumping started, the relative percent difference for time-varying chemistry during pumping varied by 11 percent for TCE and 5 percent for perchlorate. Hydraulic analysis of samples from well OC-12B indicated little (less than 1 percent) capture of groundwater from the aquifer during the sampling period (35 to 71 minutes after start of pumping; fig. 18; table 5). The small time-varying difference in relative percent difference for TCE and perchlorate concentrations are the result of two factors: the captured pumped water is entirely derived from the borehole, and the vertical concentrations in the well show negligible differences, as determined from the vertical profile of passive samplers.

At well OW-44B2, based on differences between three samples collected between 53 and 63 minutes after pumping started, the relative percent difference for time-varying chemistry during pumping varied by 71 percent for TCE and 19 percent for perchlorate. Hydraulic analysis of well OW-44B2 indicates little (less than 1 percent) capture of groundwater from the aquifer during the period of sampling (53 to 63 minutes of pumping; fig. 20; table 5). The large differences in relative percent difference for TCE result from terminating pumping to allow for recharge or water-level recovery from low water levels, and subsequent sampling of recharged waters the following day after water-level recovery. Therefore, the samples from the pre-water level recovery period are derived from borehole storage, which showed lower TCE concentrations, and the sample from post-water-level recovery represents groundwater from the aquifer, which showed a higher TCE concentration. Differences are attributed to TCE volatilization of the relatively stagnant water column of the well prior to water-level recovery. 


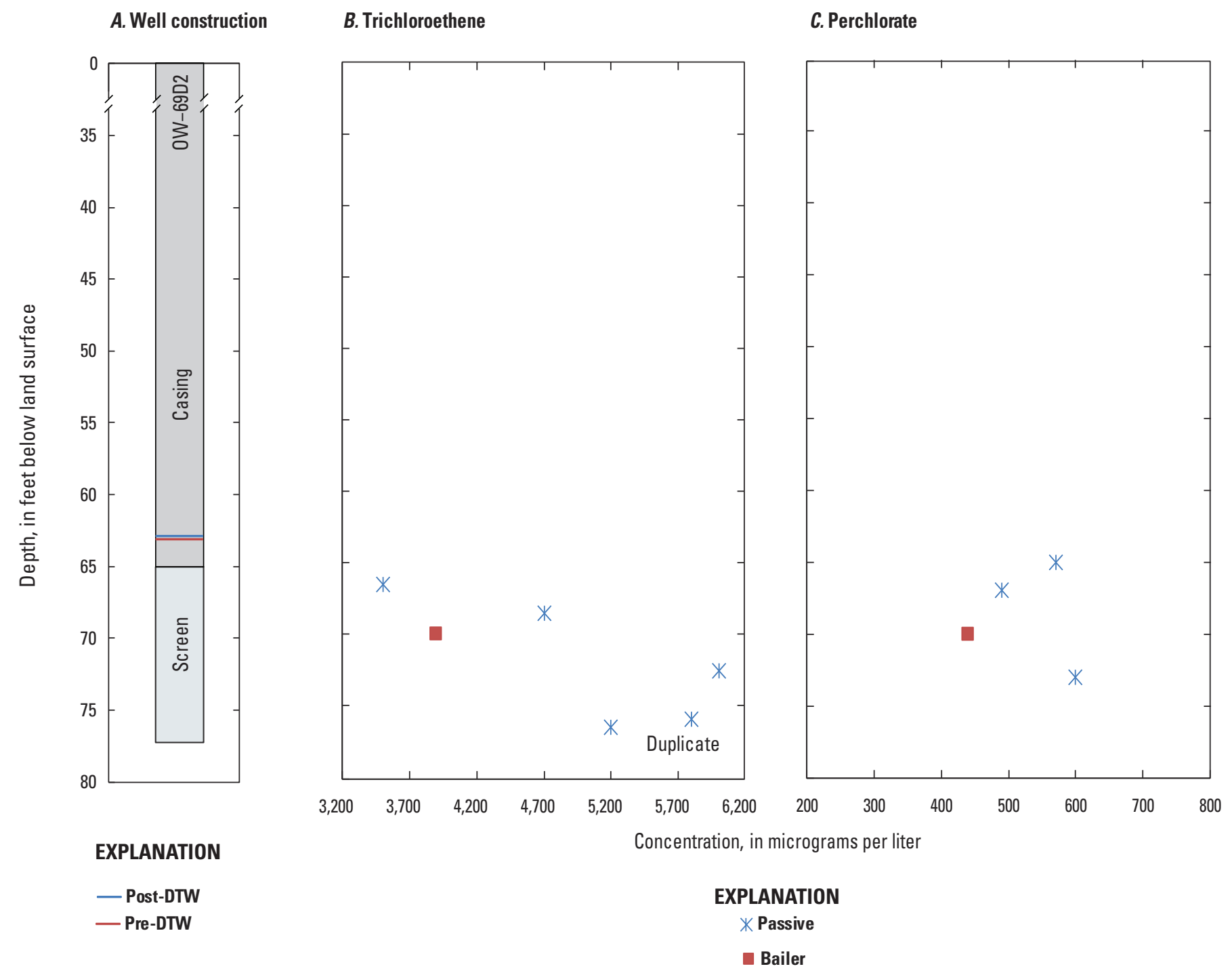

Figure 22. Graphs showing well construction information and plots of trichloroethylene and perchlorate vertical chemical profiles derived from passive and bailed samples for well OW-69D2 at the Stringfellow Superfund site in Jurupa Valley, California. Additional description on samples provided in table 5. Pre-DTW, water level before passive deployment; post-DTW, water level before retrieval; $\mu \mathrm{g} / \mathrm{L}$, microgram per liter. 


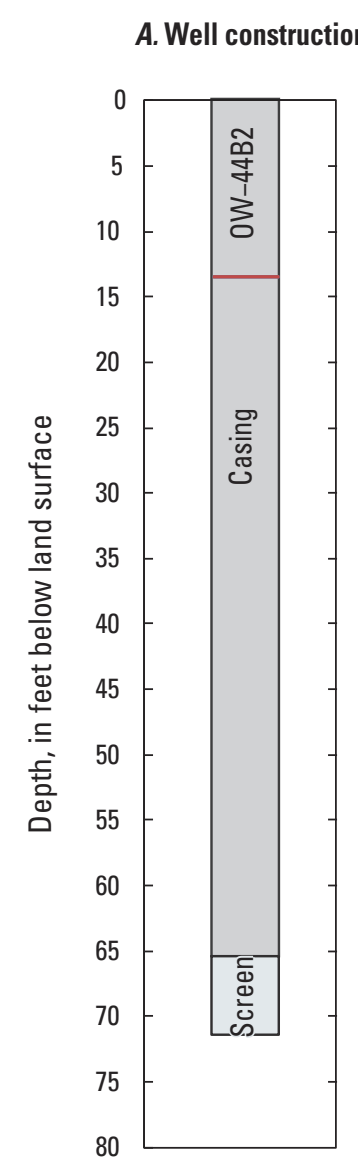

EXPLANATION

— Post-DTW (none)

- Pre-DTW

\section{B. Trichloroethene}

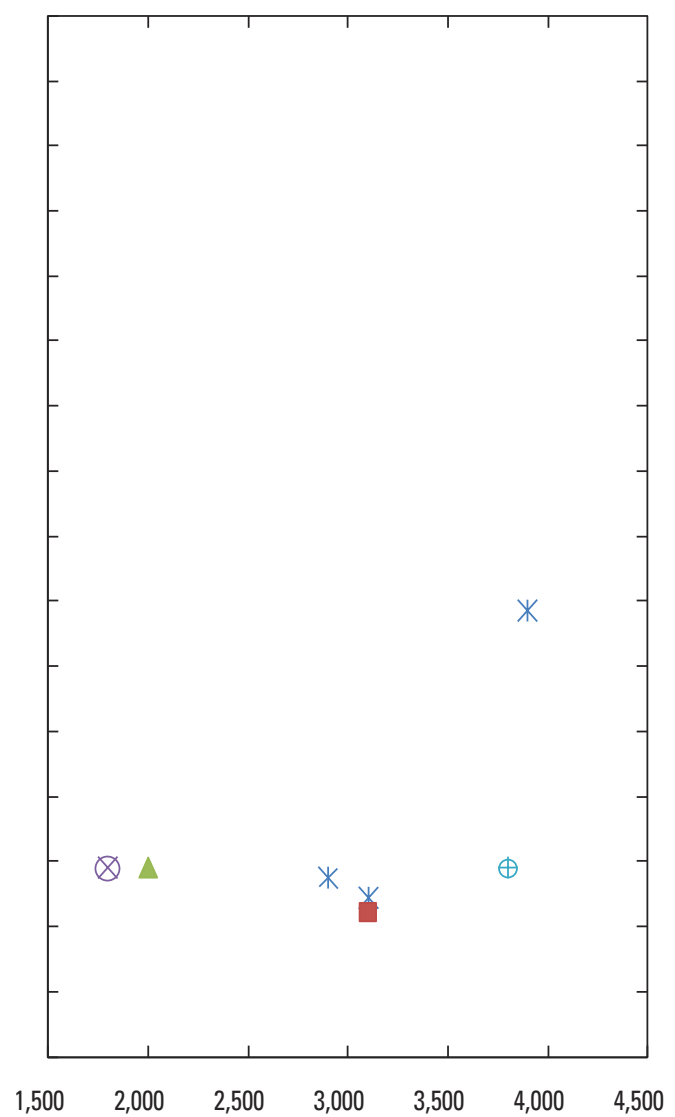

\section{Perchlorate}

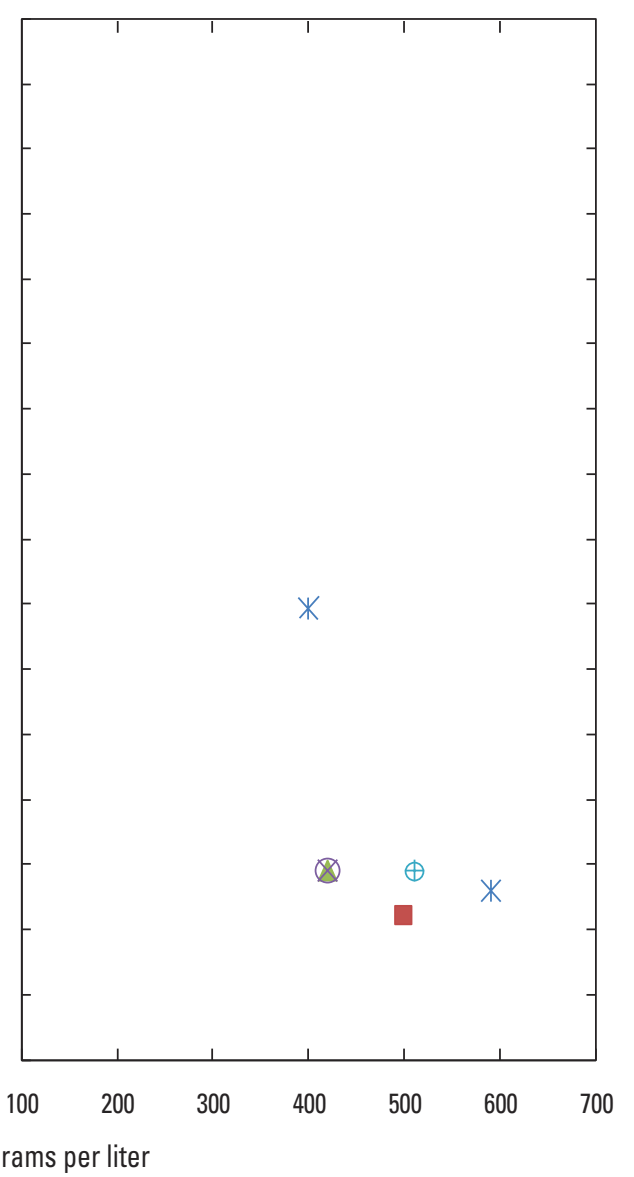

Concentration, in micrograms per liter

$$
\begin{gathered}
\text { EXPLANATION } \\
\text { X Passive } \\
\square \text { Bailer } \\
\triangle \text { Purge_1 } \\
\otimes \text { Purge_2 } \\
\oplus \text { Purge_3 }
\end{gathered}
$$

Figure 23. Well construction information and plots of trichloroethylene and perchlorate vertical chemical profiles derived from passive, bailed, and purge samples for well OW-44B2 at the Stringfellow Superfund site in Jurupa Valley, California. Additional description on samples provided in table 5. Pre-DTW, water level before passive deployment; post-DTW, water level before retrieval; $\mu \mathrm{g} / \mathrm{L}$, microgram per liter. 


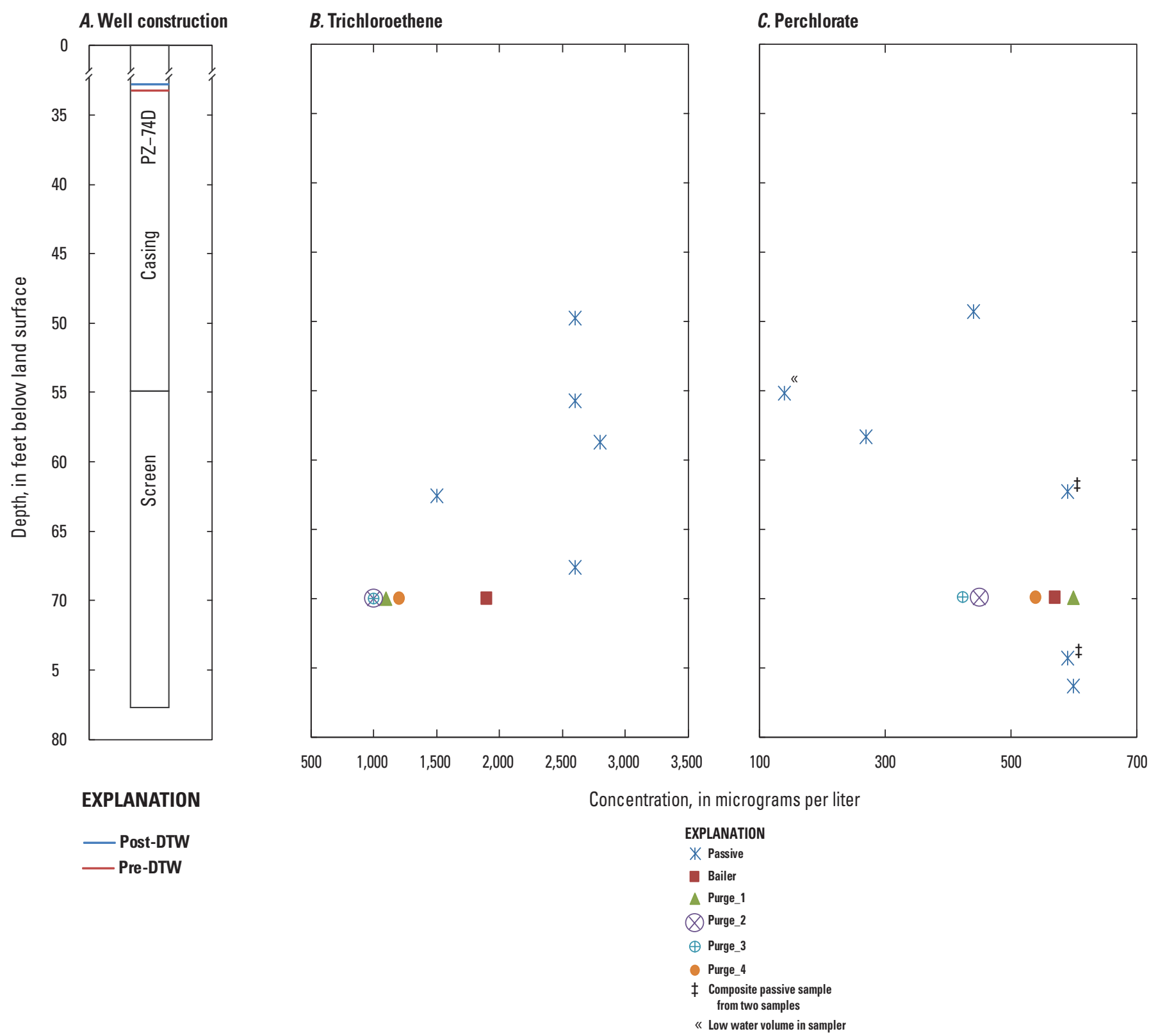

Figure 24. Graphs showing well construction information and plots of trichloroethylene and perchlorate vertical chemical profiles derived from passive, bailed, and purge samples for well PZ-74D at the Stringfellow Superfund site in Jurupa Valley, California. Additional description on samples provided in table 5. Pre-DTW, water level before passive deployment; post-DTW, water level before retrieval; $\mu \mathrm{g} / \mathrm{L}$, microgram per liter. 


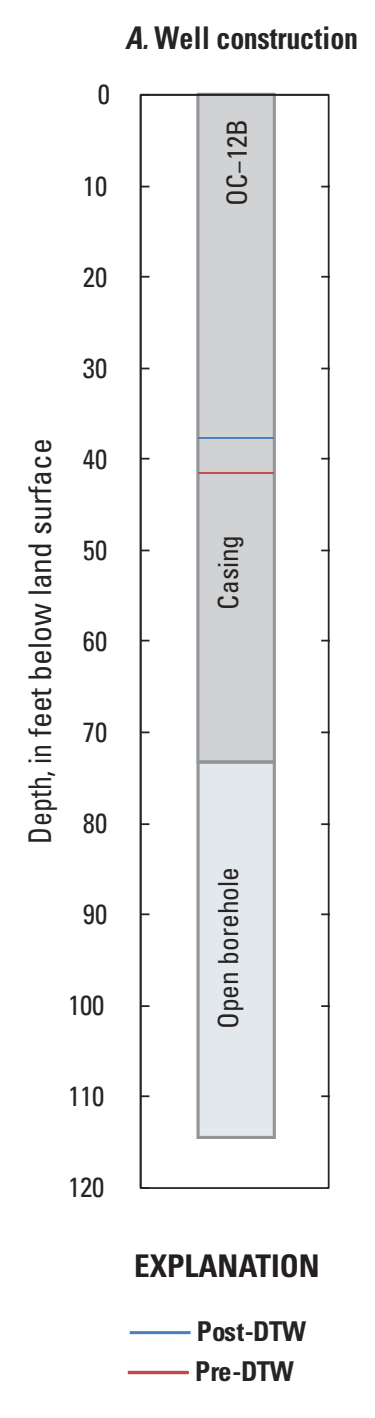

\section{B. Trichloroethene}

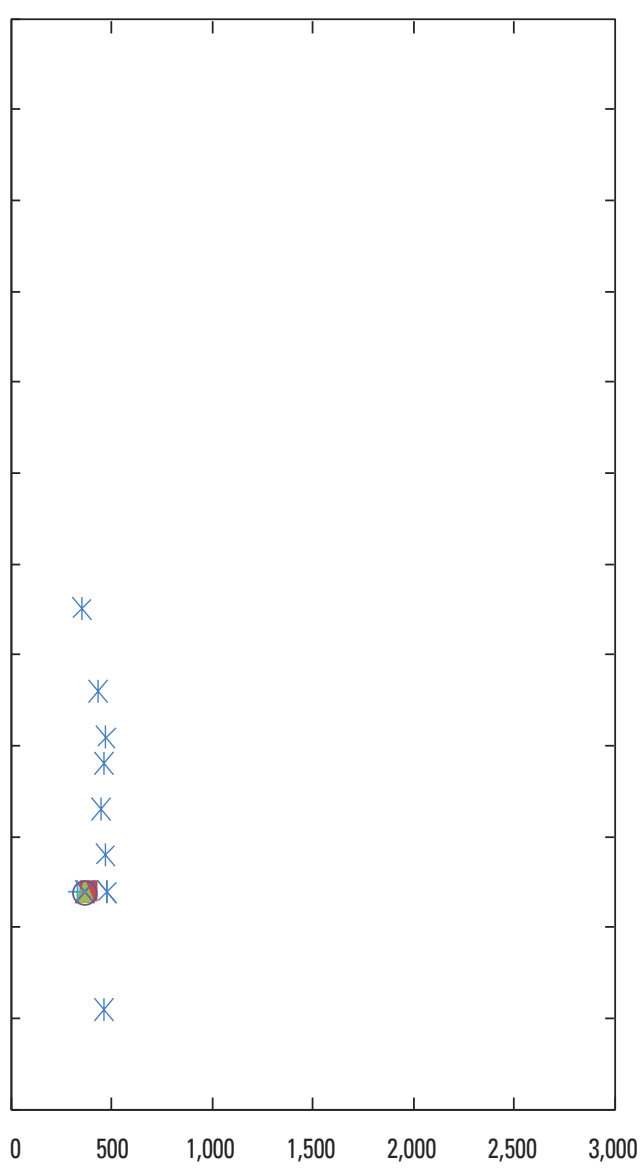

\section{Perchlorate}

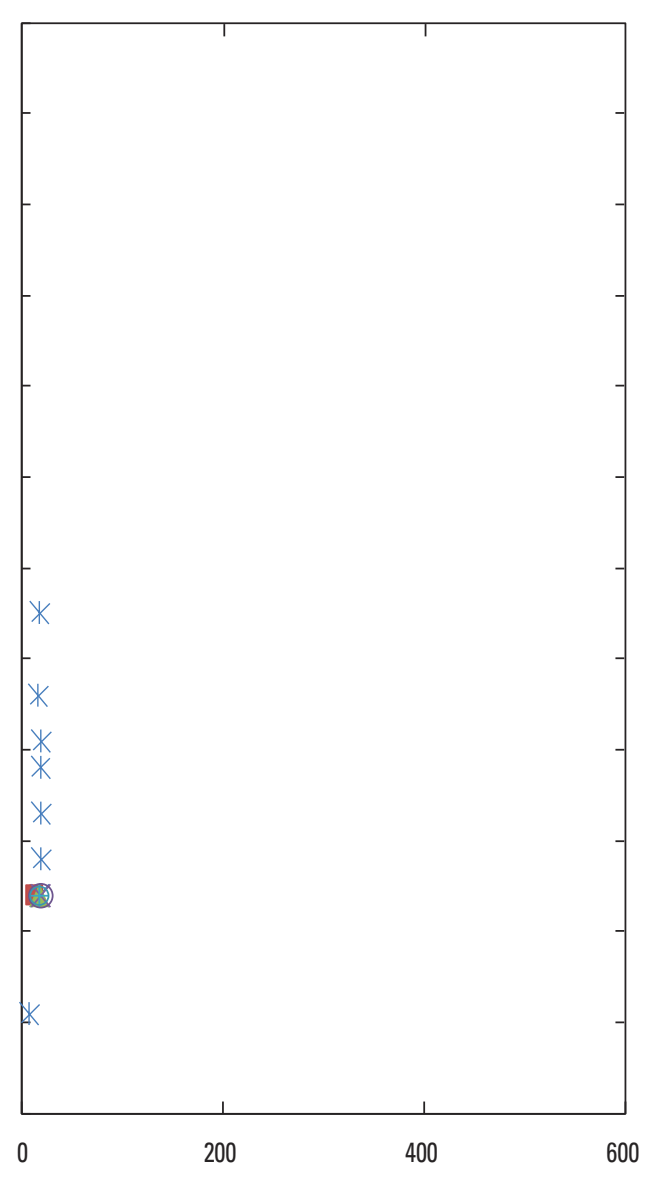

Concentration, in micrograms per liter

EXPLANATION
X Passive
B Bailer
$\triangle$ Purge_1
$\otimes$ Purge_2
$\oplus$ Purge_3

Figure 25. Graphs showing well construction information and plots of trichloroethylene and perchlorate vertical chemical profiles derived from passive, bailed, and purge samples for well OC-12B at the Stringfellow Superfund site in Jurupa Valley, California. Additional description on samples provided in table 5. Pre-DTW, water level before passive deployment; post-DTW, water level before retrieval; $\mu \mathrm{g} / \mathrm{L}$, microgram per liter. 
At each of the five wells, perchlorate concentrations from purge or pumped, bailer, and passive samples were greater than concentrations from preceding years (historical concentrations listed in table 6). Differences in concentrations between sample results from 2017 and preceding results are partly attributed to filtering. For this study, samples were collected through a $0.2-\mu \mathrm{m}$ filter, whereas historically, samples have been collected unfiltered. Filtering likely eliminates microbial perchlorate reduction (ex-situ) after the samples have been collected. According to Rikken and others (1996), a widely accepted perchlorate-reducing pathway is as follows:

$$
\mathrm{ClO}_{4}^{-} \rightarrow \mathrm{ClO}_{3}^{-} \rightarrow \mathrm{ClO}_{2}^{-} \rightarrow \mathrm{Cl}^{-}+\mathrm{O}_{2}
$$

where

$\begin{aligned} \mathrm{ClO}_{4}^{-} & \text {is perchlorate, } \\ \mathrm{ClO}_{3}{ }^{-} & \text {is chlorate, } \\ \mathrm{ClO}_{2}^{-} & \text {is chlorite, } \\ \mathrm{Cl}^{-} & \text {is chloride, and } \\ \mathrm{O}_{2} & \text { is oxygen. }\end{aligned}$

Therefore, biotic reduction of perchlorate ex-situ (after collection of samples) could follow a similar pathway and produce excess chloride.

TCE concentrations from purge, bailer, and passive samples, on average, were greater than historical concentrations at wells OW-44B2, OC-12B, and PZ-74D and less than historical concentrations at wells OW-46B1 and OW-69D2 (table 6). Most of the test wells have been historically sampled with a bailer at an unknown depth. Wells OW-46B1 and OW-69D2 have negligible casing water, and historical bailer samples from these wells would, by default, represent water collected from within the screen or open interval; therefore, the samples collected from these two wells should be representative of groundwater from the aquifer. If the historical bailer samples were collected just below the water surface during previous collections, then the samples collected from the other three wells could be more representative of the casing water than the screen water (water within the screen interval). The casing water just below the water-level surface may be expected to have lower TCE concentrations due to volatilization in most cases.

\section{Comparison of the PAT to the GWF}

The PAT simulations for the three test wells with purge samples show higher estimates of $K_{h}$ than estimates of $K_{r}$ computed by the GWF (tables 4 and 7). Both $K_{h}$ and $K_{r}$ represent radial hydraulic conductivity despite differences in notation. However, the GWF incorporates the effects of $K_{z}$ and $S_{s}$ into the computed value for $K_{r}$. The PAT-computed $K_{h}$ was $0.2166 \mathrm{ft} / \mathrm{d}$ at well PZ-74D, $0.0087 \mathrm{ft} / \mathrm{d}$ at well OW-44B2, and $0.0026 \mathrm{ft} / \mathrm{d}$ at well $\mathrm{OC}-12 \mathrm{~B}$ (table 4 ), higher by a factor of 1.6, 31, and 29, respectively, than the GWF computed $K_{r}$. Differences in estimates are attributed to the effect of aquifer storage. For hydraulic conductivity units $(>0.1 \mathrm{ft} / \mathrm{d})$, as in the case for well PZ-74D, the PAT provides approximate estimates of hydraulic conductivity. For hydraulic conductivity units $(<0.1 \mathrm{ft} / \mathrm{d}$, $)$ as in the case for wells OW-44B2 and OC-12B, the PAT overestimated hydraulic conductivity.

In contrast to the comparison to the GWF, the PAT estimates of $K_{h}$ are nearly identical to previously reported slug test results at wells $\mathrm{OC}-12 \mathrm{~B}$ and $\mathrm{OC}-44 \mathrm{~B} 2$ (table 7). At well PZ-74D, the PAT estimates are higher by a factor of 5 . Nevertheless, the overall closer comparison to results from the slug test is similar to previously reported comparisons of the PAT-computed $K_{h}$ to the reported slug test results from other sites.

Given the ranges of hydraulic conductivity from the different methods, incorporation of several methods and solutions into the computation of hydraulic conductivity would be beneficial to allow for uncertainty. Testing of different hydraulic conductivities in forward mode using the PAT would provide information on possible ranges of in-well flow and travel times that would influence purging/sampling parameters.

\section{Hydraulic Analysis and Simulation With the PAT}

The measured velocities of dyed water during pumped sampling were highest for the two wells with the lowest hydraulic conductivity (table 7). The two wells with lower hydraulic conductivities (wells OW-44B2 and OC-12B), where pumped water was composed largely of borehole storage, exhibited faster vertical velocities from the arrival times of the dye tracer than for the well with the higher hydraulic conductivity (well PZ-74D).

PAT simulations and computed vertical velocities were compared to velocities as measured with dye arrival times (fig. 26). PAT simulations incorporated homogeneity (heterogeneity factor $[\mathrm{HF}]=1$ ) and two levels of heterogeneity (HF $=10$ and $\mathrm{HF}=100$; table 7 ), utilizing a bimodal horizontal hydraulic conductivity distribution, where the saturated open interval above the pump intake had values for $K_{h}$ specified as 10 and 100 times greater than saturated open interval below the pump intake. This distribution of $K_{h}$ is based on the general stratigraphy of the site with a surficial weathering sequence overlying less weathered rock. For example, at well PZ-74D, the high- $K_{h}$ layers in the PAT were specified as corresponding to the interval noted as permeable in the lithologic log: at a contact between weathered and unweathered (much less weathered) rock.

The PAT cannot replicate the measured velocities for wells OW-44B2 and OC-12B (fig. 26). Given that pumped water in these wells is largely from borehole storage, it is likely that the lack of radial inflow into the well due to the low $\mathrm{K}_{\mathrm{h}}$ results in a large vertical pressure differential from the pump intake outward within the water well column or borehole. The PAT assumes that there is no vertical pressure differential in a well and that the head is vertically constant throughout the water column; the later assumption appears reasonable 


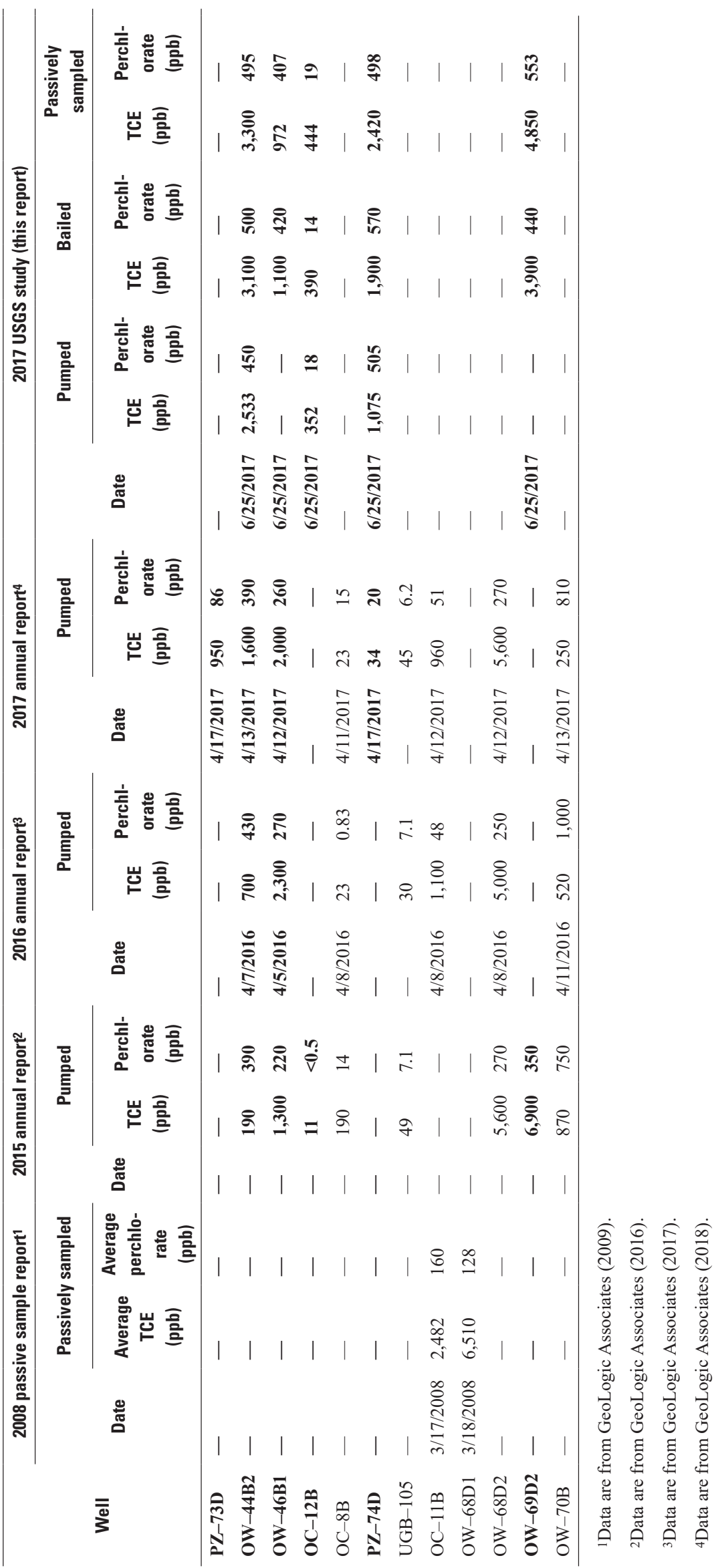


Table 7. Summary of well information and PAT parameters for test wells at the Stringfellow Superfund site in Jurupa Valley, California.

[PAT, Purge Analyzer Tool; N, no; Y, yes; ft, foot; in., inch; L/min, liter per minute; min, minute; $\mathrm{ft} / \mathrm{min}$, foot per minute; $\mathrm{ft} / \mathrm{d}$, foot per day; $\mathrm{ft} 3 / \mathrm{min}, \mathrm{cubic}$ foot per minute; HF, heterogeneity factor; e, estimated, - , no data; GWF, general well function (Perina and Lee (2006), and Perina (2020); *, at well OW-44B2, because of a wide and spread out dye peak, the observed dye arrival used the time to the first large dye increase]

\begin{tabular}{|c|c|c|c|}
\hline \multirow{2}{*}{ Parameter } & \multicolumn{3}{|c|}{ Well } \\
\hline & ${ }^{*} 0 \mathrm{~W}-44 \mathrm{~B} 2$ & PZ-74D & OC-12B \\
\hline Hydraulic response in drawdown pumping (ft) & 49.85 & 28 & 26.16 \\
\hline Static water level below land surface (ft) & 14.4 & 32.8 & 38.1 \\
\hline Depth to top of screen below land surface (ft) & 65 & 55 & 70 \\
\hline Length of screen $(\mathrm{ft})$ & 5 & 20 & 45 \\
\hline Well diameter (in.) & 4 & 3.5 & 6.33 \\
\hline Volumetric pump rate (L/min) & 1.3 & 2.74 & 2.33 \\
\hline Purge time (min) & 81 & 240 & 72 \\
\hline Pump intake location from top of opening (negative value means casing; $\mathrm{ft}$ ) & 2.5 & 10 & 22.5 \\
\hline Lower measured dye time of travel (first arrival lower; ft/min) & - & 0.042 & 0.75 \\
\hline GWF-estimated bulk hydraulic conductivity from sampling (ft/d) & 0.00535 & 0.12 & $5.78 \times 10^{-6}$ \\
\hline Purge Analyzer Tool-estimated bulk hydraulic conductivity from sampling (ft/d) & 0.0083 & 0.221 & 0.0026 \\
\hline Simulated average pump rate ( $\mathrm{ft} 3 / \mathrm{min})$ & 0.0618 & 0.0966 & 0.0824 \\
\hline Simulated average effective pump rate (average pumping rate - well storage rate; $\mathrm{ft} 3 / \mathrm{min}$ ) & 0.00221 & 0.0888 & 0.0787 \\
\hline Mixing zone, $1 / 2$ width (ft) & 0.5 & 0.2 & 0.5 \\
\hline Upper computed velocity for $\mathrm{HF}=1(\mathrm{ft} / \mathrm{min})$ & 0.00446 & 0.0172 & 0.00780 \\
\hline Upper computed velocity for $\mathrm{HF}=10(\mathrm{ft} / \mathrm{min})$ & 0.00853 & 0.0962 & 0.0212 \\
\hline
\end{tabular}



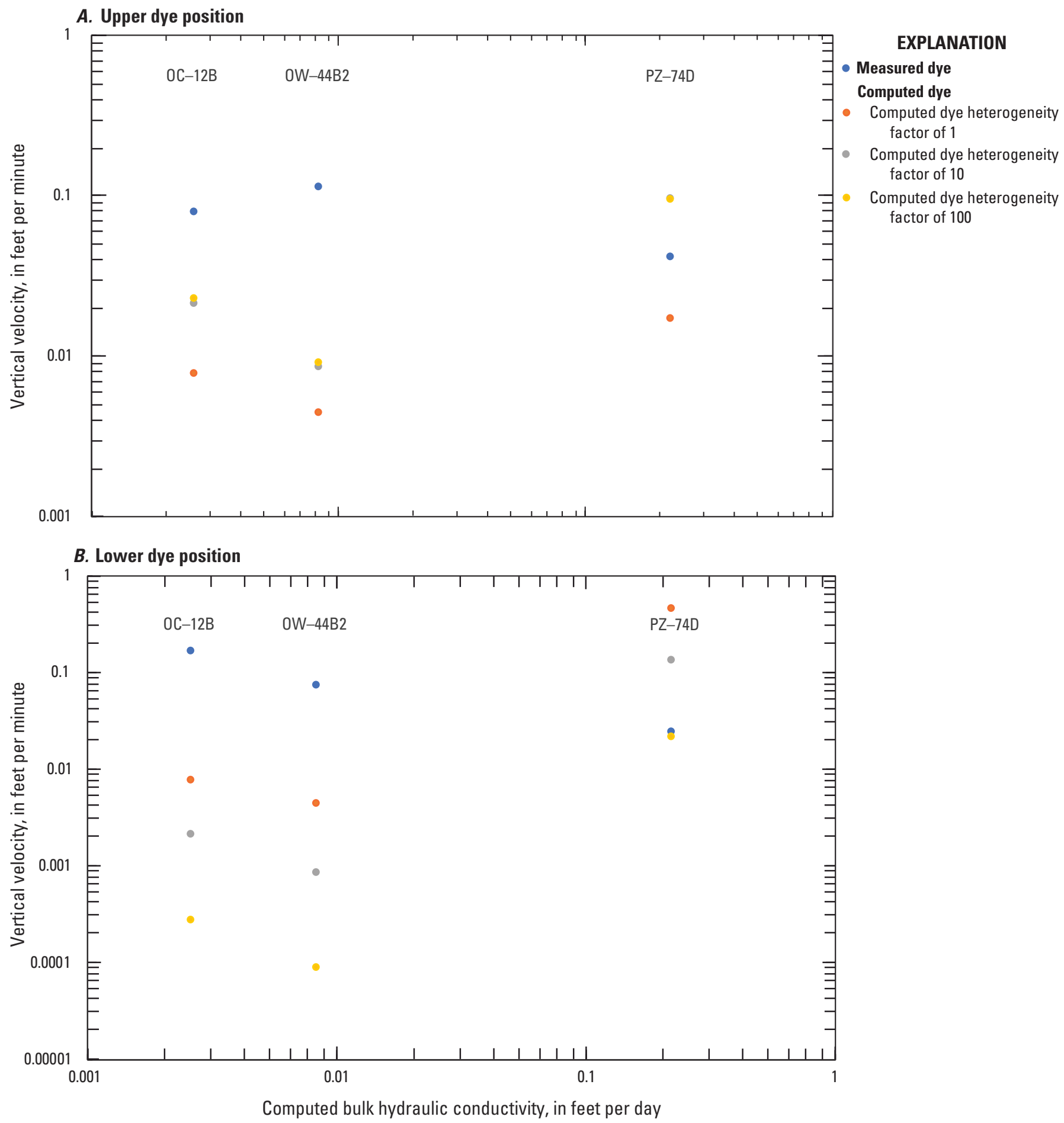

Figure 26. Graphs showing measured vertical velocities from peak dye arrival and PAT-computed vertical velocities associated with the water column $A$, above and $B$, below the pump intake at wells $0 \mathrm{C}-12 \mathrm{~B}, 0 \mathrm{~W}-44 \mathrm{~B} 2$, and $\mathrm{PZ}-74 \mathrm{D}$ at the Stringfellow Superfund site in Jurupa Valley, California. PAT, Purge Analyzer Tool; $\mathrm{ft} / \mathrm{min}$, foot per minute; $\mathrm{ft} / \mathrm{d}$, foot per day; HF_1, heterogeneity factor 1; HF_10, heterogeneity factor 10; HF_100, heterogeneity factor 100 . 
when borehole storage is not the primary source of pumped water, given the reasonable match between estimated and computed velocities at well PZ-74D. Measured velocities may be better replicated with the inclusion of a pipe-flow equation in PAT for the wells with very low $\mathrm{K}_{\mathrm{h}}(<0.1 \mathrm{ft} / \mathrm{d})$. Further testing would provide more well comparisons, additional data points and, thus, improved inferences on the relation between travel times, hydraulic conductivity, and borehole storage.

\section{Estimates of Pump Time for Monitoring Wells With the PAT}

Some wells onsite can be sampled with low-flow methods based on simulations of the PAT and using time of travel as a criterion for evaluation of optimal purge times. However, according to PAT simulations, only 4 (UGB-105, OW-68D2, OW-46B1, and PZ-73D) of the 11 wells simulated with PAT (all wells other than OW-68D1 and OW-37D1 listed in table 8 ) can sustain low pumping rates $(0.1$ to $0.3 \mathrm{~L} / \mathrm{min})$ during sampling within a reasonable timeframe as based on the time to achieve 80 percent capture of groundwater from the aquifer (table 8). Two wells from the 13 reconnaissance wells were not simulated because well OW-68D1 was dry and well OW-37D1 could not be accessed.

Existing hydraulic conductivity measurements from previous studies were used in the simulation to compute drawdown, model radial inflow, and compute in-well travel times as reported in table 8 . Most values for hydraulic conductivity were derived from site reports by Environ International Corp. $(2012,2015)$. Drawdown was constrained during PAT simulations, such that water levels were not allowed to drop below $1.5 \mathrm{ft}$ above the top of the well screen to avoid dewatering of the aquifer. Based on this constraint, four wells could not sustain pumping rates of $0.1 \mathrm{~L} / \mathrm{min}$, another two wells could not sustain rates of $0.3 \mathrm{~L} / \mathrm{min}$, and one well had such an excessively long pump time (1,715 minutes) as to make it impractical to purge (table 8 ). Another well had moderately long purge times (270 minutes), making it inefficient to sample at low pumping rates.

PAT simulations assumed a simple homogeneous condition that would be analogous to a zone of a porous sedimentary rock rather than a competent rock with permeable fractures. Wells that intersect a single fracture may achieve faster travel times based on the relative positioning of the fracture and the pump intake (Harte and others, 2019).

\section{Additional Vertical Profiles of Wells}

Vertical profiles of specific conductance before and immediately after purging for the three pumped wells (PZ-74D, OC-12B, and OW-44B2) where purge samples were collected show that the largest specific conductance differences occurred in the well casings. All three wells show an increase in specific conductance within the well casing after purging. A possible reason for these differences is the agitation of conductive particulates off the well casing into the well water from insertion of the pump and from downward flow of casing water to the pump intake during pumping (figs. 27 to 29). Walters (1997) found that encrusting materials on well casings and screens on Long Island, New York, consisted primarily of amorphous ferric hydroxide with lesser amounts of goethite, hematite, maghemite or magnetite, and quartz, and that chemically these materials were composed of iron with some silica, manganese, and trace elements. At the Stringfellow Superfund site, redox-sensitive water in the well casing is exposed to atmospheric oxidation. As the ambient groundwater in its reduced state and with associated high concentrations of dissolved trace elements flows into the well, exposure to dissolved oxygen in the well forms the encrustation materials (likely from the formation of oxyhydroxide metals) on the well casing.

Specific conductance differences along the well screen or open borehole are smaller than differences observed in the casing. Specific conductance along the screen at well PZ-74D exhibited the least amount of difference before and after purging despite being the most permeable of the three wells (fig. 27). This finding suggests that the ambient well water chemistry in the screen or open interval is a good representation of the groundwater chemistry of the aquifer. Specific conductance along the screen at well OW-44B2 also exhibited minimal difference before and after purging (fig. 28). Specific conductance along the screen at well OC-12B exhibited the largest difference before and after purging (fig. 29), primarily near the top of the open borehole at a depth of $70 \mathrm{ft}$ below land surface, which is indicative of inflow with relatively low specific conductance at that depth. The water chemistry at well $\mathrm{OC}-12 \mathrm{~B}$ is indicative of some nonindigenous or anthropogenic reactions induced by the well construction, as noted by the presence of gray particulates on the RPP samplers when retrieved from the well; the particulates were likely a byproduct of one or more redox-induced reactions resulting from the mixing of reduced groundwater from the aquifer with the oxygenated well water or oxygenated water in the passive sample. The video log for well OC-12B also showed some deterioration of the well casing at the bottom of the well that could be attributed to nonindigenous reactions outside of native aquifer material (fig. 30).

A comparison of the specific conductance profile with the specific conductance measured from pumped water from each of the three wells allows for insight into the relative amount of existing borehole water and recent inflowing groundwater from the aquifer captured during pumping. The specific conductance of the pumped water (tables 9, 10, and 11) was bracketed by the ranges of specific conductance measured from the profiles collected before and after purging (figs. 27 to 29). At well PZ-74D, the specific conductance of the pumped water varied from 5,907 to 6,096 microsiemens per centimeter at 25 degrees Celsius $(\mu \mathrm{S} / \mathrm{cm})$ during the first 2 hours and 10 minutes of pumping, and based on the ranges of specific conductance on the well profiles, most of the pumped water was capturing well-casing water (fig. 27). Afterwards, the specific 


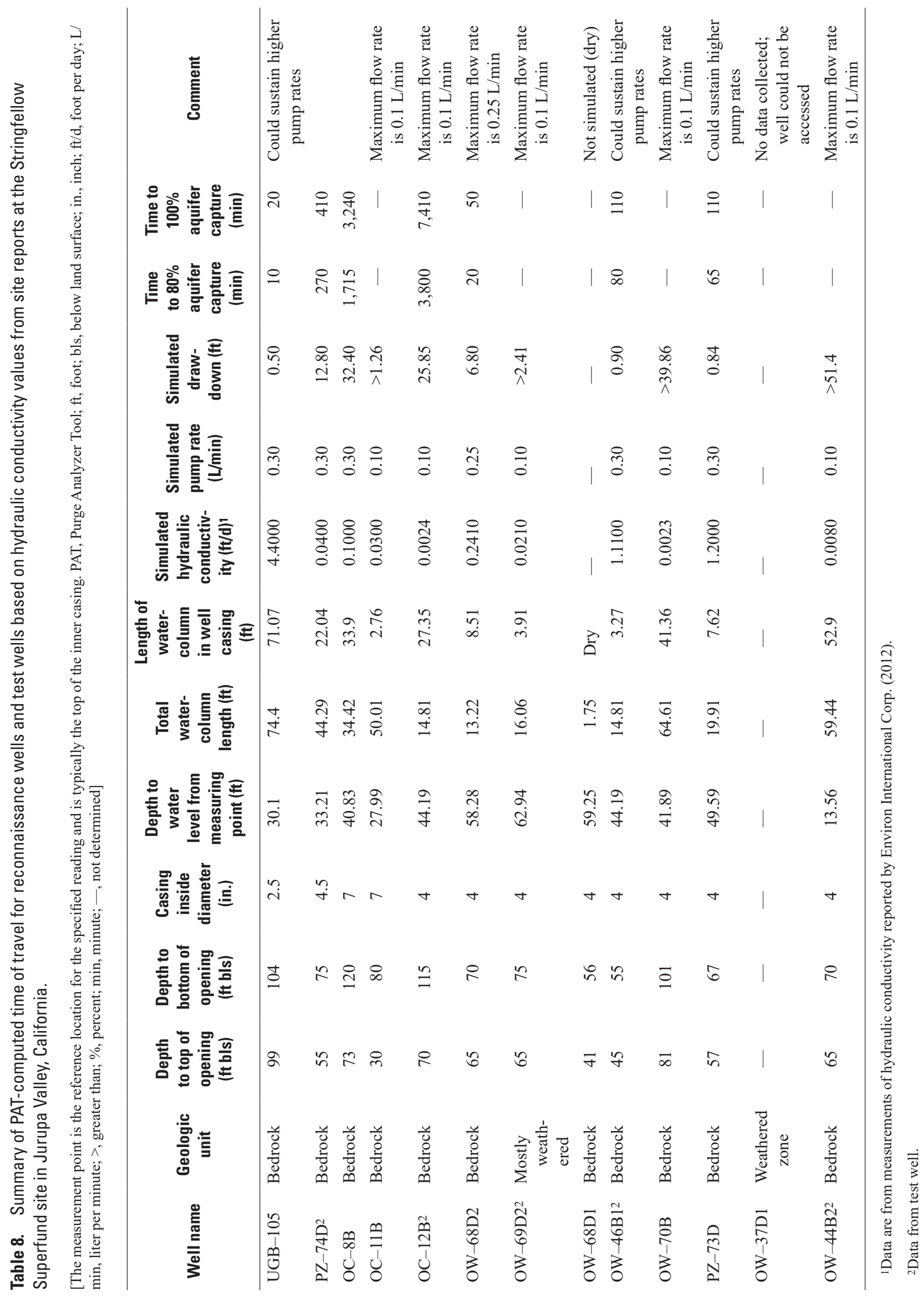




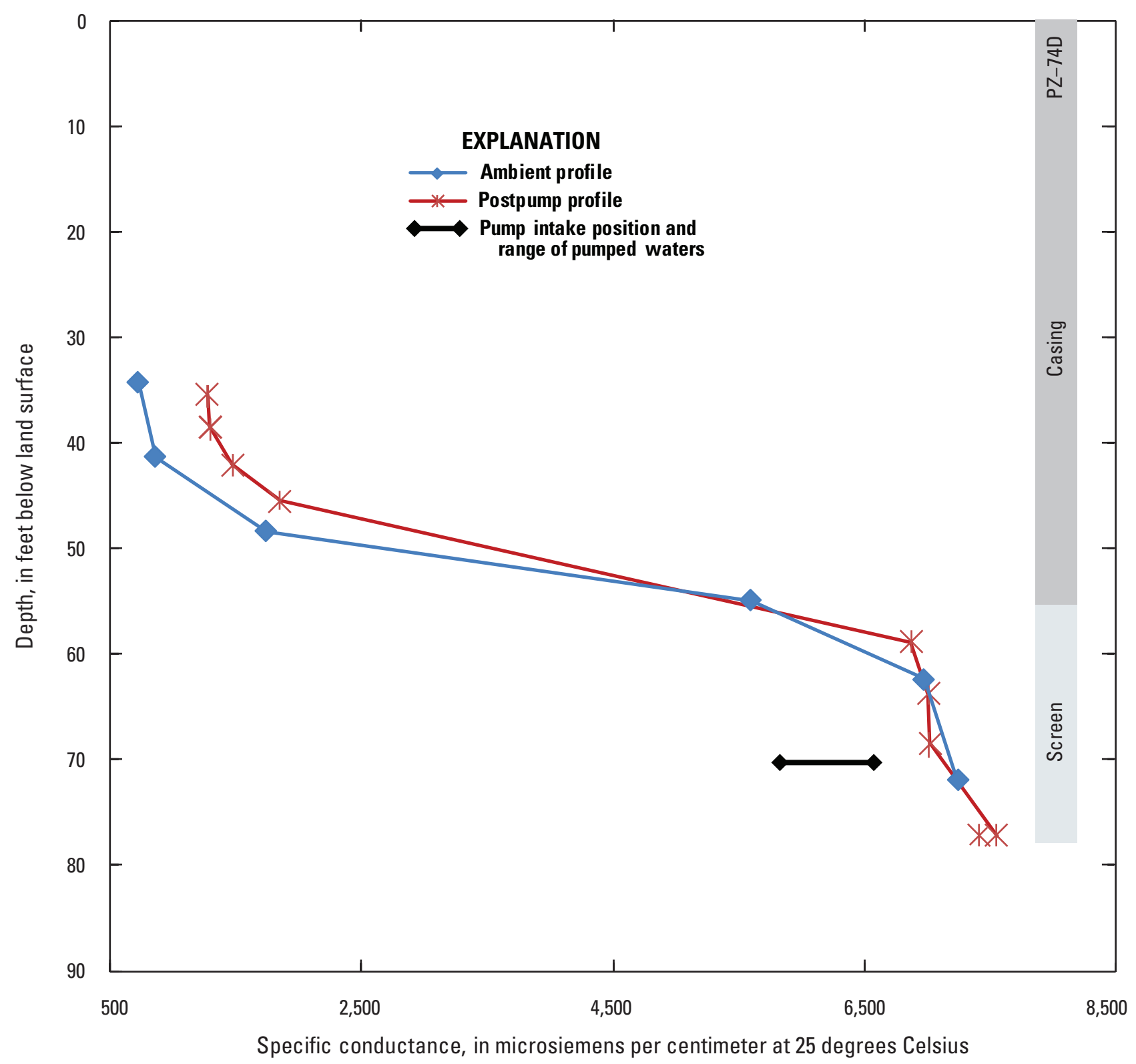

Figure 27. Graph showing vertical profile of specific conductance before (ambient) and after purging for well PZ-74D at the Stringfellow Superfund site in Jurupa Valley, California. $\mathrm{mS} / \mathrm{cm}$, microsiemens per centimeter; $\mathrm{ft}$, foot; bls, below land surface. 


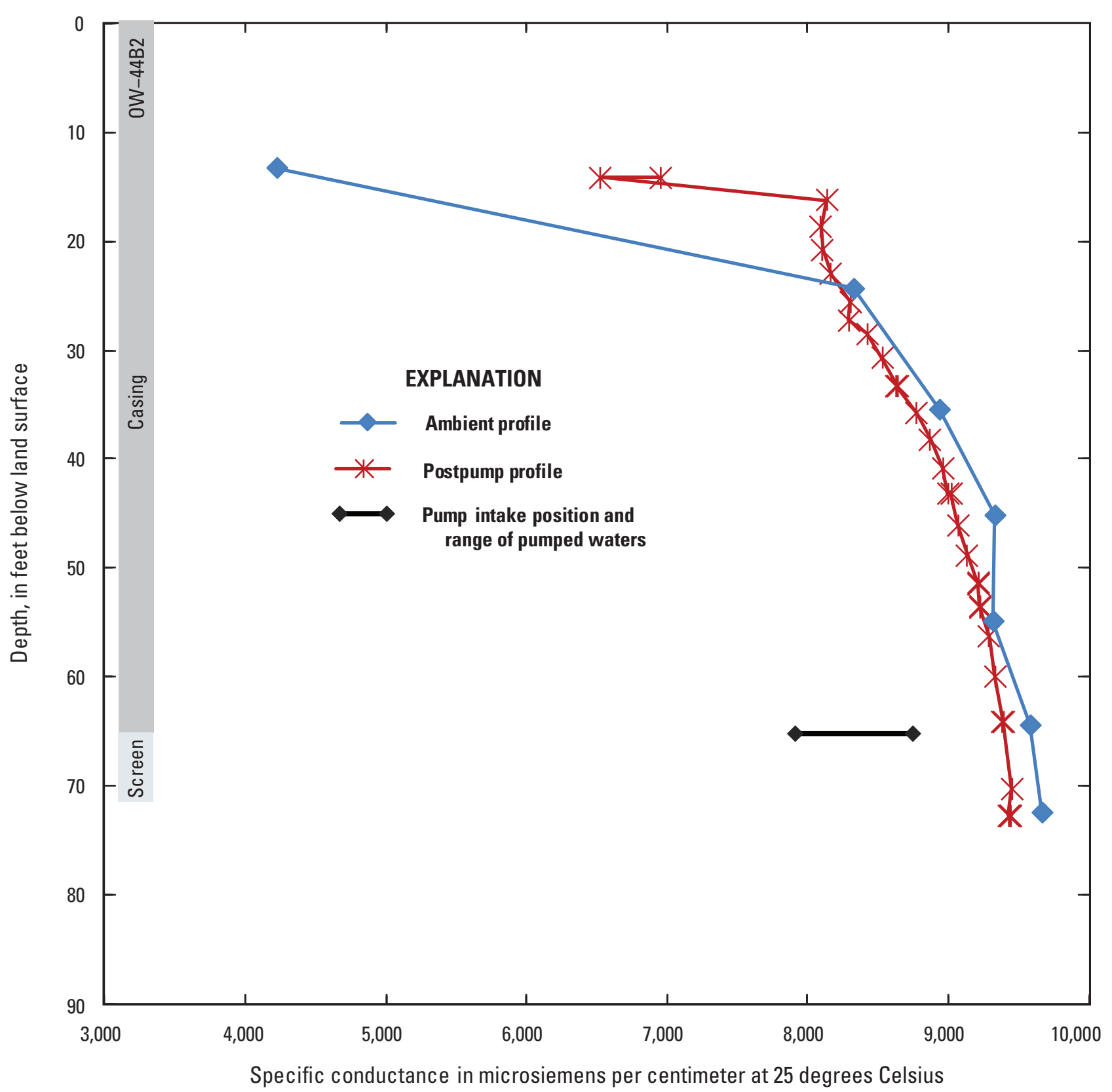

Figure 28. Graph showing vertical profile of specific conductance before (ambient) and after purging for well OW-44B2 at the Stringfellow Superfund site in Jurupa Valley, California. $\mathrm{mS} / \mathrm{cm}$, microsiemens per centimeter; $\mathrm{ft}$, foot; bls, below land surface. 


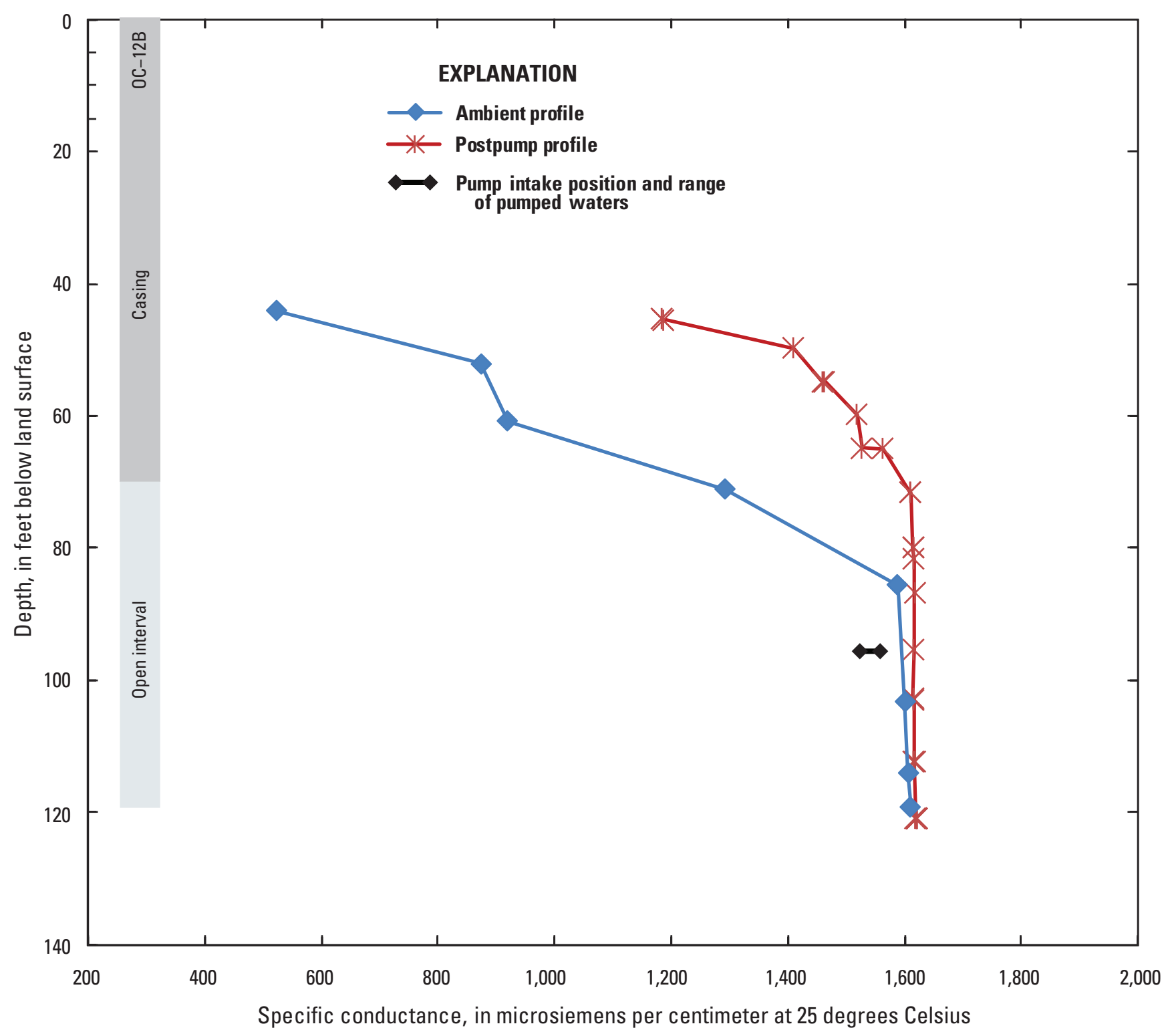

Figure 29. Graph showing vertical profile of specific conductance before (ambient) and after purging for well OC-12B at the Stringfellow Superfund site in Jurupa Valley, California. $\mathrm{mS} / \mathrm{cm}$, microsiemens per centimeter; ft, foot; bls, below land surface. 


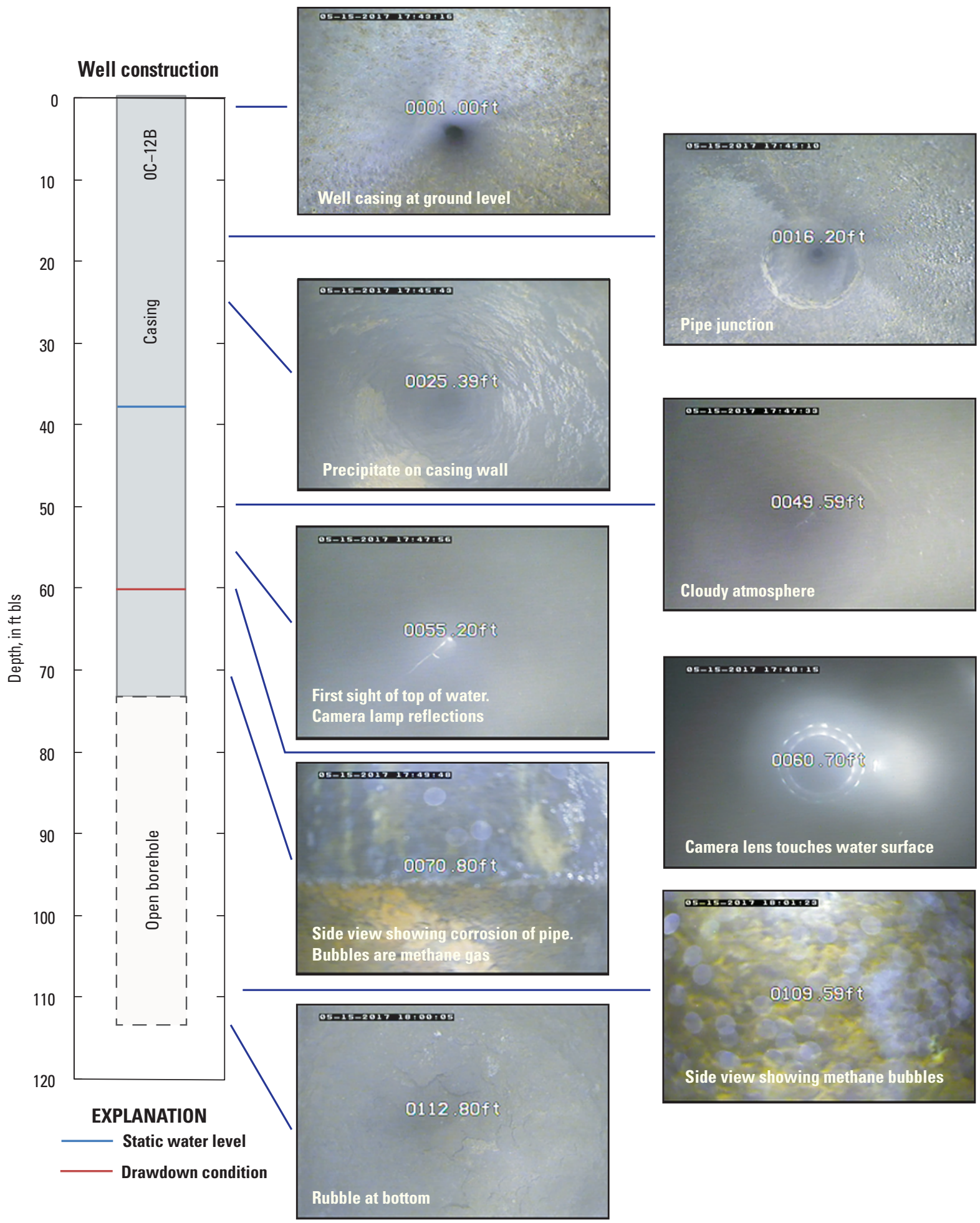

Figure 30. Diagram showing well costruction and images from a video log at indicated positions for well OC-12B at the Stringfellow Superfund site in Jurupa Valley, California. The image at a depth of 70 feet below land surface shows deterioration of the metal casing; the edges of the steel casing show some corrosion. 


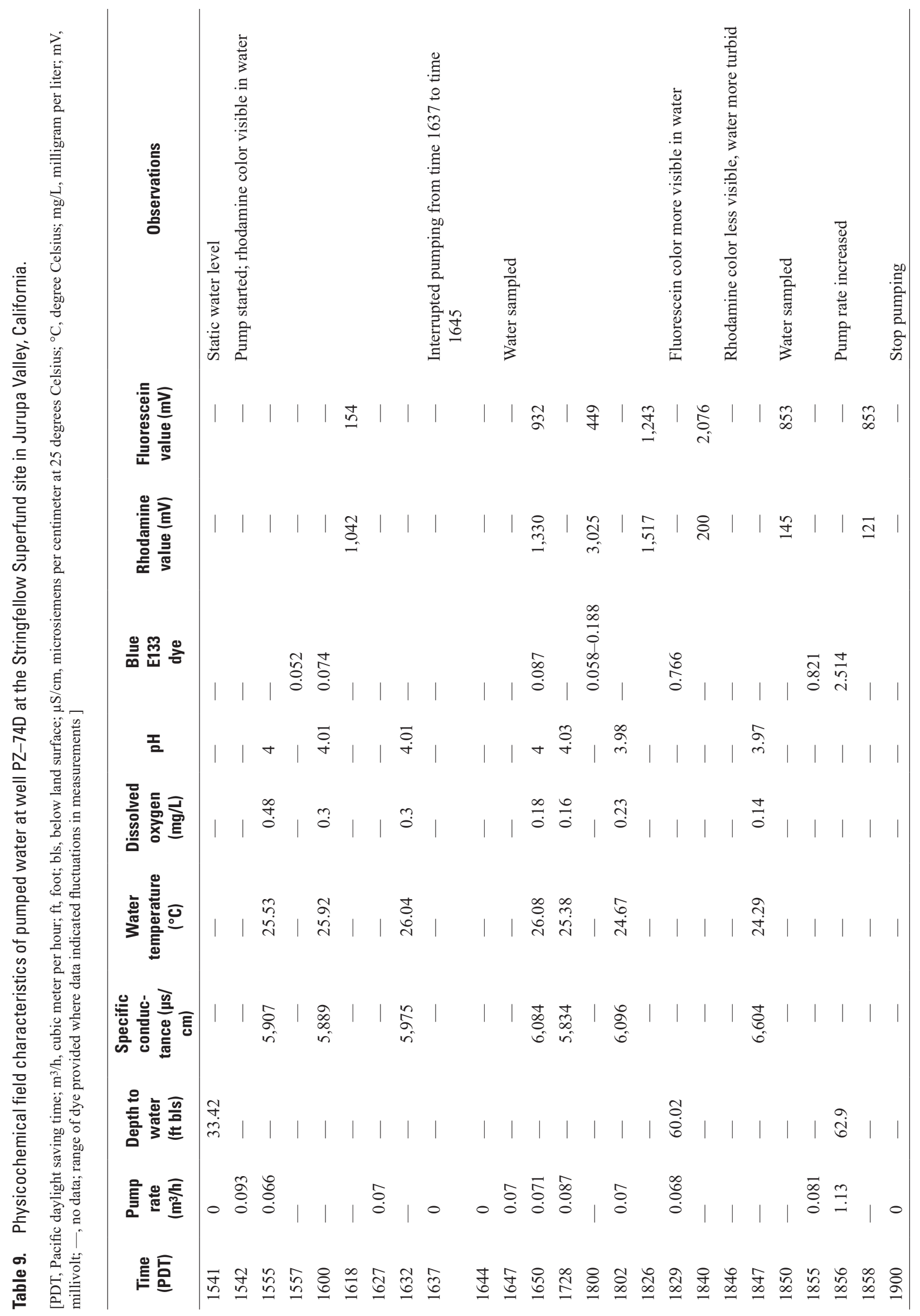


Table 10. Physicochemical field characteristics of pumped water at well OW-44B2 at the Stringfellow Superfund site in Jurupa Valley, California.

[PDT, Pacific daylight-saving time; $\mathrm{m}^{3} / \mathrm{h}$, cubic meter per hour; ft, foot; $\mu \mathrm{S} / \mathrm{cm}$, microsiemens per centimeter at 25 degrees Celsius; ${ }^{\circ} \mathrm{C}$, degree Celsius; $\mathrm{mg} / \mathrm{L}$, milligram per liter; 一, no data]

\begin{tabular}{|c|c|c|c|c|c|c|c|c|}
\hline $\begin{array}{l}\text { Time } \\
\text { (PDT) }\end{array}$ & $\begin{array}{c}\text { Pump rate } \\
\left(\mathrm{m}^{3} / \mathrm{h}\right)\end{array}$ & $\begin{array}{c}\text { Depth to } \\
\text { water } \\
\text { below land } \\
\text { surface (ft) }\end{array}$ & $\begin{array}{c}\text { Specific } \\
\text { conductance } \\
(\mu \mathrm{s} / \mathrm{cm})\end{array}$ & $\begin{array}{l}\text { Water tempera- } \\
\text { ture }\left({ }^{\circ} \mathrm{C}\right)\end{array}$ & $\begin{array}{c}\text { Dissolved } \\
\text { oxygen } \\
\text { (mg/L) }\end{array}$ & $\mathrm{pH}$ & $\begin{array}{c}\text { Blue } \\
\text { \#E133 } \\
\text { dye }\end{array}$ & Observations \\
\hline 1213 & 0 & 13.57 & - & - & - & - & - & \\
\hline 1214 & - & - & - & - & - & - & - & Start pumping \\
\hline 1228 & 0.161 & 31.12 & 8,813 & 24.58 & 0.22 & 4.05 & - & \\
\hline 1235 & 0.146 & - & - & - & - & - & - & \\
\hline 1244 & - & - & 8,432 & 25.06 & 0.18 & 4.05 & - & \\
\hline 1247 & - & - & - & - & - & - & 0.084 & \\
\hline 1254 & 0.077 & - & - & - & - & - & - & \\
\hline 1259 & 0.056 & - & - & - & - & - & - & \\
\hline 1306 & - & - & - & - & - & - & - & Sample purge 1 \\
\hline 1310 & - & - & 7,995 & 27.06 & 0.13 & 4.14 & 0.085 & \\
\hline 1316 & - & - & - & - & - & - & & Sample purge 2 \\
\hline 1324 & 0.025 & 63.82 & - & - & - & - & 0.018 & \\
\hline 1334 & 0 & - & - & - & - & - & - & Stop pumping for the day \\
\hline 1336 & - & - & - & - & - & - & - & Stop pumping; dewatered \\
\hline Next day & - & - & - & - & - & - & - & Recovery overnight \\
\hline 914 & - & - & - & - & - & - & - & Sample purge 3 \\
\hline
\end{tabular}

Table 11. Physicochemical field characteristics of pumped water at well OC-12B at the Stringfellow Superfund site in Jurupa Valley, California.

[PDT, Pacific daylight-saving time; $\mathrm{m}^{3} / \mathrm{h}$, cubic meter per hour; $\mathrm{ft}$, foot; $\mu \mathrm{S} / \mathrm{cm}$, microsiemens per centimeter at 25 degrees Celsius; ${ }^{\circ} \mathrm{C}$, degree Celsius; $\mathrm{mg} / \mathrm{L}$, milligram per liter; -, no data]

\begin{tabular}{|c|c|c|c|c|c|c|c|c|}
\hline Time, PDT & $\begin{array}{c}\text { Pump rate } \\
\qquad\left(\mathrm{m}^{3} / \mathrm{h}\right)\end{array}$ & $\begin{array}{l}\text { Depth to water } \\
\text { below land } \\
\text { surface (ft) }\end{array}$ & 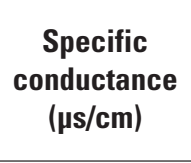 & $\begin{array}{l}\text { Water tem- } \\
\text { perature }\left({ }^{\circ} \mathrm{C}\right)\end{array}$ & $\begin{array}{c}\text { Dissolved } \\
\text { oxygen } \\
\text { (mg/L) }\end{array}$ & $\mathrm{pH}$ & $\begin{array}{l}\text { Blue dye } \\
\text { food- } \\
\text { grade } \\
\text { value }\end{array}$ & Observation \\
\hline 1800 & 0 & 38.1 & - & - & - & - & - & Static water level \\
\hline 1804 & 0.196 & - & 1,584 & 24.11 & 6.69 & 1.3 & - & Start pumping \\
\hline 1805 & - & - & - & - & - & - & 0.067 & \\
\hline 1827 & 0.093 & - & - & - & - & - & - & \\
\hline 1829 & - & - & 1,584 & 24.18 & 6.7 & 0.08 & - & \\
\hline 1830 & 0.056 & - & - & - & - & - & - & \\
\hline 1852 & - & - & - & - & - & - & 0.018 & \\
\hline 1902 & 0.14 & - & - & - & - & - & - & \\
\hline 1907 & - & - & - & - & - & - & 0.031 & \\
\hline 1911 & 0 & - & - & - & - & - & - & Stop pumping \\
\hline 1912 & 0 & - & - & - & - & - & - & \\
\hline
\end{tabular}


conductance of the pumped water steeply increased from 6,096 to $6,604 \mu \mathrm{S} / \mathrm{cm}$ during the next 50 minutes of pumping, and based on the well profile, the pumped water captured more water from the well screen (fig. 27). At well OW-44B2, the specific conductance of the pumped water varied from 7,995 to $8,813 \mu \mathrm{S} / \mathrm{cm}$ after approximately 40 minutes of pumping, and based on the well profile, the continued pumping progressively captured well-casing water (fig. 28). At well OC-12B, the specific conductance of the pumped water was consistently around 1,584 to $1,587 \mu \mathrm{S} / \mathrm{cm}$ during the 50 minutes of pumping, which is similar to the specific conductance of the water in the open interval of the well (fig. 29).

\section{Assessment of Existing Monitoring- Well Network}

The low permeability of the rock underlying the site is potentially problematic for collection of representative groundwater samples because the exchange of groundwater between the aquifer and wells is slow. Chemical reactions in the well are not fully understood and are likely sensitive to the slow flushing by ambient groundwater flow from the aquifer. Some deterioration of the metal casing at well OC-12B was visible in the video log (fig. 30). The video log also showed degassing in the water column. Differences in the TCE concentrations between the well casing and screen were observed at some wells. There were also large differences in specific conductance of the well water in the casing compared with the screen/open interval, which suggests differences in some inorganic ion concentrations. There were no large differences in perchlorate concentrations between the well casing and screen.

Filtering helps decrease biotic activity in samples. Historical samples of perchlorate from wells may have been collected unfiltered and biotic reduction (ex-situ) could be occurring after collection and before laboratory analysis; however, in this study, the sample routine included filtration. Concentrations for perchlorate for this study were greater than previous perchlorate concentrations at coincident wells.

Many of the rock wells are screened in sand pack. Sand pack is an additional complexity to the identification of flow zones in the well and to the collection of discrete samples because the sand pack redistributes flow between the aquifer and the well. However, data collected with passive samplers helped identify some vertical trends in chemistry in the test wells for this study that maybe associated with discrete flow zones; this technique shows promise in delineating contamination zones in other wells. Subsequent sampling could target the specific depth of contamination zones to better account for contaminant mass transport.

\section{Optimizing Monitoring at Wells}

The hydrogeologic units underlying the site consist of sediments and rock in a range of weathered states. Groundwater flow appears to be focused along contacts between weathered and less weathered rock. Potentially, the highest concentrations of contaminants could occur at these intervals and, correspondingly, the highest amount of mass would be transported through them. Therefore, focusing groundwater sampling at these intervals would provide information on a primary transport pathway of contaminants. A thorough examination of driller and lithologic logs could be used to assess wells that intercept these contacts. Where logs are unavailable or unreliable, natural gamma-ray logging could help identify such contacts.

An analysis of in-well groundwater flow and travel times, which can provide insight into sample representativeness and optimization of purging parameters like pumping rate, location of pump intake, and duration of pumping, can be done quickly using the PAT as an assessment tool. For this study, a subset of 11 wells was evaluated. Expanding the assessment to all actively sampled wells could allow for a more comprehensive assessment of the current [2020] well-monitoring network. Although it is impractical to collect samples using a pump at many wells at the Stringfellow Superfund site, the assessment could provide insights into the relative amount of groundwater exchange between the aquifer and the wells based on rock permeability. Wells with greater exchange capability should yield samples that are more representative of the aquifer than wells with less exchange. Further, exchange rates may play a role in TCE volatilization out of the well water column to the atmosphere. Where exchange rates are slow, additional time for volatilization of TCE in the water column to the atmosphere takes place that would decrease TCE concentrations in the well water.

In addition to an assessment with the PAT, the methods used to assess the representativeness of well water through the identification of differences between well-casing water chemistry and screen/open borehole water chemistry can help identify wells where sampled water may be less representative of the aquifer than other wells. These methods include vertical profiles within the well casing and screen through the use of probes and passive samplers. Care must be taken in avoiding collection of casing water (water from the cased part of the well). To improve sample representativeness based on this assessment, either the sampling techniques can be modified, or a lower priority can be assigned to those wells where casing water may adversely affect results. Conversely, wells can be sampled where representative samples are expected to be collected. The volumetric relation between well-casing water and well-screen water can be used to identify wells that have the potential to capture large amounts of casing water when sampled (table 12). When collecting bailer samples, at a minimum, bailer samples should be collected at the midpoint of the well screen. For wells with little well-casing water, bailer samples would, by default, collect water from whatever water column exists within the screen/opening of the well. 
Table 12. Volumetric calculations of water for select wells at the Stringfellow Superfund site in Jurupa Valley, California.

[Total well volume is casing plus screen volume; excludes filter. $\mathrm{ft}$, foot; $\mathrm{ft}^{3}$, cubic foot; - , no data; bls, below land surface]

\begin{tabular}{lccccc}
\hline Well & $\begin{array}{c}\text { Depth to water from } \\
\text { bls(ft) }\end{array}$ & $\begin{array}{c}\text { Volume of water in } \\
\text { screen or open interval } \\
\left(\mathbf{f t}^{3}\right)\end{array}$ & $\begin{array}{c}\text { Volume of water } \\
\text { in casing }\left(\mathbf{f t}^{\mathbf{3}} \mathbf{)}\right.\end{array}$ & $\begin{array}{c}\text { Total well volume } \\
\left(\mathbf{f t}^{\mathbf{3}} \mathbf{)}\right.\end{array}$ & $\begin{array}{c}\text { Ratio of casing to } \\
\text { screen volume }\end{array}$ \\
\hline UGB-105 & 28.06 & 0.17 & 2.35 & 2.52 & 13.8 \\
PZ-74D1 & 32.96 & 2.20 & 2.40 & 4.60 & 1.1 \\
OC-8B & 39.09 & 12.50 & 8.60 & 21.10 & 0.7 \\
OC-11B1 & 27.24 & 13.30 & 0.54 & 13.84 & 0.0 \\
OC-12B1 & 36.5 & 3.90 & 2.80 & 6.70 & 0.7 \\
OW-68D2 & 56.49 & 0.43 & 0.59 & 1.02 & 1.4 \\
OW-69D21 & 61.09 & 0.87 & 0.34 & 1.21 & 0.4 \\
OW-68D1 & Dry & - & - & - & -1 \\
OW-46B11 & 41.73 & 0.87 & 0.07 & 0.94 & 0.1 \\
OW-70B & 39.64 & 1.74 & 3.61 & 5.35 & 2.1 \\
PZ-73D & 49.38 & 0.87 & 0.65 & 1.52 & 0.7 \\
OW-44B21 & 12.1 & 0.44 & 4.61 & 5.05 & 10.6 \\
\hline
\end{tabular}

1Data from test well.

\section{Conclusions}

Differences in casing and screen water chemistry were identified for TCE concentrations from groundwater sampling. At one well, TCE concentrations in the casing water were greater than TCE concentrations in the screen water. Remnant water within the casing from a previous period, where the concentration of TCE exceeded that of the current period was presumed to be the cause; in these cases, screen water represented a contemporaneous period, where the concentration of TCE is less. At other wells, TCE concentrations in the casing water were less than in the screen water. TCE volatilization up the water column out to the atmosphere is presumed to be a mechanism of a decreasing TCE trend as the depth decreases below the water surface and becomes closer to the water/atmospheric interface.

Perchlorate concentrations showed negligible differences between the cased and screened intervals. Perchlorate volatilization is negligible owing to its low vapor pressure. Further, small differences in the concentrations of perchlorate between the cased and screened intervals may also suggest less temporal change in perchlorate unlike TCE.

Wells with metal casing may be susceptible to deterioration, if saturated. Further, other reactions, such as chemical precipitation of minerals or adsorption onto the well-casing materials, are possible from oxidation closer to the water/ atmosphere interface when the water column is in the casing. Vertical profiles of specific conductance showed increasing values from the casing water into the screen water with greater depth; however, vertical profiles before and after purging showed an increase in specific conductance in the well casing in the three pumped wells. It is likely that mobilization of particulates off of the well casing after purging occurs from the insertion of pumps into the well and the inducement of downward flow from pumping at lower depths (most wells were pumped at the base of the casing or in the screen).

It is difficult to purge sample many of the wells that were examined using a pump because of the long pumping times required with the PAT. Other sampling methods, including passive sampling and depth-focused bailer samples, would be preferable. Bailer samples are appropriate if the bailer is deployed so that water is collected at the midpoint of the well screen or at depths where inflow of contaminants is noted. If mobilization of particulates off of the well casing (if saturated) is of concern, then passive samples would likely provide a condition of least disturbance because of their deployment time.

The PAT derives in-well vertical velocities and travel times of inflowing groundwater to pump intakes based on the distribution of well inflow derived from the pumping rates during purging and sampling of the well. The PAT estimates of bulk hydraulic conductivity are used to partition layered hydraulic conductivity and derive layered inflow. To provide a more robust understanding of travel times, it would be beneficial to incorporate several estimates of bulk hydraulic conductivity particularly from low-permeability hydrogeologic units. Velocities simulated in the PAT compared with observed dye velocities from tests showed a poor fit with a relatively large difference in the two wells where the permeability of the rock was very low (hydraulic conductivity less than 0.01 $\mathrm{ft} / \mathrm{d}$ ). In these cases, the poor comparison can be attributed to accelerated vertical flow by vertical pressure differences in the well water column; vertical pressure is a component 
unaccounted for and not simulated in the PAT. In one test well that had a higher permeability (hydraulic conductivity greater than $0.1 \mathrm{ft} / \mathrm{d}$ ), PAT velocities were comparable to observed dye velocities. In this case, vertical flow is attributed to and largely controlled by the summation of radial inflow into the well as modeled by the PAT.

Perchlorate concentrations in samples collected for this study appear to be much higher than previously collected, unfiltered concentrations (GeoLogic Associates, 2015).

Because the samples for this study were filtered with a $0.2-\mu \mathrm{m}$ filter, potential differences from biotic alteration and reduction of perchlorate (to chloride) after collection exists between the two sample sets. A systematic study of quantifying perchlorate concentrations from unfiltered and filtered groundwater samples collected from the same wells would potentially allow for a more definitive conclusion. This study could be coupled with monitoring of chloride from the potential accumulation of chloride production during the reaction of perchlorate after sampling.

\section{References Cited}

American Society of Testing and Materials, 2004, Standard guide for conducting borehole logging-Mechanical caliper: American Society of Testing and Materials D 6767-97, $6 \mathrm{p}$.

American Society of Testing and Materials, 2007, Standard guide for conducting borehole geophysical logging Electromagnetic induction: American Society of Testing and Materials D 6726-01, 8 p.

American Society of Testing and Materials, 2010, Standard guide for planning and conducting borehole geophysical logging: American Society of Testing and Materials D 5753-05, 9 p.

Anderson, J.A., Williams, J.H., Eckhardt, D.A.V., and Miller, T.S., 2004, Geophysical, stratigraphic, and flow-zone logs of selected test, monitor, and water-supply wells in Cayuga County, New York: U.S. Geological Survey Open-File Report 2003-468, 10 p., 1 app., accessed April 4, 2011, at https://doi.org/10.3133/ofr03468.

Aqua Bailers, 2020, Teflon (FEP) bailers: Aqua Bailers web page, accessed March 16, 2020, at https://www.aquabailers.com/product-category/ groundwater-sampling-bailers/fep-bailers/.

Canadian Well Logging Society, 2013, Log ASCII standard (LAS): Canadian Well Logging Society web page, accessed May 13, 2013, at http://www.cwls.org/las_info.php.
Century Geophysical LLC, 2018, Century Geophysical LLC home page: Century Geophysical LLC web page, accessed February 22, 2018, at https://www.century-geo.com/.

Cooley, R.L., and Cunningham, A.B., 1979, Consideration of energy loss in theory of flow to wells: Journal of Hydrology (Amsterdam), v. 43, nos. 1-4, p. 161-184. [Also available at https://doi.org/10.1016/0022-1694(79)90171-9.]

Environ International Corp., 2012, Bedrock aquifer testing report, Stringfellow Superfund site: Sacramento, California Environmental Protection Agency, Department of Toxic Substances Control, 186 p.

Environ International Corp., 2015, Bedrock aquifer testing report, Stringfellow Superfund site: Sacramento, California Environmental Protection Agency, Department of Toxic Substances Control, $253 \mathrm{p}$.

GeoLogic Associates, 2009, Passive sampling pilot study report, Stringfellow hazardous waste site: Sacramento, California Environmental Protection Agency, Department of Toxic Substances Control, $75 \mathrm{p}$.

GeoLogic Associates, 2014, January 2014 non-routine groundwater monitoring report, Stringfellow Superfund site, Jurupa Valley, California: Sacramento, California Environmental Protection Agency, Department of Toxic Substances Control, 355 p.

GeoLogic Associates, 2015, Revised final 2014 annual groundwater sampling and analysis report, Stringfellow Superfund site, Jurupa Valley, California: Sacramento, California Environmental Protection Agency, Department of Toxic Substances Control, $500 \mathrm{p}$.

GeoLogic Associates, 2016, Final 2015 annual groundwater sampling and analysis report, Stringfellow Superfund site, Jurupa Valley, California: Sacramento, California Environmental Protection Agency, Department of Toxic Substances Control, $500 \mathrm{p}$.

GeoLogic Associates, 2017, Final 2016 annual groundwater sampling and analysis report, Stringfellow Superfund site, Jurupa Valley, California: Sacramento, California Environmental Protection Agency, Department of Toxic Substances Control, $500 \mathrm{p}$.

GeoLogic Associates, 2018, Final 2017 annual groundwater sampling and analysis report, Stringfellow Superfund site, Jurupa Valley, California: Sacramento, California Environmental Protection Agency, Department of Toxic Substances Control, $500 \mathrm{p}$.

GSI Environmental, 2019, Perchlorate: GSI Environmental chemical database, accessed October 3, 2019, at https://www.gsi-net.com/en/publications/gsi-chemicaldatabase/single/436-CAS-na.html. 
Harte, P.T., 2002, Comparison of temporal trends in VOCs as measured with PDB samplers and low-flow sampling methods: Ground Water Monitoring and Remediation, v. 22, no. 2, p. 45-47. [Also available at https://doi.org/10.1111/ j.1745-6592.2002.tb00311.x.]

Harte, P.T., 2005, Results of a monitoring program of continuous water levels and physical water properties at the operable unit 1 area of the savage municipal well superfund site, Milford, New Hampshire, water years 2000-03: U.S. Geological Survey Open-File Report 2005-1303, 44 p. [Also available at https://doi.org/10.3133/ofr20051303.]

Harte, P.T., 2013, Hydraulically controlled groundwater sampling in fractured-rock aquifers: Ground Water, v. 51, no. 6, p. 822-837. [Also available at https://doi.org/10.1111/ gwat. 12120.]

Harte, P.T., 2017, In-well time-of-travel approach to evaluate optimal purge duration during low-flow sampling of monitoring wells: Journal of Environmental Earth Sciences, v. 76, no. 6, article 251 (2017), 13 p., accessed December 3, 2019, at https://doi.org/10.1007/s12665-017-6561-5.

Harte, P.T., 2020, Data associated with the evaluation of the PAT (Purge Analyzer Tool), Stringfellow Superfund site, Jurupa Valley, California, 2017: U.S. Geological Survey data release, https://doi.org/10.5066/P9CGINH0.

Harte, P.T., Huffman, B.J., Perina, T., Levine, H., and RojasMickelson, D., 2019, Instructions for running the analytical code PAT (Purge Analyzer Tool) for computation of in-well time of travel of groundwater under pumping: U.S. Geological Survey Open-File Report 2019-1104, 23 p., accessed January 5, 2020, at https://doi.org/10.3133/ ofr20191104.

Imbrigiotta, T.E., and Harte, P.T., 2020, Passive sampling of groundwater wells for determination of water chemistry: U.S. Geological Survey Techniques and Methods, book 1, chap. D8, 80 p., accessed [April 15, 2020] at https://doi.org/ $10.3133 / \mathrm{tm} 1 \mathrm{~d} 8$.

Interstate Technology and Regulatory Council, 2006, Technology overview of passive sampler technologies: Washington, D.C., Interstate Technology and Regulatory Council DSP-4, 115 p., accessed June 5, 2019, at https://www.itrcweb.org/Guidance/GetDocument? documentID $=26$.

Interstate Technology and Regulatory Council, 2007, Protocol for use of five passive samplers to sample for a variety of contaminants in groundwater: Washington, D.C., Interstate Technology and Regulatory Council DSP-5, 121 p., accessed June 5, 2019, at https://www.itrcweb.org/ Guidance/GetDocument?documentID=27.
Keys, W.S., 1990, Borehole geophysics applied to groundwater investigations: U.S. Geological Survey Techniques of Water-Resources Investigations, book 2, chap. E2, 150 p., accessed June 3, 2019, at https://doi.org/10.3133/twri02E2.

Laval Underground Surveys, 2018, R-cam portable water well camera: Laval Underground Surveys web page, accessed December 10, 2018 at https://www.lavalunderground.com/ index.php?id=9.

Mount Sopris Instruments, 2018, Mount Sopris Instruments home page: Mount Sopris Instruments web page, accessed February 22, 2018, at https://mountsopris.com/.

Parsons Engineering Science, Inc., 2005, Results report for the demonstration of no-purge groundwater sampling devices at former McClellan Air Force Base, California: U.S Air Force, contract F44650-D-0005, work order DK01, prepared by U.S. Army Corps of Engineers Omaha District, Air Force Center for Environmental Excellence, and Air Force Real Property Agency, 79 p., accessed June 23, 2019, at https://www.itrcweb.org/Documents/McClellan\%20Rpt_ Oct2005.pdf.

Perina, T., 2020, Improved parameter resolution with Markov chain Monte Carlo simulation of different aquifer tests: Ground Water, v. 58, no. 6, p. 993-999, accessed April 8, 2002, at https://doi.org/10.1111/gwat.13003.

Perina, T., and Lee, T.-C., 2006, General well function for pumping from a confined, leaky, or unconfined aquifer: Journal of Hydrology (Amsterdam), v. 317, no. 3-4, p. 239-260. [Also available at https://doi.org/10.1016/ j.jhydrol.2005.05.020.]

Puls, R.W., and Barcelona, M.J., 1996, Low-flow (minimal drawdown) ground-water sampling procedures: U.S. Environmental Protection Agency EPA/540/S-95/504, 12 p., accessed June 5, 2019, at https:/www.epa.gov/ remedytech/low-flow-minimal-drawdown-ground-watersampling-procedures.

Rikken, G.B., Kroon, A.G.M., and Van Ginkel, C.G., 1996, Transformation of (per)chlorate into chloride by a newly isolated bacterium-Reduction and dismutation: Applied Microbiology and Biotechnology, v. 45, no. 3, p. 420-426. [Also available at https://doi.org/10.1007/s002530050707.]

Robert, C.P., and Casella, G., 2010, Monte Carlo statistical methods 2d ed.: New York, Springer, 649 p.

Tarantola, A., 2005, Inverse problem theory and methods for model parameter estimation: Philadelphia, Penn., Society for Industrial and Applied Mathematics, $342 \mathrm{p}$.

Tetra Tech, Inc., 2000, Clay barrier testing well construction report in zone 1: Sacramento, California Environmental Protection Agency, 39 p. 
Turner Designs Inc, 2018, Cyclops-7F submersible sensors: Turner Designs Inc. web page, accessed June 4, 2019, at https://www.turnerdesigns.com/cyclops-7f-submersiblefluorometer.

U.S. Army Corps of Engineers, 2016, Fifth five-year report for the Stringfellow Superfund site, Riverside County: California, U.S. Environmental Protection Agency, 137 p.

U.S. Environmental Protection Agency, 2005, Method 331.0 Determination of perchlorate in drinking water by liquid chromatography electrospray ionization mass spectrometry: U.S. Environmental Protection Agency 815-R-05-007, 34 p., accessed April 23, 2020, at https://nepis.epa.gov/Exe/ ZyPDF.cgi?Dockey=901U0000.txt.

U.S. Environmental Protection Agency, 2006, Method 8260D - Volatile organic compounds by gas chromatography-mass spectrometry (revision 4, February 2017): U.S. Environmental Protection Agency, 52 p., accessed April 23, 2020, at https:/www.epa.gov/sites/production/ files/2017-04/documents/method_8260d_update_ vi_final_03-13-2017.pdf.

U.S. Geological Survey, 2019, National field manual for the collection of water-quality data: U.S. Geological Survey Techniques and Methods, book 9, chaps. A1A10, [variously paged], accessed June 3, 2019, at https://pubs.water.usgs.gov/twri9A.

U.S. Geological Survey, 2020, USGS GeoLog locator: U.S. Geological Survey web application, accessed April 23, 2020, at https://webapps.usgs.gov/geologlocator/\#!/.
Vroblesky, D.A., 2001a, User's guide for polyethylene-based passive diffusion bag samplers to obtain volatile organic compound concentrations in wells. Part 1-Deployment, recovery, data interpretation, and quality control and assurance: U.S. Geological Survey Water-Resources Investigations Report 01-4060, 18 p. [Also available at https://doi.org/10.3133/wri014060.]

Vroblesky, D.A., 2001b, User's guide for polyethylene-based passive diffusion bag samplers to obtain volatile organic compound concentrations in wells. Part 2-Field tests: U.S. Geological Survey Water-Resources Investigations Report 01-4061, 120 p., accessed June 3, 2019, at https://doi.org/ 10.3133/wri014061.

Vroblesky, D.A., Casey, C.C., and Lowery, M.A., 2007, Influence of dissolved oxygen convection on well sampling: Ground Water Monitoring and Remediation, v. 27, no. 3, p. 49-58. [Also available at https://doi.org/10.1111/j.17456592.2007.00156.x.]

Walters, D.A., 1997, Effects and distribution of iron-related well-screen encrustation and aquifer biofouling in Suffolk County, Long Island, New York: U.S. Geological Survey Water-Resources Investigations Report 96-4217, 33 p. [Also available at https://doi.org/10.3133/wri964217.]

Williams, J.H., and Johnson, C.D., 2004, Acoustic and optical borehole-wall imaging for fractured-rock aquifer studies: Journal of Applied Geophysics, v. 55, no. 1-2, p. 151-159.

Yeskis, D., and Zavala, B., 2002, Ground-water sampling guidelines for Superfund and RCRA project managers: U.S. Environmental Protection Agency Ground Water Forum Issue Paper 542-S-02-001, 53 p. [Also available at https://www.epa.gov/sites/production/files/2015-06/ documents/gw_sampling_guide.pdf.] 
For more information, contact

Director, New England Water Science Center

U.S. Geological Survey

10 Bearfoot Road

Northborough, MA 01532

dc_nweng@usgs.gov

or visit our website at

https://www.usgs.gov/centers/new-england-water

Publishing support provided by the Pembroke and Indianapolis

Publishing Service Centers 
